\title{
Biodiesel production from Calophyllum inophyllum-Ceiba pentandra oil mixture: Optimization and characterization
}

\author{
Hwai Chyuan Ong a, **, Jassinnee Milano ${ }^{a}$, Arridina Susan Silitonga b, *, \\ Masjuki Haji Hassan ${ }^{a}$, Abd Halim Shamsuddin ${ }^{c}$, Chin-Tsan Wang ${ }^{\mathrm{d}}$, \\ Teuku Meurah Indra Mahlia e, Joko Siswantoro ${ }^{\mathrm{f}}$, Fitranto Kusumo ${ }^{\mathrm{c}, \mathrm{g}}$, Joko Sutrisno ${ }^{\mathrm{b}}$ \\ a Department of Mechanical Engineering, Faculty of Engineering, University of Malaya, 50603, Kuala Lumpur, Malaysia \\ ${ }^{\mathrm{b}}$ Department of Mechanical Engineering, Politeknik Negeri Medan, 20155, Medan, Indonesia \\ c Institute of Sustainable Energy, Universiti Tenaga Nasional, 43000, Kajang, Selangor, Malaysia \\ ${ }^{\mathrm{d}}$ Department of Mechanical and Electro-Mechanical Engineering, National Ilan University, Yilan City, Taiwan \\ e School of Lnformation, Systems and Modelling, Faculty of Engineering and Information Technology, University of Technology Sydney, NSW, 2007, Australia \\ ${ }^{\mathrm{f}}$ Department of Informatics Engineering, Faculty of Engineering, Universitas Surabaya, Surabaya, 60293, Indonesia \\ ${ }^{g}$ Department of Computer Science \& Information Technology, College of Computer Science \& Information Technology Universiti Tenaga Nasional, 43000 , \\ Kajang, Selangor, Malaysia
}

\section{A R T I C L E I N F O}

\section{Article history:}

Received 27 January 2018

Received in revised form

1 February 2019

Accepted 4 February 2019

Available online 7 February 2019

\section{Keywords:}

Biodiesel

Alternative fuel

Artificial neural networks

Ant colony optimization

Kinetics study

Renewable energy

\begin{abstract}
A B S T R A C T
In this study, a novel modeling approach (artificial neural networks (ANN) and ant colony optimization (ACO)) was used to optimize the process variables for alkaline-catalyzed transesterification of CI40CP60 oil mixture (40 wt\% of Calophyllum inophyllum oil mixed with $60 \mathrm{wt} \%$ of Ceiba pentandra oil) in order to maximize the biodiesel yield. The optimum values of the methanol-to-oil molar ratio, potassium hydroxide catalyst concentration, and reaction time predicted by the ANN-ACO model are 37\%, $0.78 \mathrm{wt} \%$, and $153 \mathrm{~min}$, respectively, at a constant reaction temperature and stirring speed of $60^{\circ} \mathrm{C}$ and $1000 \mathrm{rpm}$, respectively. The ANN-ACO model was validated by performing independent experiments to produce the CI40CP60 methyl ester (CICPME) using the optimum transesterification process variables predicted by the ANN-ACO model. There is very good agreement between the average CICPME yield determined from experiments (95.18\%) and the maximum CICPME yield predicted by the ANN-ACO model (95.87\%) for the same optimum values of process variables, which corresponds to a difference of $0.69 \%$. Even though the ANN-ACO model is only implemented to optimize the transesterification of process variables in this study. It is believed that the model can be used to optimize other biodiesel production processes such as seed oil extraction and acid-catalyzed esterification for various types of biodiesels and biodiesel blends.
\end{abstract} (c) 2019 Elsevier Ltd. All rights reserved.

\section{Introduction}

\subsection{Importance of non-edible oils for biodiesel production}

Biodiesels are promising diesel substitutes and they can be produced from a variety of feedstocks such as edible oils (firstgeneration biodiesels). Even though the production of biodiesels from edible oils facilitates reducing the dependency on fossil fuels, this approach has received worldwide criticism because of the food

\footnotetext{
* Corresponding author.

** Corresponding author.

E-mail addresses: onghc@um.edu.my (H.C. Ong), ardinsu@yahoo.co.id (A.S. Silitonga)
}

versus fuel dilemma. With the increasing global population, there will be more people that need to be fed and therefore, producing biodiesels from food crops may lead to food security issues and inflation in food prices when food demand exceeds food supply. The production of biodiesels from food crops may also require increased acreage, which will lead to deforestation. In addition, the cost of edible oils accounts for $\sim 80 \%$ of the final price of the produced biodiesel.

In order to address these issues, much effort has been made to produce biodiesels from non-edible oils (second-generation biodiesels). One of the inexpensive potential feedstocks for biodiesel production is palm fatty acid distillate (PFAD), which is a processing residue of crude palm oil (CPO) refinery plants. According to the Malaysian Palm Oil Board (2018), 649,459 tons of PFAD were 


\section{List of abbreviations}

ASTM American Society for Testing and Materials ANN ACO Artificial neural network Ant colony algorithm CCD CCIO CCPO Central composite design Crude Calophyllum inophyllum oil Crude Ceiba pentandra oil

CICPB Calophyllum inophyllum-Ceiba pentandra biodiesel CICPO Crude Calophyllum inophyllum-Ceiba pentandra oil mixture

CICPME Calophyllum inophyllum-Ceiba pentandra methyl ester

CI20CP80 Crude Calophyllum inophyllum-Ceiba pentandra oil mixture (20:80 wt\%)

CI40CP60 Crude Calophyllum inophyllum-Ceiba pentandra oil mixture (40:60 wt\%)

CI60CP40 Crude Calophyllum inophyllum-Ceiba pentandra oil mixture (60:40 wt\%)

CI80CP20 Crude Calophyllum inophyllum-Ceiba pentandra oil mixture (80:20 wt\%)

CIME Calophyllum inophyllum methyl ester

CPME CPO Ceiba pentandra methyl ester Crude palm oil

$\mathrm{CV} \quad$ Coefficient of variation

DOE Design of experiment

EN European standard

FAC Fatty acid composition

FFA MAPE PFAD RSM Free fatty acid Mean absolute percentage error Palm fatty acid distillate Response surface methodology

produced in Malaysia in 2015, which is equivalent to $3.25 \%$ of PFAD produced from processing 1 ton of CPO. Indonesia is a leading CPO producer, producing 32.5 million tons of CPO in 2015, which corresponds to $\sim 1$ million tons of PFAD (Abdul Kapor et al., 2017). Malaysia is the second-largest producer of CPO with a total plantation area of $\sim 5.64$ million hectares (Abdul Kapor et al., 2017). Palm trees produce 10-35 tons of fresh fruit bunches per hectare, which yields about 5 tons of oil per hectare annually (Silitonga et al., 2016). Many studies have been carried out to explore different types of non-edible oils such as Calophyllum inophyllum, Ceiba pentandra, Cerbera manghas, Hevea brasiliensis, Jatropha curcas, Madhuca indica, and Sterculia foetida seed oils as well as fish waste oils and waste cooking oils for biodiesel production including those by (Dharma et al., 2016; Damanik et al., 2017; Hadiyanto et al., 2018; Silitonga et al., 2018).

In recent years, efforts are being made to produce biodiesels from inexpensive non-edible oil mixtures and studies have shown that biodiesels with favorable physicochemical properties can be obtained by transesterification of crude non-edible oil mixtures with methanol in the presence of an alkaline catalyst. Dharma et al. (2016) showed that the J50C50 biodiesel produced from transesterification of Jatropha curcas and Ceiba pentandra oil mixture had higher oxidation stability (10.01 h). Damanik et al. (2017) were the first to produce biodiesel from transesterification of crude Calophyllum inophyllum and palm oil mixture (50:50 vol\%) and there was a remarkable improvement in the oxidation stability of the resultant biodiesel, with a value of 114.21 h. Hadiyanto et al. (2018) produced biodiesel from transesterification of waste cooking oil and castor oil mixture (50:50 vol\%) and the cetane number was improved to 100 .

The aforementioned studies indicate that the use of inexpensive non-edible oil mixtures appears to be a promising solution for biodiesel production for the following reasons: (1) The price of the final product (biodiesel) will be reduced because non-edible oils are generally cheaper compared with edible oils (Atabani et al., 2013; Hajjari et al., 2017); (2) The use of non-edible oils will reduce the dependency on edible oils for biodiesel production; (3) Various types of non-edible oils can be blended at different weight or volume ratios to produce biodiesels with favorable physicochemical properties and improve the engine performance and exhaust emission characteristics (Meneghetti et al., 2007; Dias et al., 2008). The mass production and usage of second-generation biodiesels from these oils will increase the net energy gain, which will significantly impact fuel price stability in the long term.

\subsection{Calophyllum inophyllum and Ceiba pentandra oils}

Owing to the benefits of non-edible oil mixtures for biodiesel production, this study is focused on producing second-generation biodiesels from crude Calophyllum inophyllum-Ceiba pentandra oil mixtures.

Calophyllum inophyllum oil (also known as honne, tamanu, polanga, or nyamplung oil) is a non-edible oil derived from the seeds of Calophyllum inophyllum fruits and it is commonly used for biodiesel production. Calophyllum inophyllum is one of the favorable agricultural crops because this plant produces fruits throughout the year upon maturity. Calophyllum inophyllum begins to fruit at the age of seven years and continues to produce fruits up to 58 years. Calophyllum inophyllum oil is a feasible biodiesel feedstock in the long term because of its ease of cultivation and it does not require high investment costs for cultivation (SathyaSelvabala et al., 2011). Calophyllum inophyllum seeds have high oil content (65-75\%). The extracted Calophyllum inophyllum seed oil has a greenish tinge with a nutty scent. Calophyllum inophyllum oil consists of oleic acid (38.1\%), linoleic acid (29.3\%) which are all unsaturated fatty acids, as well as palmitic acid (16.3\%), which is a saturated fatty acid (Belagur and Chitimi, 2013; Arumugam and Ponnusami, 2014).

Ceiba pentandra (also known as kapok or kekabu) is an oleaginous species native to Southeast Asia, India, and Sri Lanka, well as tropical regions in the Americas. Ceiba pentandra belongs to the Malvaceae family (Yunus Khan et al., 2015) and this plant is found naturally in humid and sub-humid tropical regions. Ceiba pentandra oil consists of cyclopropene fatty acids, which have higher reactivity towards ring opening reactions than polyunsaturated fatty acids (Silitonga et al., 2013). Linoleic acid (39.7\%) and malvalic acid (18.5\%) are among the constituents of Ceiba pentandra oil, which are both unsaturated fatty acids. Ceiba pentandra oil also consists of palmitic acid (19.2\%), which is a saturated fatty acid (Belagur and Chitimi, 2013; Kusumo et al., 2017). The cyclopropene fatty acids present in Ceiba pentandra oil leads to higher kinematic viscosity and faster oxidation (Bindhu et al., 2012).

Calophyllum inophyllum and Ceiba pentandra oils were chosen in this study simply because they are inexpensive feedstocks. Calophyllum inophyllum and Ceiba pentandra plants are widely cultivated in Indonesia and their seed oils can be readily sourced from local farmers (Handayani et al., 2013, 2018; Hafshah et al., 2017), which will facilitate the production of Calophyllum inophyllumCeiba pentandra biodiesels in this work.

\subsection{Modeling techniques used to optimize the process variables of biodiesel production from non-edible oils}

One of the issues in biodiesel production (including those produced from non-edible oil mixtures) is to optimize the process variables of the acid-catalyzed esterification and/or alkalinecatalyzed transesterification in order to maximize the biodiesel yield. Many studies have shown that the optimum values of the 
process variables for biodiesel production vary depending on the types of feedstocks (Yogish et al., 2012; Fadhil et al., 2017; Keera et al., 2018). In other words, the optimum values of the process variables are more or less application-specific (Milano et al., 2018). It is a rather arduous task to determine the optimum values of the process variables using traditional experimentation because the whole procedure is costly in terms of material, time, labor, and financial resources due to the large number of experimental runs. In addition, there is no guarantee that the optimum values of the process variables can be determined with this approach because traditional experimentation is based on trial and error. For this reason, it is imperative to develop a simple technique that is capable of accurately predicting the optimum values of the process variables in order to maximize the biodiesel yield.

Various modeling techniques have been used to optimize the esterification and/or transesterification process variables for biodiesel production from non-edible oils. For instance, Hasni et al. (2017) optimized the transesterification process parameters (methanol-to-oil ratio, catalyst concentration, and reaction temperature) using response surface methodology (RSM) based on the Box-Behnken design in order to maximize the conversion of Brucea javanica seed oil into biodiesel. Muthukumaran et al. (2017) used RSM to optimize the process variables for transesterification of non-edible Madhuca indica (mahua) oil and the maximum biodiesel yield was predicted to be $91.76 \%$ when the amount of methanol, potassium hydroxide $(\mathrm{KOH})$ catalyst concentration, reaction temperature, and reaction time were $0.32 \%(\mathrm{v} / \mathrm{v}), 1.5 \%, 60^{\circ} \mathrm{C}$, and $90 \mathrm{~min}$, respectively. Miraculas et al. (2018) used multivariate design of experiments to optimize the oil-to-methanol ratio, catalyst concentration, reaction time, reaction temperature of the transesterification process to maximize the biodiesel yield produced from a mixture of three non-edible oils: Calophyllum inophyllum, Jatropha curcas, and Pongamia pinnata oils. They obtained a biodiesel yield of $98 \%$ for the following optimum process conditions: (1) oil-to-methanol ratio: $2.5 \%(\mathrm{v} / \mathrm{v}),(2)$ catalyst concentration: $1.17 \%(\mathrm{w} / \mathrm{v}),(3)$ reaction time: $95 \mathrm{~min}$, and (4) reaction temperature: $53^{\circ} \mathrm{C}$. Cardoso et al. (2019) used RSM based on the central composite design (CCD) to optimize the parameters of alkaline-catalyzed transesterification (ethanol-to-oil molar ratio, sodium hydroxide $(\mathrm{NaOH})$ catalyst concentration, and reaction temperature) to maximize the biodiesel yield produced from fish waste oil. Dhawane et al. (2018) used the Taguchi method (L9 orthogonal array) to optimize the oil-to-methanol molar ratio, sulfuric acid $\left(\mathrm{H}_{2} \mathrm{SO}_{4}\right)$ catalyst concentration, reaction temperature, and reaction time of the esterification process to maximize the free fatty acid conversion of waste cooking oil into biodiesel. The maximum free fatty acid conversion was $95.38 \%$ for the following process conditions: (1) oil-to-methanol ratio: $1: 12$, (2) $\mathrm{H}_{2} \mathrm{SO}_{4}$ catalyst concentration: $5 \mathrm{wt} \%,(3)$ reaction time: $3 \mathrm{~h}$, and (4) reaction temperature: $60^{\circ} \mathrm{C}$. Joshi et al. (2018) optimized the operating conditions for ultrasonic-assisted acid-catalyzed esterification of Pongamia pinnata (karanja) oil using RSM. Mueanmas et al. (2018) used RSM based on CCD to optimize the methanol-to-free fatty acid molar ratio, catalyst concentration, reaction temperature, and reaction time to minimize the free fatty acid concentration of nonedible oil extracted from an unconventional feedstock, which was waste coffee grounds.

Artificial neural networks (ANN), which is an artificial intelligence technique (Esen et al., 2008, 2009), has also gained prominence in biodiesel research because of its capability to solve complex problems involving a large number of process variables. ANN has also been used in conjunction with other modeling techniques to optimize the process variables of biodiesel production from non-edible oils. For instance (Rajendra et al., 2009), used ANN coupled with genetic algorithm (GA) to optimize the methanol-to-oil ratio, catalyst concentration, and reaction time of the pretreatment process in order to minimize the high free fatty content (indicated by the initial acid value) of various plant-based oils. Likewise, Dhingra et al. (2014) used ANN with GA to optimize the ethanol-to-oil molar ratio, catalyst concentration, reaction temperature, reaction time, and agitation speed of the transesterification process to maximize the biodiesel yield from Calophyllum inophyllum oil. Betiku and Ajala (2014) used RSM to optimize the process variables of $\mathrm{H}_{2} \mathrm{SO}_{4}$-catalyzed esterification and then compared the use of RSM and ANN to optimize the process variables (methanol-to-oil ratio, reaction time, and amount of calcinated plantain peels used as catalyst) of the transesterification process in order to maximize the Thevetia peruviana (yellow oleander) biodiesel yield. In a later work (Betiku et al., 2015), used RSM to optimize the process variables of acid-catalyzed esterification in order to minimize the free fatty acid content of shea butter oil. Following this, they compared the use of two modeling techniques (RSM and ANN with GA) to optimize the oil-to-methanol molar ratio, $\mathrm{KOH}$ catalyst concentration, reaction temperature, and reaction time of the transesterification process in order to attain high shea butter biodiesel yield. The results showed that the ANN model with GA was a superior prediction model because of its higher coefficient of determination and significantly lower absolute average deviation compared to RSM. Prakash Maran and Priya (2015b) compared two modeling techniques (RSM based on CCD versus ANN) to predict the Azadirachta indica (neem) biodiesel yield produced by ultrasonic-assisted biodiesel synthesis and the results showed that ANN was more reliable to predict the biodiesel yield compared to RSM. In another work, Prakash Maran and Priya (2015a) compared both of these techniques to optimize the methanol-to-oil molar ratio, $\mathrm{KOH}$ catalyst concentration, reaction temperature, and reaction time of the ultrasonic-assisted alkalinecatalyzed transesterification in order to maximize the biodiesel yield from muskmelon seed oil. The results also showed that ANN was a better tool than RSM in terms of the prediction capability.

\subsection{Motivation and scope of the study}

Based on the studies presented in the preceding section, it is evident that much effort has been made to optimize the process variables of biodiesel production from non-edible oils. RSM is typically used for this purpose though there are a few studies in which other modeling techniques are used such as multivariate design of experiments and the Taguchi method. Several studies have been carried out to optimize the process variables of biodiesel production using ANN and the results showed that ANN is generally superior to RSM. ANN has also been coupled with GA in order to improve the prediction capability of the model. Despite the ongoing developments in this field, none of the studies are focused on the application of ANN with ant colony optimization (ACO) to optimize the process variables for biodiesel production.

ACO is an optimization algorithm introduced in the 1990s by Dorigo et al. (1996) and it is used to solve combinatorial optimization problems (i.e., problems in which an optimum solution is determined from a finite set of solutions). In nature, ants work cooperatively and communicate through pheromone trails in search of food. Each ant deposits pheromone as it navigates from its nest to the food source. Ants with shorter routes will leave more pheromone compared with those with longer routes. The higher the amount of pheromone deposited on a particular route, the higher the probability the ants will follow that route. The route that is rich in pheromone is the optimum route for the ant colony (Shweta and Singh, 2013; Kaabachi et al., 2017). Likewise, in the ACO algorithm, the optimization problem is first converted into a weighted graph (a graph consisting of nodes and edges). Each 
artificial ant starts from a randomly selected starting node and travels towards the destination node in order to find the shortest route that maximizes/minimizes the objective function (Dorigo, 2007; Kaabachi et al., 2017). ACO has been proven to be efficient for the Traveling Salesman Problem, Job Shop Flow Scheduling Problem, and Economic Dispatch Problem, and it is deemed that it will be useful to maximize biodiesel yields by optimizing the process variables for biodiesel production.

Hence, in this study, ANN followed by ACO (herein named the ANN-ACO model for brevity) is used to predict and optimize the process variables of the alkaline-catalyzed transesterification process (methanol-to-oil molar ratio, $\mathrm{KOH}$ catalyst concentration, and reaction time) in order to maximize the Calophyllum inophyllumCeiba pentandra biodiesel yield. The ANN-ACO model offers a simple, reliable alternative to other prediction and optimization tools to optimize the process variables of the transesterification process in order to maximize the biodiesel yield, and eliminates the trial and error associated with traditional experimentation. Even though the ANN-ACO model is only implemented to maximize the biodiesel yield from transesterification of Calophyllum inophyllumCeiba pentandra oil mixture in this study, it is believed that the model can be used to optimize other biodiesel production processes such as seed oil extraction and acid-catalyzed esterification for various types of biodiesels and biodiesel blends. It is believed that the ANN-ACO model will be a useful prediction and optimization tool for biodiesel research.

This study is divided into four phases: (1) measurement of physicochemical properties of the crude oils, (2) modeling and optimization of the alkaline-catalyzed transesterification process variables using the ANN-ACO model, (3) biodiesel production by acid-catalyzed esterification followed by alkaline-catalyzed transesterification, and (4) kinetics study of the transesterification process. Each of these phases is described briefly as follows, which provides an overall view of the scope of this study.

In the first phase, four crude Calophyllum inophyllum-Ceiba pentandra oil (CICPO) mixtures were prepared with different weight ratios (20:80, 40:60, 60:40, and 80:20 wt\%) and the physicochemical properties (kinematic viscosity at $40^{\circ} \mathrm{C}$, density at $15^{\circ} \mathrm{C}$, acid value, and higher heating value) of these oil mixtures were measured according to the ASTM standard test methods. The physicochemical properties of crude Calophyllum inophyllum oil (CCIO) and crude Ceiba pentandra oil (CCPO) were also measured for comparison. The best crude CICPO mixture, which gave the best trade-off in these physicochemical properties, was chosen for in situ esterification-transesterification and optimization of the process variables for alkaline-catalyzed transesterification of the crude CICPO mixture. The fatty acid compositions of this crude CICPO mixture as well as CCIO and CCPO oils were also measured.

In the second phase, RSM based on the Box-Behnken design was used to generate the experimental design for the alkaline-catalyzed transesterification process based on three factors: (1) methanol-tooil molar ratio, (2) $\mathrm{KOH}$ catalyst concentration, and (3) reaction time. The experimental data from the Box-Behnken design were used to train the ANN model to predict the Calophyllum inophyllumCeiba pentandra methyl ester (CICPME) yield produced from the best crude CICPO mixture obtained from the previous phase. Following this, ACO was performed on the well-trained ANN model to optimize the alkaline-catalyzed transesterification process variables in order to maximize the CICPME yield. Independent experiments were then performed to produce CICPME using the optimum values of process variables predicted by the ANN-ACO model and the average CICPME yield was determined to validate the reliability of the ANN-ACO model. The performance of the ANNACO model was evaluated based on the coefficient of determination $\left(R^{2}\right)$ and mean absolute percentage error (MAPE). Sensitivity analysis was performed to determine the relative importance of each process variable on the CICPME yield.

In the third phase, acid-catalyzed esterification was carried out on the best crude CICPO mixture obtained from the first phase, followed by alkaline-catalyzed transesterification in order to produce the CICPME. The methanol-to-oil molar ratio was varied from $30 \%$ to $60 \%$, the $\mathrm{KOH}$ catalyst concentration was varied from $0.5 \mathrm{wt} \%$ to $2.0 \mathrm{wt} \%$, and the reaction time was varied from $60 \mathrm{~min}$ to $180 \mathrm{~min}$ in order to examine the effects of these process variables on the CICPME yield. Calophyllum inophyllum methyl ester (CIME) and Ceiba pentandra methyl ester (CPME) were also produced by acidcatalyzed esterification followed by alkaline-catalyzed transesterification for comparison purposes. The fatty acid methyl ester (FAME) content was measured in order to determine the CICPME, CIME, and CPME yields. The physicochemical properties of the CICPME, CIME, and CPME were measured according to ASTM standard test methods and compared with those of other fuels.

In the fourth phase, kinetics study was performed to obtain a better understanding on the mechanism of the alkaline-catalyzed transesterification of the crude CICPO mixture obtained from the first phase.

\section{Materials and methods}

\subsection{Phase 1: Measurement of the physicochemical properties of CCIO, ССРO, and crude CICPO mixtures}

The CCIO and CCPO oils were sourced from local farmers in Cilacap, Indonesia. Methanol (purity: 99.5\%), $\mathrm{H}_{2} \mathrm{SO}_{4}$ (purity: 95-97\%), $\mathrm{KOH}$ pellets, and qualitative filter papers (Grade 121, Filtres Fioroni, France) were purchased from Merck Sdn. Bhd., Malaysia.

Four CICPO mixtures were prepared by mixing CCIO with CCPO at the following ratios: (1) $20: 80 \mathrm{wt} \%$, (2) $40: 60 \mathrm{wt} \%$, (3) $60: 40 \mathrm{wt} \%$, and (4) $80: 20 \mathrm{wt} \%$. These crude oil samples were labelled as CI20CP80, CI40CP60, CI60CP40, and CI80CP20, respectively, where $\mathrm{CI}$ denotes Calophyllum inophyllum and $\mathrm{CP}$ denotes Ceiba pentandra. The kinematic viscosity at $40^{\circ} \mathrm{C}$, density at $15^{\circ} \mathrm{C}$, acid value, and higher heating value of the CICPO mixtures were measured according to the ASTM standard test method. The CICPO mixtures were heated at $50^{\circ} \mathrm{C}$ for 30 min prior to measuring the physicochemical properties and the results are summarized in Table 1 .

Based on the results, it was found that the crude CI40CP60 oil mixture was the best mixture for biodiesel production and optimization of the alkaline-catalyzed transesterification process variables because it gave the best trade-off in the kinematic viscosity at $40^{\circ} \mathrm{C}$, density at $15^{\circ} \mathrm{C}$, acid value, and higher heating value compared to the other CICPO mixtures. The CI40CP60 oil mixture has the lowest kinematic viscosity at $40{ }^{\circ} \mathrm{C}$ and density at $15^{\circ} \mathrm{C}$ among all CICPO mixtures, with a value of $25.33 \mathrm{~mm}^{2} \mathrm{~s}^{-1}$ and $903.3 \mathrm{~kg} \mathrm{~m}^{-3}$, respectively. The CI40CP60 oil mixture has the second lowest acid value $\left(16.66 \mathrm{mg} \mathrm{KOH} \mathrm{g}^{-1}\right)$ compared with the other CICPO oil mixtures, which is indicative of its lower free fatty acid content. The CI40CP60 oil mixture also has a relatively high higher heating value $\left(38.167 \mathrm{MJ} \mathrm{kg}^{-1}\right)$, which is comparable to the higher heating values for CCIO (Jahirul et al., 2015), CPCO (Senthil Kumar et al., 2015) and Jatropha curcas-Pongamia pinnata (JCPPO) oil mixture (Yogish et al., 2012). In general, the CI40CP60 oil mixture gave the best trade-off between the four physicochemical properties, which was why this oil mixture was selected for biodiesel production. The CCIO and CCPO were also chosen for biodiesel production for comparison purposes.

The fatty acid compositions of the CCIO, CCPO, and CI40CP60 oil mixture were measured using a gas chromatography system (Model: GC-14B, Shimadzu Corporation, Japan) and the results are 
Table 1

Comparison of the physicochemical properties between the CICPO oil mixtures and other crude oils.

\begin{tabular}{|c|c|c|c|c|c|c|c|c|c|}
\hline \multirow[t]{2}{*}{ Property } & \multicolumn{4}{|c|}{ Crude oils } & \multicolumn{5}{|c|}{ Crude CICPO and other oil mixtures } \\
\hline & $\mathrm{CCIO}^{\mathrm{a}}$ & $\begin{array}{l}\text { CCIO (Jahirul et al., } \\
\text { 2015) }\end{array}$ & $\mathrm{CCPO}^{\mathrm{a}}$ & $\begin{array}{l}\text { CCPO (Senthil Kumar et al., } \\
\text { 2015) }\end{array}$ & CI20CP80 & $\mathrm{CI} 40 \mathrm{CP} 60^{\mathrm{a}}$ & $\mathrm{CI} 60 \mathrm{CP} 40^{\mathrm{a}}$ & $\mathrm{CI} 80 \mathrm{CP} 20^{\mathrm{a}}$ & $\begin{array}{l}\text { JCPO (Yogish et al., } \\
\text { 2012) }\end{array}$ \\
\hline $\begin{array}{l}\text { Kinematic viscosity at } 40^{\circ} \mathrm{C} \\
\qquad\left(\mathrm{mm}^{2} \mathrm{~s}^{-1}\right)\end{array}$ & 38.22 & 56.74 & 28.97 & 30.20 & 26.96 & 25.33 & 29.57 & 33.49 & 48.00 \\
\hline Density at $15^{\circ} \mathrm{C}\left(\mathrm{kg} \mathrm{m}^{-3}\right)$ & 910.1 & 964.0 & 908.6 & 921.0 & 904.9 & 903.3 & 906.2 & 909.5 & 901.0 \\
\hline Acid value (mg KOH g ${ }^{-1}$ ) & 35.77 & 36.26 & 15.38 & 21.00 & 17.27 & 16.66 & 15.82 & 18.18 & - \\
\hline Higher heating value $\left(\mathrm{MJ} \mathrm{kg}^{-1}\right)$ & 38.229 & 38.100 & 38.112 & 39.590 & 38.026 & 38.167 & 38.226 & 38.571 & 39.750 \\
\hline
\end{tabular}

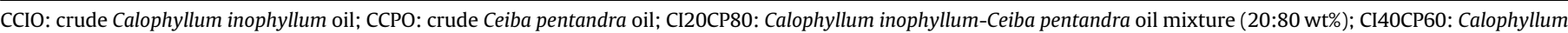

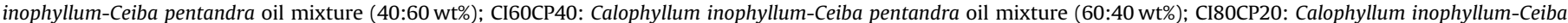
pentandra oil mixture (80:20 wt\%); JCPO: Jatropha curcas-Pongamia pinnata oil mixture (50:50 wt\%).

a Physicochemical properties measured in this study.

presented in Table 2. Among these crude oil samples, CCIO has the highest total unsaturated fatty acids ( $66.6 \mathrm{wt} \%$ ), followed by the CI40CP60 oil mixture (64.61 wt\%), and least of all, CCPO (59.8 wt\%). In general, all of the crude oil samples have higher total unsaturated fatty acids compared with the total saturated fatty acids, which is desirable for biodiesel production because the methyl esters produced from oils containing high levels of unsaturated fatty acids have good cold flow properties (Jurac and Zlatar, 2013). The CI40CP60 oil mixture has lower saturated fatty acids (32.64 wt\%) than CCPO (38.6 wt\%) and slightly higher saturated fatty acids than CCIO (28.9 wt\%). In general, oils with higher unsaturated fatty acid content has more double and triple bonds in the fatty acid structure and therefore, these oils are more prone to oxidation (Pullen and Saeed, 2014). On this premise, it is likely that the CI40CP60 oil mixture will produce a methyl ester with higher oxidation stability compared with CCIO and CCPO.

\subsection{Phase 2: Modeling and optimization of the alkaline-catalyzed transesterification process variables using the ANN-ACO model}

\subsubsection{Design of experiments based on Box-Behnken design}

RSM based on the Box-Behnken design was used to design the experiments for the alkaline-catalyzed transesterification of the CI40CP60 oil mixture. Design-Expert ${ }^{\circledR}$ Version 9.0 software (StatEase, Inc., USA) was used to generate the Box-Behnken

Table 2

Comparison of fatty acid compositions between the crude CI40CP60 oil mixture and other crude oils.

\begin{tabular}{|c|c|c|c|c|}
\hline \multirow[t]{2}{*}{ Fatty acid (wt\%) } & \multirow[t]{2}{*}{ Carbon chain number } & \multirow{2}{*}{$\frac{\text { Crude oil mixtures }}{\mathrm{CI}^{4} \mathrm{CP} 60^{\mathrm{a}}}$} & \multicolumn{2}{|c|}{ Crude oils } \\
\hline & & & $\mathrm{CCIO}^{\mathrm{a}}$ & $\mathrm{CCPO}^{\mathrm{a}}$ \\
\hline Lauric acid & $\mathrm{C} 12: 0$ & 0.1 & 0.1 & 0.1 \\
\hline Myristic acid & $\mathrm{C} 14: 0$ & 0.1 & 0.1 & 0.1 \\
\hline Palmitic acid & $\mathrm{C} 16: 0$ & 16.88 & 14.7 & 19.2 \\
\hline Palmitoleic acid & C16:1 & 0.2 & 0.3 & 0.3 \\
\hline Stearic acid & C18:0 & 15.26 & 13.2 & 16.4 \\
\hline Oleic acid & C18:1 & 39.33 & 45.1 & 38.7 \\
\hline Linoleic acid & $\mathrm{C} 18: 2$ & 19.68 & 20.7 & 1.5 \\
\hline Linolenic acid & C18:3 & 0.3 & 0.2 & 0.5 \\
\hline Arachidic acid & C20:0 & 0.2 & 0.5 & 0.1 \\
\hline Eicosenoic acid & C20:1 & 0.2 & 0.2 & 0.2 \\
\hline Erucic acid & $\mathrm{C} 22: 1$ & 0.1 & 0.1 & 0.1 \\
\hline Lignoceric acid & $\mathrm{C} 24: 0$ & 0.1 & 0.1 & 0.1 \\
\hline Malvalic acid & $18: \mathrm{CE}$ & 5.3 & 0 & 18.54 \\
\hline \multicolumn{2}{|c|}{ Total saturated fatty acids } & 32.64 & 28.9 & 38.6 \\
\hline \multicolumn{2}{|c|}{ Total unsaturated fatty acids } & 64.61 & 66.6 & 59.8 \\
\hline
\end{tabular}

CI40CP60: Calophyllum inophyllum-Ceiba pentandra oil mixture (40:60 wt\%); CCIO: crude Calophyllum inophyllum oil; CCPO: crude Ceiba pentandra oil; CE: Cyclopropene ester.

a Fatty acid compositions measured in this study using gas chromatography system (Model: GC-14B, Shimadzu Corporation, Japan). experimental design in order to predict the CICPME yield in response to changes in the process variables (Prakash Maran and Priya, 2015b). In this study, three alkaline-catalyzed transesterification process variables (methanol-to-oil molar ratio, $\mathrm{KOH}$ catalyst concentration, and reaction time) were chosen as the factors of the experiment and each factor has three levels, resulting in 17 experimental runs. The coded and uncoded values of the process variables are presented in Table 3.

\subsubsection{Development of the ANN-ACO model}

MATLAB Version 7.10 R2010a software (The MathWorks Inc., USA) was used to develop the ANN model. A three-layer feedforward ANN model was developed in this study, with one input layer, hidden layer, and output layer, respectively. The number of input neurons was 3 (one for the methanol-to-oil ratio, KOH catalyst concentration, and reaction time, respectively) whereas the number of output neuron was 1 (CICPME yield).

Seventeen datasets from the Box-Behnken experimental design were used as the inputs for the ANN model, where each dataset represents a different combination of alkaline-catalyzed transesterification process variables (methanol-to-oil molar ratio, $\mathrm{KOH}$ catalyst concentration, and reaction time). The data were divided into three subsets, where 70,15 , and $15 \%$ of the total data points were used for training, validation, and testing, respectively. The Levenberg-Marquardt algorithm was used to train the ANN model. The hyperbolic tangent sigmoid transfer function (tansig) was used for the input layer to the hidden layer while the linear transfer function (purelin) was used from the hidden layer to the output layer. The tansig and purelin transfer functions are given by (Pinjare and Kumar, 2012):

$\operatorname{tansig}(x)=\frac{2}{\left(1+\mathrm{e}^{-2 x}\right)}-1$

$A=\operatorname{purelin}(x)=x$

The ANN model was trained until the mean squared error (MSE) reached the minimum value and average correlation coefficient $(R)$ was close or equal to 1 . Based on the heuristic procedure, the

Table 3

List of independent variables (process variables) used in the Box-Behnken experimental design for transesterification of the CI40CP60 oil mixture.

\begin{tabular}{llllll}
\hline Process variable & Unit & Coded variable & \multicolumn{3}{c}{ Coded factor levels } \\
\cline { 4 - 6 } & & & -1 & 0 & 1 \\
\hline Methanol-to-oil molar ratio & $\%$ & X1 & 30 & 45 & 60 \\
KOH catalyst concentration & wt\% & X2 & 0.50 & 1.25 & 2.00 \\
Reaction time & min & X3 & 60 & 120 & 180 \\
\hline
\end{tabular}


optimum number of hidden neurons such that the ANN architecture fulfills these requirements was found to be 9. Hence, the ANN architecture chosen for the alkaline-catalyzed transesterification process was 3-9-1, as shown in Fig. 1. The values of the weights and biases used for the ANN model are summarized in Table 4.

Following this, ACO was performed on the well-trained ANN model to optimize the alkaline-catalyzed transesterification process variables in order to maximize the CICPME yield (Toksari, 2006). The ACO refers to a swarm intelligence technique. This method solves difficult combinatorial optimization problems. It is interesting how the technique derived its name as it is foraging the behaviour of ants in the wild. This method observes the ant behaviour on how the ants leaving the pheromone along the path when they are searching their food. The quantity of pheromone deposited, which may depend on the quantity and quality of the food, will guide member of the ant colony to follow the same path to the food source. The following is a probability of an ant moving from node $i$ to node $\mathrm{j}$ : The equation (3) is the probability of an ant moving from node $\mathrm{i}$ to node $\mathrm{j}$ and equation (4) is the amount of pheromone is calculated:

$P_{i, j}=\frac{\left(\tau_{i, j}^{\alpha}\right) \cdot\left(n_{i, j}^{\beta}\right)}{\sum\left(\tau_{i, j}^{\alpha}\right) \cdot\left(n_{i, j}^{\beta}\right)}$

$\tau_{i, j}=(1-\rho) \tau_{i, j}+\Delta \tau_{i, j}$

where $\tau_{i, j}$ refers to amount of pheromone on edge $i, j$ and $\alpha$ is a parameter to control the influence of $\tau_{i, j}$ while $n_{i, j}$ is the desirability of edge $i, j$ (usually $1 / d_{i, j}$ ), [fx] is a parameter to control the influence of $n_{i, j}, \rho$ is the rate of its evaporations, and $\Delta \tau_{i, j}$ is the amount deposited.

If ant $k$ travels on edge $i, j$, the amount of pheromone deposited is given by: Supposing $k$ refers to ant that travels on edge $i, j$, the pheromone amount deposit is calculated by:

$\Delta \tau_{i, j}^{k}=\left\{\begin{array}{c}0, \text { Otherwise } \\ \frac{1}{L_{k}}\end{array}\right.$

where $L_{k}$ is the cost of the $k$ th ant's tour (typical length).

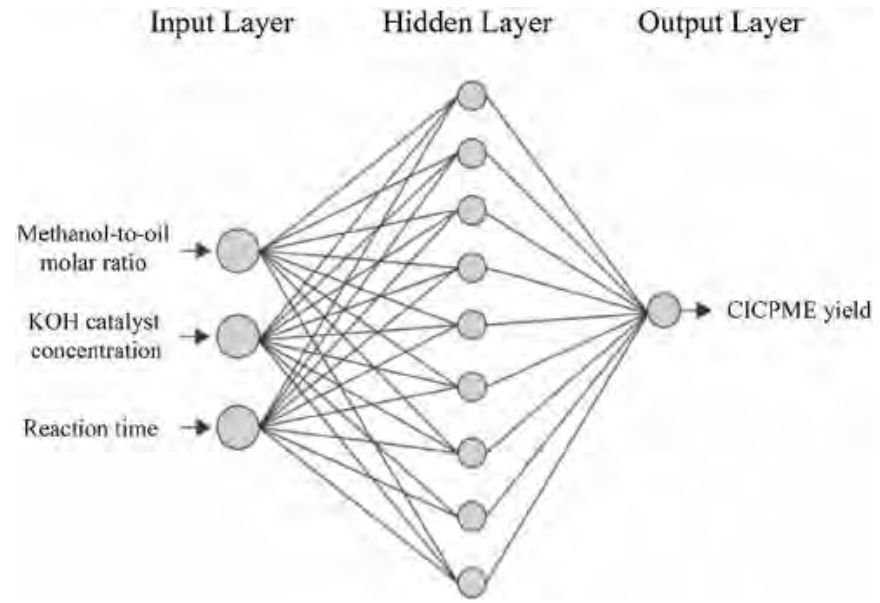

Fig. 1. ANN architecture used to predict the CICPME yield in response to variations in the methanol-to-oil molar ratio, KOH catalyst concentration, and reaction time of the alkaline-catalyzed transesterification process.

\subsubsection{Assessment of the performance and validation of the ANN-} ACO model

The $R^{2}$ value and MAPE were used to evaluate the performance of the ANN-ACO model using the following equations (Betiku et al., 2014):

$R^{2}=1-\sum_{i=1}^{n}\left(\frac{\left(y_{e i}-y_{p i}\right)^{2}}{\left(y_{m}-y_{p i}\right)^{2}}\right)$

$\operatorname{MAPE}(\%)=\sum_{i=1}^{n}\left|\frac{y_{e i}-y_{p i}}{y_{e i}}\right| \times 100$

where $n$ is the number of experimental data, $y_{e i}$ is the CICPME yield predicted by the Box-Behnken experimental design, $y_{p i}$ is the CICPME yield predicted by the ANN-ACO model, and $y_{m}$ is the average CICPME yield determined from the Box-Behnken experimental design. The ANN-ACO model is said to have superior performance (high prediction capability) if the $R^{2}$ value is maximum and the MAPE is minimum. In general, the $R^{2}$ value should not be less than $80 \%$ (Stamenković et al., 2013).

Independent experiments were then performed to produce the CICPME by acid-catalyzed esterification and alkaline-catalyzed transesterification of the CI40CP60 oil mixture using the optimum values of transesterification process variables predicted by the ANN-ACO model. The average CICPME yield was determined from the experimental replicates and compared with the maximum CICPME yield predicted by the ANN-ACO model in order to validate the reliability of the ANN-ACO model.

\subsubsection{Sensitivity analysis}

Sensitivity analysis was performed to determine the relative importance of each process variable on the CICPME yield. In this study, the equation proposed by Garson (1991) was used to determine the relative importance of each input variable (methanol-tooil ratio, $\mathrm{KOH}$ catalyst concentration, and reaction time) on the response variable (CICPME yield). This equation is based on partitioning the connection of the weights, as follows:

$K_{l}=\frac{\sum_{p=1}^{p=N_{y}}\left(\left(\left|S_{l p}^{x y}\right| / \sum_{r=1}^{N_{x}}\left|S_{r p}^{x y}\right|\right) \times\left|S_{p q}^{y z}\right|\right)}{\sum_{r=1}^{r=N_{x}}\left\{\sum_{p=1}^{p=N_{y}}\left(\left|S_{r p}^{x y}\right| / \sum_{r=1}^{N_{x}}\left|S_{r p}^{x y}\right|\right) \times\left|S_{p q}^{y z}\right|\right\}}$

where $K_{l}$ represents the percentage of influence of the input variable $l$ on the output variable, $N_{x}$ represents the input neuron, $N_{y}$ represents the hidden neuron, and $S$ is the connection weight. The superscripts $x, y$, and $z$ represent the input, hidden, and output layers, respectively, whereas the subscripts $r, p$, and $q$ represent the input, hidden, and output neurons, respectively.

\subsection{Phase 3: Biodiesel production by acid-catalyzed esterification followed by alkaline-catalyzed transesterification}

\subsubsection{Experimental setup}

The experimental setup used for acid-catalyzed esterification and alkaline-catalyzed transesterification is described in this section. In this study, acid-catalyzed esterification is necessary because of the high acid values of the CI40CP60 oil mixture (16.66 mg KOH $\mathrm{g}^{-1}$ ), CCIO (35.77 $\mathrm{mg} \mathrm{KOH} \mathrm{g}^{-1}$ ), and CCPO (15.38 $\mathrm{mg} \mathrm{KOH} \mathrm{g}^{-1}$ ), which will lead to saponification during alkaline-catalyzed transesterification. The acid value is a measure of the free fatty acid content of the crude oil and it is measured by the amount of $\mathrm{KOH}$ (in $\mathrm{mg}$ ) required to neutralize the acid constituents in $1 \mathrm{~g}$ of oil sample. 
Table 4

Values of the weights and biases used in the ANN model.

\begin{tabular}{|c|c|c|c|c|c|c|}
\hline \multirow[t]{2}{*}{ Neuron } & \multicolumn{3}{|c|}{ Input weights } & \multirow[t]{2}{*}{ Output weight } & \multirow[t]{2}{*}{ Bias to layer 1} & \multirow[t]{2}{*}{ Bias to layer 2} \\
\hline & $\mathrm{X} 1$ & $\mathrm{X} 2$ & $\mathrm{X} 3$ & & & \\
\hline 1 & 0.738 & 1.245 & 2.057 & 0.783 & -3.209 & -0.181 \\
\hline 2 & -1.052 & 1.609 & 1.754 & -0.071 & 2.486 & \\
\hline 3 & -1.643 & -1.609 & -1.753 & -0.145 & 1.389 & \\
\hline 4 & -2.655 & -1.405 & -0.300 & 1.138 & 0.712 & \\
\hline 5 & -1.795 & -2.222 & 0.590 & -0.517 & -0.495 & \\
\hline 6 & -0.308 & 1.168 & 2.731 & -0.265 & -1.107 & \\
\hline 7 & -1.314 & 0.945 & 2.753 & -0.644 & -1.143 & \\
\hline 8 & 0.914 & 0.833 & 2.489 & 0.344 & 2.375 & \\
\hline 9 & -2.376 & -1.443 & -0.011 & -0.079 & -2.998 & \\
\hline
\end{tabular}

The acid value of the feedstock should be less than $2 \mathrm{mg} \mathrm{KOH} / \mathrm{g}$ (which corresponds to $\sim 1 \%$ of free fatty acid content) prior to alkaline-catalyzed transesterification. After acid-catalyzed esterification, the esterified CI40CP60 oil mixture, CCIO, and CCPO were transesterified with methanol in the presence of $\mathrm{KOH}$ catalyst to produce the CICPME, CIME, and CPME, respectively.

Both of the esterification and transesterification processes were carried out using a 1-L three-necked glass flask (with rubber stoppers) connected to a reflux condenser and a refrigerated bath circulator. The reflux condenser was used to prevent losses of the evaporated methanol during the esterification/transesterification reactions. The oil temperature (reaction temperature) was kept relatively constant using WiseCircu ${ }^{\circledR}$ precise digital refrigerated bath circulator (Model: WCR-P8, Daihan Scientific, South Korea) and monitored using a thermometer. The reaction mixture (consisting of methanol, $\mathrm{H}_{2} \mathrm{SO}_{4}$ or $\mathrm{KOH}$ catalyst, and oil sample) was stirred continuously throughout the esterification/transesterification process using a digital overhead stirrer (Model: IKA ${ }^{\circledR}$ RW 16, IKA-Werke GmbH \& Co. KG, Germany) to ensure homogeneous mixing of the reactants.

\subsubsection{In situ acid-catalyzed esterification and alkaline-catalyzed transesterification}

The procedure used for acid-catalyzed esterification and alkalinecatalyzed transesterification is described in this section. Acidcatalyzed esterification was first carried out to pretreat the crude CI40CP60 oil mixture, where the oil mixture was poured into the three-necked glass flask preheated at $60{ }^{\circ} \mathrm{C}$. Next, methanol (methanol-to-oil ratio: 9:1) and $\mathrm{H}_{2} \mathrm{SO}_{4}$ (catalyst concentration: 1 vol\%) were added into the reactor containing the oil sample. The reaction mixture was stirred continuously using the digital overhead stirrer throughout the esterification process at a stirring speed of $1000 \mathrm{rpm}$ for $3 \mathrm{~h}$. The reaction temperature was kept constant at $60^{\circ} \mathrm{C}$.

Following this, alkaline-catalyzed transesterification was carried out on the esterified CI40CP60 oil mixture maintained at a temperature of $60^{\circ} \mathrm{C}$. The amount of methanol and $\mathrm{KOH}$ catalyst were measured and mixed together until the $\mathrm{KOH}$ pellets were completely dissolved in the methanol. Next, the methanol-KOH mixture was added into the esterified $\mathrm{CI} 40 \mathrm{CP} 60$ oil mixture. The reaction mixture was stirred continuously throughout the transesterification process using the digital overhead stirrer at a stirring speed of $1000 \mathrm{rpm}$. The reaction temperature was kept constant at $60^{\circ} \mathrm{C}$.

The following alkaline-catalyzed transesterification process variables were varied in order to examine the effects of these variables on the CICPME yield: (1) methanol-to-oil molar ratio: 30-60\%, (2) KOH catalyst concentration: $0.5-2.0$ wt\%, and (3) reaction time: $60-180 \mathrm{~min}$. Once the transesterification process was complete, the reaction mixture was transferred into a separatory funnel and the reaction mixture was left to settle for $8 \mathrm{~h}$ in order to separate the CICPME from glycerin by gravity. Indeed, two layers formed after the separation process, where the top layer was the
CICPME. The bottom layer contained a mixture of glycerin and impurities and this layer was drained off from the separatory funnel by opening the stopcock. Lastly, the CICPME was evaporated using a rotary evaporator and then stored in a vacuum chamber to prevent the methyl ester from oxidation. The CIME and CPME were prepared using the same procedure.

\subsubsection{Measurement of the FAME content and determination of the CICPME yield}

The methyl ester yield is a measure of the effectiveness of the conversion of triglycerides in the oil into FAME. Therefore, it can be said that the methyl ester yield indicates the degree of success of biodiesel production. In this study, the FAME content was analyzed using a gas chromatography system (Model: Agilent 7890, Agilent Technologies, Inc., USA) equipped with a flame ionization detector and helium was used as the carrier gas. Agilent HP-INNOWax capillary column (column length: $30 \mathrm{~m}$, inner diameter: $0.25 \mathrm{~mm}$, film thickness: $0.25 \mu \mathrm{m}$, split injection ratio: $1: 20$ ) was used for the measurements. The peaks in the gas chromatogram corresponding to the FAMEs were identified by comparing their retention times with the retention times of a highly purified FAME standard (FAME mix $\left.C_{8}-C_{24}\right)$. The FAME content was determined using the following equation:

$F A M E=\frac{\left(\sum A\right)-A_{E I}}{A_{E I}} \times \frac{m_{E I}}{m} \times 100$

Here, FAME denotes the FAME content in weight percent (wt\%), $\sum A$ denotes the total peak area of the FAME content from $C_{14}$ to $C_{24: 0}$, $A_{E I}$ denotes the peak area of the internal standard (methyl nonadecanoate, $\left.C_{19}\right), m_{E I}$ denotes the mass of the internal standard in milligrams (mg), and $m$ is the mass of the methyl ester sample in milligrams ( $\mathrm{mg})$.

The CICPME yield is defined as the mass percentage of the final product (transesterified $\mathrm{CI} 40 \mathrm{CP} 60$ oil mixture) relative to the mass of the CI40CP60 oil mixture prior to biodiesel production. In this study, the average CICPME yield (i.e., average yield of the transesterified CI40CP60 oil mixture) determined from experimental replicates based on the optimum transesterification process variables predicted by the ANN-ACO model in order to validate the ANN-ACO model. The CICPME yield was calculated using the following equation:

$C I C P M E_{Y}=\frac{F A M E \times W M E_{C I 40 C P 60}}{W O_{C I 40 C P 60}} \times 100$

where CICPME $E_{Y}$ represents the CI40CP60 methyl ester yield in percent (\%), FAME is the FAME content in weight percent (wt\%), $W M E_{C I 40 C P 60}$ is the mass of the CI40CP60 methyl ester sample in grams $(\mathrm{g})$, and $W O_{C I 40 C P 60}$ is the mass of the CI40CP60 oil mixture in grams $(\mathrm{g})$. 


\subsection{Phase 4: Kinetics study}

Kinetics study was performed to understand the mechanism underlying transesterification of the CI40CP60 oil mixture. In this case, the term "mechanism" refers to the rate at which the transesterification reaction takes place. The optimum values of the methanol-to-oil molar ratio and $\mathrm{KOH}$ catalyst concentration predicted by the ANN-ACO model were used for the kinetics study and the stirring speed was fixed at $1000 \mathrm{rpm}$. The reaction temperature $(323,328$, and $333 \mathrm{~K})$ and reaction time $(60,90,120$, and $150 \mathrm{~min})$ were varied to investigate their effects on the rate of the transesterification reaction.

In this study, the alkaline-catalyzed transesterification of the CI40CP60 oil mixture was assumed to be a three-step reversible process, as shown in Fig. 2. It was assumed that methanol was supplied in excess.

The overall transesterification reaction results in the formation of $3 \mathrm{~mol}$ of mono-alkyl esters, as given by Eq. (11):

$\mathrm{TG}+3 \mathrm{CH}_{3} \mathrm{OH} \leftrightarrow \mathrm{RCOOCH}_{3}+\mathrm{Gly}$

The transesterification reaction is described by a first-order kinetics model, where the rate constant is dependent on the increase in the concentration of product within a specific time interval. In this study, the rate constant of the transesterification reaction was evaluated based on the concentration of CICPME formed during the reaction. In other words, the rate constant of the transesterification reaction was assessed based on the variation of the CICPME yield with respect to time.

The rate of reaction for a first-order reaction is given by:

$r=\frac{d a}{d t}=k(T) f(a)$

where $a$ is the CICPME concentration in weight percent (wt\%) and $k(T)$ is the global reaction rate constant (which is a temperaturedependent term), and $T$ is the reaction temperature in Kelvin (K).

The global reaction rate constant obeys the Arrhenius law:

$k(T)=k=A \exp ^{(-E / R ̃ T)}$

where $A$ is the frequency factor, $E$ is the activation energy, and $\check{R}$ is the gas constant $\left(8.314 \mathrm{~J} \mathrm{~mol}^{-1} \mathrm{~K}^{-1}\right)$. Assuming that a simple $n^{\text {th }}$ order kinetic relationship holds true for the conversion-dependent term, $f(a)$, such that $f(a)=(1-a)^{n}$ and noting that $k(T)=k$, Eq. (12) can be written as:

$r=\frac{d a}{d t}=k(1-a)^{n}$

Eq. (14) can be rewritten in linear form as follows:

$\left[\left(1-(1-a)^{1-n}\right) /(1-n)\right]=k t(n \neq 1)$

Following this, a graph was plotted for $\left[\left(1-(1-a)^{1-n}\right) /(1-n)\right]$ against time $t$, where $k$ is the slope of the graph and it represents

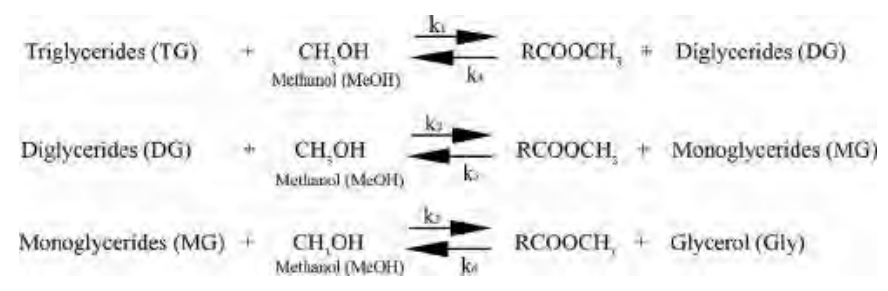

Fig. 2. Three-step reversible transesterification process. the global reaction rate constant. It shall be noted that $n \neq 1$. The proper value of $n$ would give the best straight line for all reaction temperatures considered in this study. The best straight line is defined as the line that gives the highest $R^{2}$ value for all data points in each plot. The activation energy and frequency factor of the transesterification process can be determined using Eq. (13). The plot $\ln k$ versus the reciprocal of the reaction temperature $1 / T$ can be obtained by determining the global reaction rate constants at different reaction temperatures, which will give a linear plot with a slope of $-E / \check{R}$ and intercept of $\ln A$.

\section{Results and discussion}

\subsection{ANN-ACO model}

\subsubsection{Optimization of the alkaline-catalyzed transesterification} process variables

Table 5 shows the CICPME yield values predicted by the BoxBehnken design and ANN-ACO model for different combinations of methanol-to-oil molar ratio, $\mathrm{KOH}$ catalyst concentration, and reaction time of the transesterification process. In general, it can be seen that there is good agreement between the CICPME yield values predicted by both approaches. The ANN-ACO model was then used to optimize the alkaline-catalyzed transesterification process variables in order to maximize the CICPME yield. The optimum values of the methanol-to-oil molar ratio, $\mathrm{KOH}$ catalyst concentration, and reaction time predicted by the ANN-ACO model are 37\%, $0.78 \mathrm{wt} \%$, and $153 \mathrm{~min}$, respectively. The corresponding CICPME yield was $95.87 \%$.

\subsubsection{Performance and validation of the ANN-ACO model}

The $R^{2}$ value and MAPE were determined in order to assess the performance of the ANN-ACO model. The $R^{2}$ value was determined by plotting the CICPME yield values predicted by the ANN-ACO model against those predicted by the Box-Behnken experimental design, as shown in Fig. 3. It can be seen that there is very good agreement between the predicted and experimental CICPME yield values. The $R^{2}$ value is found to be 0.9951 , which indicates that the ANN-ACO model describes $99.51 \%$ of the variability in the CICPME yield, which is desirable because the $R^{2}$ value is more than $80 \%$ (Noordin et al., 2004; Chen et al., 2008). The MAPE is found to be $0.2260 \%$, as shown in Table 5 . Based on the $R^{2}$ value and MAPE, it can be deduced that the ANN model is reliable to predict the CICPME yield in response to variations in the methanol-to-oil molar ratio, $\mathrm{KOH}$ catalyst concentration, and reaction time. Independent experiments were also performed to produce the CICPME based on the optimum alkaline-catalyzed transesterification process variables predicted by the ANN-ACO model and the average CICPME yield was determined to be $95.18 \%$, which is close to the maximum CICPME yield predicted by the ANN-ACO model (95.87\%). This further confirms that ANN-ACO model is a reliable tool to predict the optimum process variables for alkaline-catalyzed transesterification in order to boost biodiesel production.

\subsubsection{Relative importance of each process variable on the CICPME yield}

The relative importance of each process variable (i.e., methanolto-oil molar ratio, $\mathrm{KOH}$ catalyst concentration, and reaction time) on the CICPME yield was determined and the results are shown in Fig. 4. It is apparent that the methanol-to-oil molar ratio has the most significant effect on the CICPME yield (35.46\%), followed by the $\mathrm{KOH}$ catalyst concentration (33.88\%). The reaction time has the least significant effect on the CICPME yield (30.66\%). However, it is also apparent that the relative importance of each process variable does not vary considerably from one another, judging from the percentage values. 
Table 5

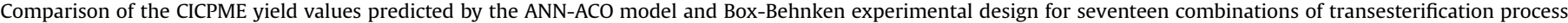
variables.

\begin{tabular}{|c|c|c|c|c|c|}
\hline Experimental run & Methanol-to-oil molar ratio (\%) & $\mathrm{KOH}$ catalyst concentration (wt\%) & Reaction time (min) & Experimental CICPME yield (\%) & Predicted CICPME yield (\%) \\
\hline 1 & 45 & 1.25 & 120 & 92.88 & 92.18 \\
\hline 2 & 45 & 1.25 & 120 & 92.72 & 92.18 \\
\hline 3 & 45 & 1.25 & 120 & 92.67 & 92.18 \\
\hline 4 & 30 & 1.25 & 180 & 86.65 & 86.88 \\
\hline 5 & 45 & 0.50 & 180 & 87.09 & 87.09 \\
\hline 6 & 45 & 2.00 & 180 & 80.33 & 80.33 \\
\hline 7 & 30 & 0.50 & 120 & 88.06 & 88.06 \\
\hline 8 & 30 & 1.25 & 60 & 87.94 & 87.94 \\
\hline 9 & 60 & 1.25 & 180 & 84.24 & 84.24 \\
\hline 10 & 60 & 2.00 & 120 & 79.26 & 79.26 \\
\hline 11 & 45 & 1.25 & 120 & 92.64 & 92.18 \\
\hline 12 & 60 & 0.50 & 120 & 82.94 & 82.94 \\
\hline 13 & 60 & 1.25 & 60 & 85.07 & 85.07 \\
\hline 14 & 30 & 2.00 & 120 & 79.22 & 79.22 \\
\hline 15 & 45 & 1.25 & 120 & 91.18 & 92.18 \\
\hline 16 & 45 & 2.00 & 60 & 81.67 & 81.97 \\
\hline 17 & 45 & 0.50 & 60 & 88.60 & 88.60 \\
\hline$R^{2}$ & 0.9951 & & & & \\
\hline MAPE (\%) & 0.2260 & & & & \\
\hline
\end{tabular}

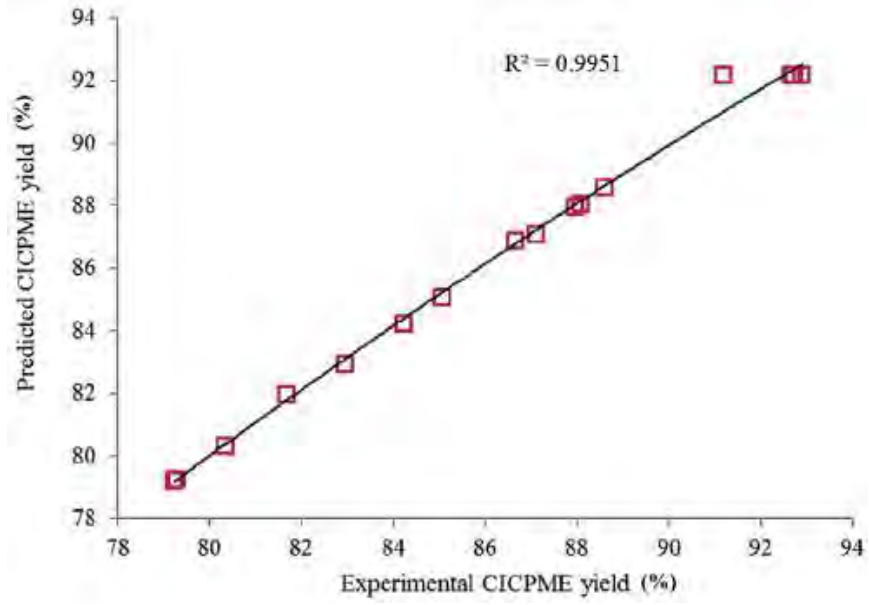

Fig. 3. Comparison between the CICPME yield values predicted by the ANN-ACO model and CICPME yield values predicted by the Box-Behnken experimental design.

\subsection{Effects of transesterification process variables on the CICPME} yield

\subsubsection{Effect of methanol-to-oil molar ratio}

Based on the results obtained from the sensitivity analysis, the methanol-to-oil molar ratio has the most significant effect on the CICPME yield. Experiments were performed to investigate the effect of the methanol-to-oil molar ratio on the CICPME yield and the results are shown in Fig. 5. The $\mathrm{KOH}$ catalyst concentration, reaction temperature, reaction time, and stirring speed were fixed at $0.78 \mathrm{wt}$

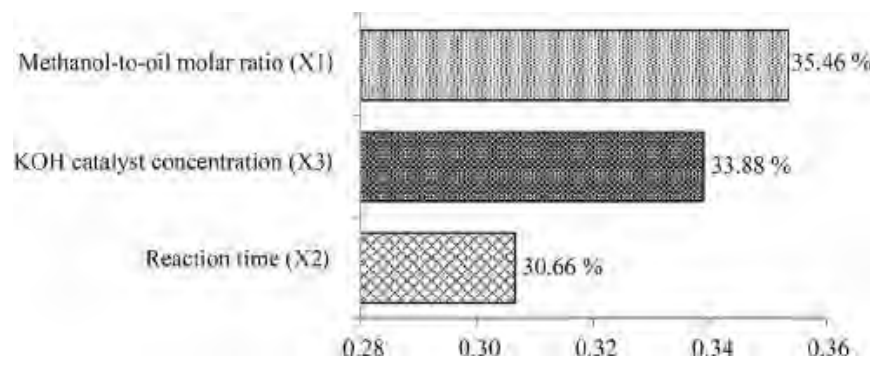

Fig. 4. Relative importance of each process variable on the CICPME yield.
$\%, 60^{\circ} \mathrm{C}, 153 \mathrm{~min}$, and $1000 \mathrm{rpm}$, respectively. It can be observed that the CICPME yield increases as the methanol-to-oil molar ratio increases from $30 \%$ to $37 \%$ where the CICPME yield reaches its maximum value (95.87\%). However, the CICPME yield gradually decreases when the methanol-to-oil molar ratio is increased further from $37 \%$ to $50 \%$. The CICPME yield decreases significantly beyond a methanol-to-oil molar ratio of $50 \%$, which is likely due to emulsification of the CICPME and glycerol. This makes it difficult to separate the CICPME from glycerol.

\subsubsection{Effect of $\mathrm{KOH}$ catalyst concentration}

The effect of $\mathrm{KOH}$ catalyst concentration on the CICPME yield is shown in Fig. 6. The methanol-to-oil molar ratio, reaction temperature, reaction time, and stirring speed were kept constant at $37 \%, 60^{\circ} \mathrm{C}, 153 \mathrm{~min}$, and $1000 \mathrm{rpm}$, respectively. The $\mathrm{KOH}$ catalyst concentration was varied from $0.50 \mathrm{wt} \%$ to $2.0 \mathrm{wt} \%$. It can be observed that the CICPME yield slightly increases from $94.68 \%$ to $95.38 \%$ when the $\mathrm{KOH}$ catalyst concentration is increased from 0.50 to $0.75 \mathrm{wt} \%$. The highest CICPME yield $(95.88 \%)$ is attained when the $\mathrm{KOH}$ catalyst concentration is $0.78 \mathrm{wt} \%$. The CICPME yield decreases gradually when the $\mathrm{KOH}$ catalyst concentration increases beyond $0.78 \mathrm{wt} \%$, which is likely due to saponification.

\subsubsection{Effect of reaction time}

Likewise, the effect of reaction time on the CICPME yield was investigated and the results are shown in Fig. 7. The methanol-tooil molar ratio, $\mathrm{KOH}$ catalyst concentration, reaction temperature, and stirring speed were fixed at $37 \%, 0.78 \mathrm{wt} \%, 60^{\circ} \mathrm{C}$, and $1000 \mathrm{rpm}$, respectively. It can be seen that the CICPME yield increases gradually from $88.23 \%$ to $95.52 \%$ when the reaction time is increased from $60 \mathrm{~min}$ to $150 \mathrm{~min}$. The CICPME yield is highest (95.87\%) when the reaction time is $153 \mathrm{~min}$ and the CICPME yield is almost invariant thereafter. Jain et al. (2011) also observed a similar trend, where the methyl ester yield increased up to the optimum reaction time $(2 \mathrm{~h})$ and then decreased as the reaction time further increased.

\subsection{Physicochemical properties of the CICPME, CIME, and CPME}

The physicochemical properties of the CICPME (i.e., methyl ester produced by acid catalyzed-esterification and alkaline-catalyzed transesterification of the CI40CP60 oil mixture) were measured and the results are summarized in Table 6. 


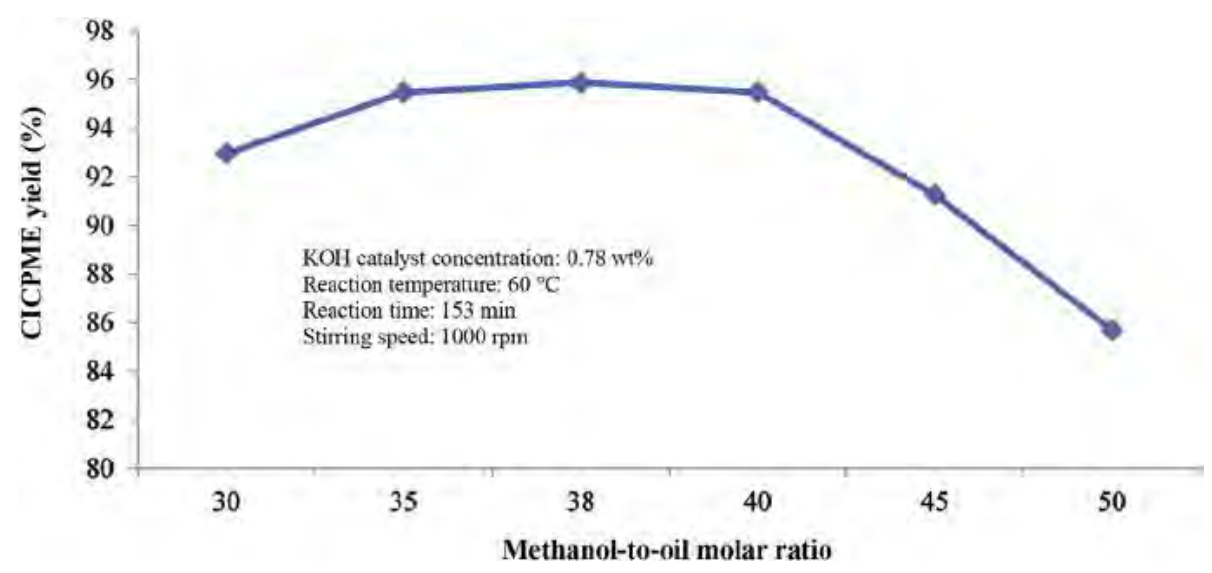

Fig. 5. Effect of methanol-to-oil molar ratio on the CICPME yield obtained from laboratory experiments.

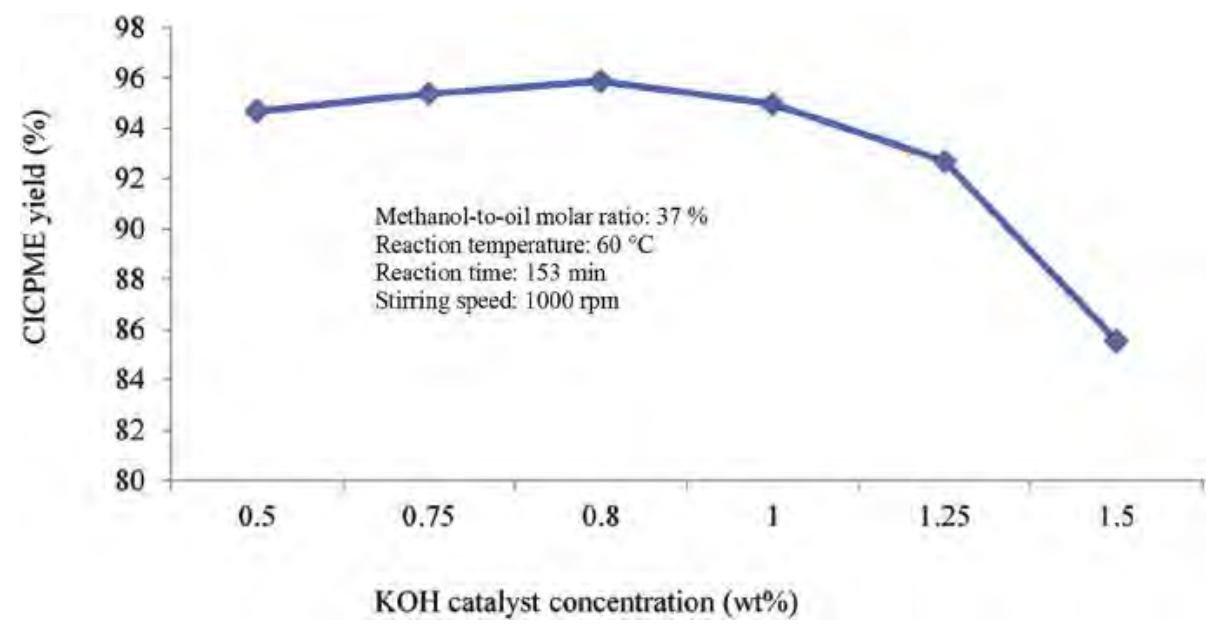

Fig. 6. Effect of $\mathrm{KOH}$ catalyst concentration on the CICPME yield obtained from laboratory experiments.

Kinematic viscosity is an important property because it will affect the fluidity of the fuel and fuel spray characteristics (droplet size and air-fuel ratio needed for complete combustion) when the fuel is injected into the combustion chamber. A high fuel kinematic viscosity is undesirable because it will lead to the formation of soot as well as engine deposits due to insufficient fuel atomization (Abedin et al., 2016). According to the ASTM D6751 and EN 14214 standards, the fuel kinematic viscosity should be within a range of
$1.90-6.00 \mathrm{~mm}^{2} \mathrm{~s}^{-1}$ and $3.50-5.00 \mathrm{~mm}^{2} \mathrm{~s}^{-1}$, respectively. The kinematic viscosity of the CICPME is $3.72 \mathrm{~mm}^{2} \mathrm{~s}^{-1}$, which fulfils the specification given in both standards. The kinematic viscosity of the CICPME is lower than those for CIME $\left(4.33 \mathrm{~mm}^{2} \mathrm{~s}^{-1}\right)$ and CPME $\left(4.62 \mathrm{~mm}^{2} \mathrm{~s}^{-1}\right)$, which is desirable. However, the kinematic viscosity of diesel $\left(2.87 \mathrm{~mm}^{2} \mathrm{~s}^{-1}\right)$ is significantly lower than that of CICPME. The kinematic viscosity of the CIME obtained in this study $\left(4.33 \mathrm{~mm}^{2} \mathrm{~s}^{-1}\right)$ is comparable to that obtained by Jahirul et al.

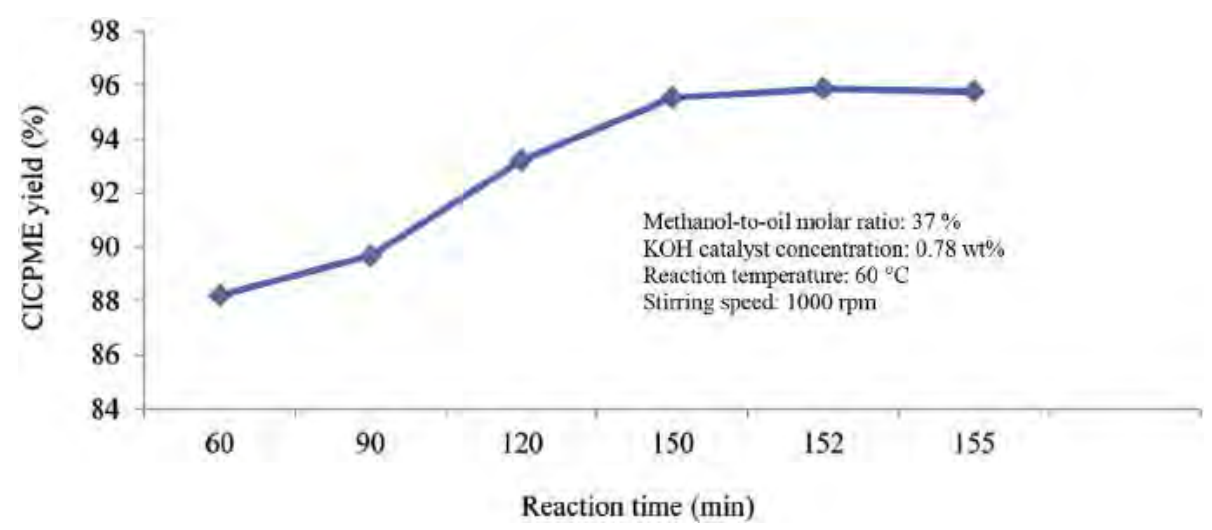

Fig. 7. Effect of reaction time on the CICPME yield obtained from laboratory experiments. 
(2015) $\left(4.46 \mathrm{~mm}^{2} \mathrm{~s}^{-1}\right)$. The kinematic viscosity of the CPME obtained in this study $\left(4.62 \mathrm{~mm}^{2} \mathrm{~s}^{-1}\right)$ is also comparable to that obtained by Senthil Kumar et al. (2015) $\left(4.20 \mathrm{~mm}^{2} \mathrm{~s}^{-1}\right)$.

Based on the ASTM D6751 and EN 14214 standards, the fuel density should be lower than $880 \mathrm{~kg} \mathrm{~m}^{-3}$ (maximum) and between 860 and $900 \mathrm{~kg} \mathrm{~m}^{-3}$, respectively. Fuel density is equally important especially in airless combustion systems because this property will affect the efficiency of fuel atomization (Atabani et al., 2013). In this study, the density of the CICPME is found to be $866.5 \mathrm{~kg} \mathrm{~m}^{-3}$, which is well within the range specified in both standards. The density of the CICPME is slightly higher than those for diesel $\left(839.4 \mathrm{~kg} \mathrm{~m}^{-3}\right)$ and CIME $\left(862.8 \mathrm{~kg} \mathrm{~m}^{-3}\right.$ ) and significantly lower than that for CPME $\left(880.5 \mathrm{~kg} \mathrm{~m}^{-3}\right)$. However, the density of the CIME obtained in this study $\left(862.8 \mathrm{~kg} \mathrm{~m}^{-3}\right)$ is significantly lower than that obtained by Jahirul et al. (2015) ( $894.0 \mathrm{~kg} \mathrm{~m}^{-3}$ ) whereas the density of the CPME obtained in this study $\left(880.5 \mathrm{~kg} \mathrm{~m}^{-3}\right)$ is significantly higher than that obtained by Senthil Kumar et al. (2015) $\left(860.0 \mathrm{~kg} \mathrm{~m}^{-3}\right)$. Despite these variations (which may be attributed to differences in the quality of the feedstocks, procedure for biodiesel production, and instruments used for physicochemical property measurements), the density values of the CIMEs and CPMEs fulfill the requirements stipulated in the EN 14214 standard.

The flash point was measured to determine the temperature at which the fuel will ignite when the fuel is exposed to flame or spark. Even though the flash point is not related to the engine performance, it is still an important property because a fuel with a high flash point will reduce the risk of fire hazards, which is crucial for transportation and long-term storage of the fuel. According to the ASTM D6751 and EN 14214 standards, biodiesels should have a minimum flash point of $100.0-170.0^{\circ} \mathrm{C}$ and $101.0^{\circ} \mathrm{C}$, respectively. The flash point of the CICPME is found to be $122.5^{\circ} \mathrm{C}$, which is slightly higher than the minimum values specified in both standards. The flash points of the CIME and CPME are also similar, with a value of 123.5 and $125.5^{\circ} \mathrm{C}$, respectively. Interestingly, the flash point of the CIME obtained by Jahirul et al. (2015) $\left(145.64^{\circ} \mathrm{C}\right)$ is similar to that of the CPME obtained by Senthil Kumar et al. (2015) $\left(148.00^{\circ} \mathrm{C}\right)$ and the values are significantly higher than those obtained for the CIME and CPME in this study. In general, all of the methyl esters have significantly higher flash points compared with diesel $\left(78.5^{\circ} \mathrm{C}\right)$, indicating that they are favorable as diesel substitutes.

The cold flow properties of the CICPME, CIME, and CPME were also measured in this study because the cold flow properties will vary from one biodiesel to another (Jurac and Zlatar, 2013). The pour point, cloud point, and cold filter plugging point of the CICPME are $-1.5,-1.0$, and $-0.5^{\circ} \mathrm{C}$, respectively. In contrast, the pour point, cloud point, and cold filter plugging point of the CIME are $1.5,1.5$, and $0.5^{\circ} \mathrm{C}$, respectively, while the values of these properties for the CPME are $2.0,2.0$, and $1.8^{\circ} \mathrm{C}$, respectively. The pour point, cloud point, and cold filter plugging point of diesel are $2.0,2.0$, and $0.0^{\circ} \mathrm{C}$, respectively, which are similar to those for CIME and CPME. In general, the cold flow properties of the CICPME are superior compared with those for diesel and other biodiesels produced in this study. The lower the pour point, cloud point, and cold filter plugging point, the better the behaviour of the fuel in cold weather. These properties are important especially for cold climate regions because they determine the point at which the fuel will begin to crystalize and then solidify. The fuel will clog the fuel lines as it solidifies and loses its ability to flow (Dwivedi and Sharma, 2014), which will create starting problems in the engine. In addition, the engine control unit will not be able to collect accurate data for fuel control as a result of the clogged fuel lines, which will induce instability in the ignition system and lead to more nitrogen oxide and particulate matter emissions.

The heating value reflects the energy content of the fuel. Biodiesels typically have lower heating values compared with diesel because of their oxygen content. It is found that the heating value of the CICPME is $41.43 \mathrm{MJ} \mathrm{kg}^{-1}$, which is lower than that for diesel $\left(45.67 \mathrm{MJ} \mathrm{kg}^{-1}\right)$. The heating values of the CIME and CPME are similar, with a value of 39.67 and $39.78 \mathrm{MJ} \mathrm{kg}^{-1}$, respectively. The EN 14214 standard recommends a minimum heating value of $35.00 \mathrm{MJ} \mathrm{kg}^{-1}$ and therefore, all of the methyl esters produced in this study fulfils this requirement, which is more than satisfactory. The heating value of the CIME obtained in this study (39.67 $\mathrm{MJ} \mathrm{kg}^{-1}$ ) is slightly lower than that obtained by Jahirul et al. (2015) (40.85 $\mathrm{MJ} \mathrm{kg}^{-1}$ ) whereas the heating value of the CPME obtained in this study $\left(39.78 \mathrm{MJ} \mathrm{kg}^{-1}\right)$ is comparable to that obtained by Senthil Kumar et al. (2015) (39.40 $\mathrm{MJ} \mathrm{kg}^{-1}$ ).

Table 6

Comparison of the physicochemical properties between CICPME and other fuels.

\begin{tabular}{|c|c|c|c|c|c|c|c|c|c|c|}
\hline \multirow[t]{2}{*}{ Property } & \multirow[t]{2}{*}{ Unit } & \multirow[t]{2}{*}{ Diesel $^{\mathrm{a}}$} & \multirow[t]{2}{*}{ ASTM D6751 } & \multirow[t]{2}{*}{ EN 14214} & \multicolumn{6}{|c|}{ Biodiesels and biodiesel blends } \\
\hline & & & & & $\mathrm{CIME}^{\mathrm{a}}$ & $\begin{array}{l}\text { CIME (Jahirul et al., } \\
\text { 2015) }\end{array}$ & $\mathrm{CPME}^{\mathrm{a}}$ & $\begin{array}{l}\text { CPME (Senthil Kumar et al., } \\
\text { 2015) }\end{array}$ & $\mathrm{CICPME}^{\mathrm{a}}$ & $\begin{array}{l}\text { JCPPM (Yogish et al., } \\
\text { 2012) }\end{array}$ \\
\hline $\begin{array}{l}\text { Kinematic viscosity at } \\
40^{\circ} \mathrm{C}\end{array}$ & $\mathrm{mm}^{2} \mathrm{~s}^{-1}$ & 2.87 & $1.90-6.00$ & $\begin{array}{l}3.50 \\
-5.00\end{array}$ & 4.33 & 4.46 & 4.62 & 4.20 & 3.72 & 2.55 \\
\hline Density at $15^{\circ} \mathrm{C}$ & $\mathrm{kg} \mathrm{m}^{-3}$ & 839.4 & 880.0 (max.) & $\begin{array}{l}860.0 \\
-900.0\end{array}$ & 862.8 & 894.0 & 880.5 & 860.0 & 866.5 & 828.0 \\
\hline Flash point & ${ }^{\circ} \mathrm{C}$ & 78.50 & $\begin{array}{l}100.00-170.00 \\
\text { (min.) }\end{array}$ & $>101$ & 123.50 & 145.64 & 125.50 & 148.00 & 122.50 & 121.00 \\
\hline Pour point & ${ }^{\circ} \mathrm{C}$ & 2.0 & - & - & 1.5 & - & 2.0 & 4.0 & -1.5 & - \\
\hline Cloud point & ${ }^{\circ} \mathrm{C}$ & 2.0 & - & - & 1.5 & - & 2.0 & -4.4 & -1.0 & - \\
\hline $\begin{array}{l}\text { Cold filter plugging } \\
\text { point }\end{array}$ & ${ }^{\circ} \mathrm{C}$ & 0.00 & - & - & 0.50 & 2.45 & 1.80 & - & -0.50 & - \\
\hline Heating value & $\mathrm{MJ} \mathrm{kg}^{-1}$ & 45.67 & - & 35 (min.) & 39.67 & 40.85 & 39.78 & 39.40 & 41.43 & 45.51 \\
\hline Acid value & $\begin{array}{l}\mathrm{mg} \mathrm{KOH} \\
\mathrm{g}^{-1}\end{array}$ & 0.15 & 0.50 (max.) & $\begin{array}{l}0.50 \\
(\max .)\end{array}$ & 0.41 & - & 0.38 & - & 0.25 & 0.480 \\
\hline Copper strip corrosion & - & $1 \mathrm{a}$ & 3 (max.) & - & $1 \mathrm{a}$ & - & $1 \mathrm{a}$ & - & $1 \mathrm{a}$ & - \\
\hline $\begin{array}{l}\text { Oxidation stability at } \\
110^{\circ} \mathrm{C}\end{array}$ & $\mathrm{h}$ & 13.20 & 3.00 (min.) & $\begin{array}{l}8.00 \\
(\min .)\end{array}$ & 10.02 & 4.14 & 5.22 & - & 8.44 & - \\
\hline FAME content & wt\% & - & - & 96.5 & 98.5 & - & 97.5 & - & 99.2 & - \\
\hline Cetane number & - & 48.50 & 47.00 (min.) & $\begin{array}{l}51.00 \\
(\min .)\end{array}$ & 57.00 & 56.53 & 55.00 & 51.00 & 56.00 & - \\
\hline
\end{tabular}

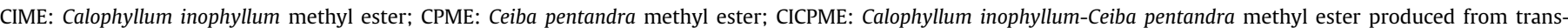
esterification of the CI40CP60 oil mixture; JCPPM: Jatropha curcas-Pongamia pinnata methyl ester (50:50 wt\%).

a Physicochemical properties measured in this study using gas chromatography system (Model: Agilent 7890, Agilent Technologies, Inc., USA). 
The acid value is a measure of the free fatty acid content of both crude oils and fuels (Ashraful et al., 2014). It is important to measure the acid value because the amount of free fatty acids affects aging of the fuel and can lead to corrosion of the fuel system. The maximum acid value of the fuel specified in the ASTM D6751 and EN 14214 standards is $0.50 \mathrm{mg} \mathrm{KOH} \mathrm{g}^{-1}$. In this study, it is found that the acid value of the CICPME is $0.25 \mathrm{mg} \mathrm{KOH} \mathrm{g}^{-1}$, which is desirable. The lower acid value of the CICPME can be attributed to the sufficient removal of methanol, glycerin, and foreign impurities after the alkaline-catalyzed transesterification process. The acid values were also measured for the CIME $\left(0.41 \mathrm{mg} \mathrm{KOH} \mathrm{g}^{-1}\right)$ and CPME (0.38 $\mathrm{mg} \mathrm{KOH} \mathrm{g}^{-1}$ ) for comparison and it is evident that the CICPME has the lowest acid value among the biodiesels prepared in this study. This indicates the advantage of producing biodiesel from non-edible oil mixture and the benefits of acid-catalyzed esterification and alkaline-catalyzed transesterification. The acid value of the CICPME is only slightly higher than that for diesel $(0.15 \mathrm{mg} \mathrm{KOH}$ $\mathrm{g}^{-1}$ ) and therefore, it is a favorable substitute for diesel as it is likely to have lower corrosion rate compared with the CIME and CPME. Based on the results of the corrosion strip test, it is found that the CICPME, CIME, and CPME only result in a slight tarnish on coppercontaining materials, as indicated by the value " $1 \mathrm{a}$ ". This indicates that the presence of acidic and sulfuric compounds is low (even though there are no quantitative measurements) for the biodiesels produced in this study, which is complementary to the acid value results.

Because the CICPME, CIME, and CPME are all produced from crude non-edible oils with high unsaturated fatty acid content (Table 1) and therefore, they have higher reactivity with oxygen, it is important to measure the oxidation stability of these fuels. Oxidation stability is the tendency of a fuel to react with oxygen at temperatures close to the ambient temperature and it indicates the susceptibility of the fuel to degradation as a result of this reaction (Pullen and Saeed, 2012). The lower the oxidation stability, the higher the tendency of the fuel to oxidize, which will lead to the formation of acids and these by-products will corrode the components of the diesel engine. According to the ASTM D6751 and EN 14214 standards, the fuel oxidation stability at $110^{\circ} \mathrm{C}$ should be at least 3.00 and $6.00 \mathrm{~h}$, respectively. It found that the CICPME has a rather low oxidation stability $(8.44 \mathrm{~h})$, which is midway between those for CIME (10.02 h) and CPME (5.22 h). This is indeed expected because of the high unsaturated fatty acid content of the CCIO and CCPO used as the feedstocks, with a value of 66.6 and $59.8 \mathrm{wt} \%$, respectively. Even though the CICPME fulfills the minimum oxidation stability requirement specified in the standards, there is a need to improve the oxidation stability of this biodiesel by other means such as the addition of antioxidants. Interestingly, the oxidation stability of the CIME produced by Jahirul et al. (2015) is significantly lower than that obtained in this study, with a value of $4.14 \mathrm{~h}$. Senthil Kumar et al. (2015) did not measure the oxidation stability of the CPME produced in their work and therefore, comparison cannot be made here. In contrast, diesel has higher oxidation stability compared to all of the biodiesels produced in this study.

Based on the results shown in Table 6, it can be seen that the FAME content is highest for the CICPME (99.2 wt\%), followed by CIME (98.5 wt\%), and least of all, CPME (97.5 wt\%). A high FAME content is desirable because it indicates that most of the triglycerides have been converted into biodiesel. In order to support these results, Fourier transform infrared (FTIR) spectroscopy was performed to analyze the functional groups in the CI40CP60 oil mixture and CICPME, and the FTIR spectrum of the CICPME is shown in Fig. 8. The CICPME has unique absorption features in the FTIR spectrum because it is composed of long-chain FAMEs. The presence of carboxylates was confirmed based on the three absorption bands caused by the bonds in the $A-\mathrm{COOH}$ functional group. It can be seen from Fig. 8 that there is an intense peak at $2923 \mathrm{~cm}^{-1}$, which is ascribed to $\mathrm{CH}$ stretching of the strong carbonyl group, whereas the intense peak at $1742 \mathrm{~cm}^{-1}$ is attributed to stretching of the $\mathrm{C}=\mathrm{O}$ bonds. The absorption peaks at 1169 , 1198,1359 , and $1438 \mathrm{~cm}^{-1}$ are typical FTIR features of biodiesels. The decrease in the intensities of the absorption peaks between a wavenumber of $1000 \mathrm{~cm}^{-1}$ and $1800 \mathrm{~cm}^{-1}$ indicates an increase in FAME content, which confirms that the triglycerides in the CI40CP60 oil mixture have been converted into FAMEs and the alkaline-catalyzed transesterification process was successful.

Cetane number is measure of the ignition quality of diesel and biodiesels. The cetane number is determined based on the amount of cetane (a clear, colorless hydrocarbon that ignites at high pressures) present in a fuel. The cetane number does not give the amount of cetane (e.g. biodiesel contains no cetane, but has a cetane number), but a similarity in ignition behaviour to pure cetane. A cetane number of 100 indicates that the fuel is of highest purity. In general, a fuel with a higher cetane number is more favorable because it will minimize ignition delay, which is the delay between the time at which the fuel is injected into the combustion chamber and the time at which combustion takes place. It is important to minimize the ignition delay in order to achieve a more complete combustion and reduce the formation of pollutants (SánchezBorroto et al., 2014; Afework et al., 2018). In this study, it is found that the cetane number of the CICPME is 56.00 , which is similar to those for CIME (57.00) and CPME (55.00), as shown in Table 6. The cetane numbers of the biodiesels are higher than those for diesel (48.50). The biodiesels produced in this study fulfil the minimum cetane number requirements stipulated in the ASTM D6751 and EN 14214 standards, with a value of 47.00 and 51.00, respectively, whereas diesel does not fulfil the minimum cetane number requirement in the EN 14214 standard. The cetane number of the CIME obtained in this study is similar to that obtained by Jahirul et al. (2015) (56.53) whereas the cetane number of the CPME obtained in this study is slightly higher than that obtained by Senthil Kumar et al. (2015) (51.00). Based on these results, it can be deduced that all of the biodiesels produced in this work are favorable substitutes for diesel.

Based on the physiochemical properties presented and discussed in this section, it can be deduced that the CICPME is a potential substitute for diesel and it fulfills the fuel property specifications given in the ASTM D6751 and EN 14214 standards. The CICPME has lower kinematic viscosity and acid value, higher heating value, and superior cold flow properties compared with CIME and CPME, indicating the advantages of producing biodiesel from a mixture of Calophyllum inophyllum and Ceiba pentandra oils compared with those produced from a single feedstock. The high acid value of the CI40CP60 oil mixture $\left(16.66 \mathrm{mg} \mathrm{KOH} \mathrm{g}^{-1}\right)$ is not an issue because this can be significantly reduced by acid-catalyzed esterification and indeed, it is proven that the CICPME has the lowest acid value $\left(0.25 \mathrm{mg} \mathrm{KOH} \mathrm{g}^{-1}\right)$ after acid-catalyzed esterification and alkaline-catalyzed transesterification. However, there is a need to improve the oxidation stability of the CICPME, which is still lower than that compared to diesel. In addition, some of the physicochemical properties of the CIME and CPME obtained in this study are comparable to those obtained by Jahirul et al. (2015) and Senthil Kumar et al. (2015), indicating that the physicochemical property measurements in this work are reliable.

\subsection{Kinetics study}

As mentioned in Section 2.4, kinetics study was conducted to understand the mechanism underlying alkaline-catalyzed transesterification of the CI40CP60 oil mixture using the optimum values of the methanol-to-oil molar ratio (37\%) and $\mathrm{KOH}$ catalyst 


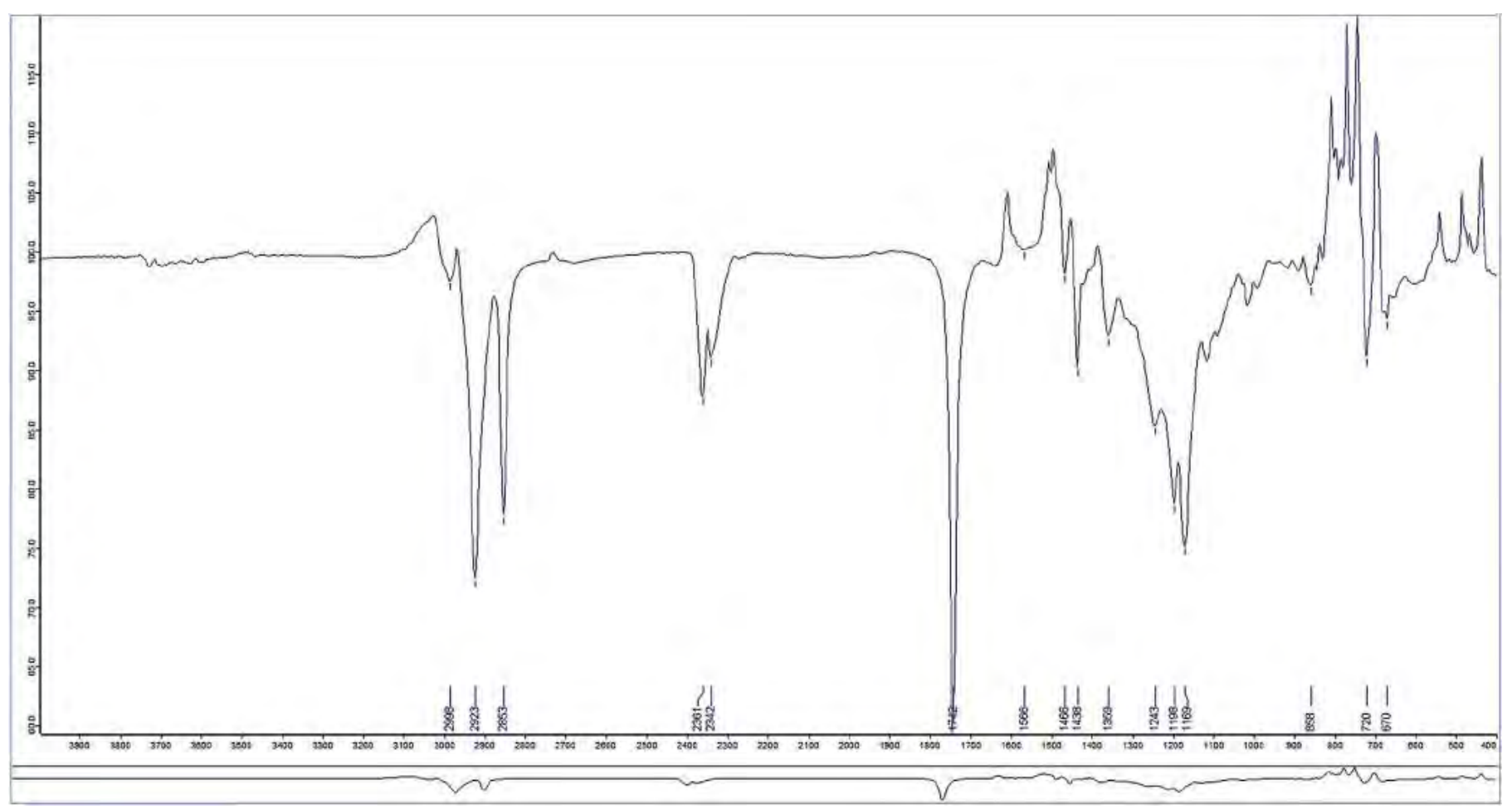

Fig. 8. FTIR spectrum of the CICPME.

concentration $(0.78 \mathrm{wt} \%)$ predicted by the ANN-ACO model. The stirring speed of the alkaline-catalyzed transesterification process was fixed at $1000 \mathrm{rpm}$. The reaction temperature was varied at 323 , 328 , and $333 \mathrm{~K}\left(\approx 50,55\right.$, and $60^{\circ} \mathrm{C}$, respectively, based on a conversion of $1 \mathrm{~K}=-273.15^{\circ} \mathrm{C}$ and rounded to the nearest integer) and the reaction time was varied at $60,90,120$, and $150 \mathrm{~min}$. The FAME contents of the CICPME in weight percent (wt\%) at these reaction temperatures and reaction times are summarized in Table 7. It can be seen that the FAME content of the CICPME increases with an increase in the reaction temperature and reaction time of the alkaline-catalyzed transesterification process, and the highest FAME content is attained at a reaction temperature and reaction time of $60^{\circ} \mathrm{C}$ and $150 \mathrm{~min}$, respectively. This explains why the CICPME yield is highest (95.87\%) when the reaction time is $153 \mathrm{~min}$, as described in Section 3.2.3.

Following this, the FAME contents of the CICPME determined previously were used to plot $\left[\left(1-(1-a)^{1-n}\right) /(1-n)\right]$ versus the reaction time $t$ for all reaction temperatures considered in this study $(323,328$, and $333 \mathrm{~K})$, as shown in Fig. 9. Here, $a$ is the CICPME concentration or the FAME content of the CICPME. In this study, the proper value of $n$ that resulted in the best straight line for the plot $\left[\left(1-(1-a)^{1-n}\right) /(1-n)\right]$ versus $t$ was 1.1 . The $R^{2}$ value was determined for each plot and it is found that the $R^{2}$ values are $0.9963,0.9577$, and 0.9814 for a reaction temperature of 323,328 ,

Table 7

CICPME conversion yield in weight percent (wt\%) at various reaction temperatures and reaction times.

\begin{tabular}{lllll}
\hline \multirow{2}{*}{ Reaction temperature $(\mathrm{K})$} & \multicolumn{4}{l}{ Reaction time (min) } \\
\cline { 2 - 5 } & 60 & 90 & 120 & 150 \\
\hline 323 & 0.6486 & 0.7286 & 0.7982 & 0.8426 \\
328 & 0.7646 & 0.7953 & 0.8425 & 0.9039 \\
333 & 0.8578 & 0.8878 & 0.9039 & 0.9546 \\
\hline
\end{tabular}

and $333 \mathrm{~K}$, respectively. The $R^{2}$ values are close to 1 , indicating that the assumption where the global reaction rate constant obeys the Arrhenius law is valid. The global reaction rate constants for all reaction temperatures were determined from the slopes of the respective plots and the values are summarized in Table 8. It can be seen that the global reaction rate constant increases from 0.0347 to $0.0496 \mathrm{~min}^{-1}$ as the temperature is increased from 323 to $333 \mathrm{~K}$.

Fig. 10 shows the plot of $\ln k$ versus $1 / T$, which is also known as the Arrhenius plot. The result proves that the global reaction rate constants obey the Arrhenius law for the three reaction temperatures considered in this study. The activation energy $E$ (which is the minimum energy that the molecules of the reactants must possess to form the CICPME) was determined from the slope of the Arrhenius plot (Johns and Hutton, 2017), noting that $\check{R}$ is the gas constant $\left(8.314 \mathrm{~J} \mathrm{~mol}^{-1} \mathrm{~K}^{-1}\right)$, and the value is found to be $42.63 \mathrm{~kJ} \mathrm{~mol}^{-1}$. The frequency factor $A$ (which represents the number of times the molecules will hit in the orientation necessary

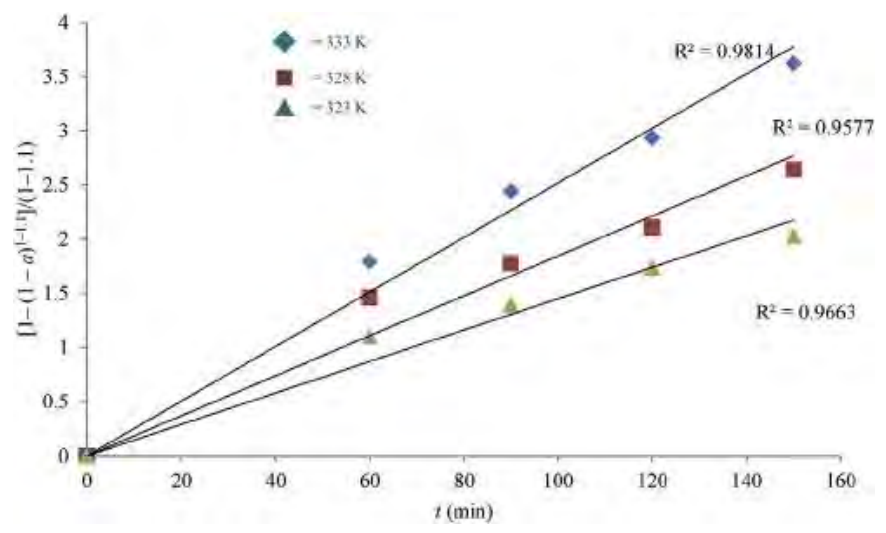

Fig. 9. Plot of $\left[\left(1-(1-a)^{1-1.1}\right) /(1-1.1)\right]$ versus $t$. 
Table 8

Global reaction rate constant and coefficient of determination values determined from the $\left[\left(1-(1-a)^{1-1.1}\right) /(1-1.1)\right]$ versus $t$ plot.

\begin{tabular}{lll}
\hline Reaction temperature, $T(\mathrm{~K})$ & Global reaction rate constant, $k\left(\min ^{-1}\right)$ & Coefficient of determination, $R^{2}$ \\
\hline 318 & 0.0347 & 0.9712 \\
323 & 0.0402 & 0.9736 \\
328 & 0.0496 & 0.9618 \\
\hline
\end{tabular}

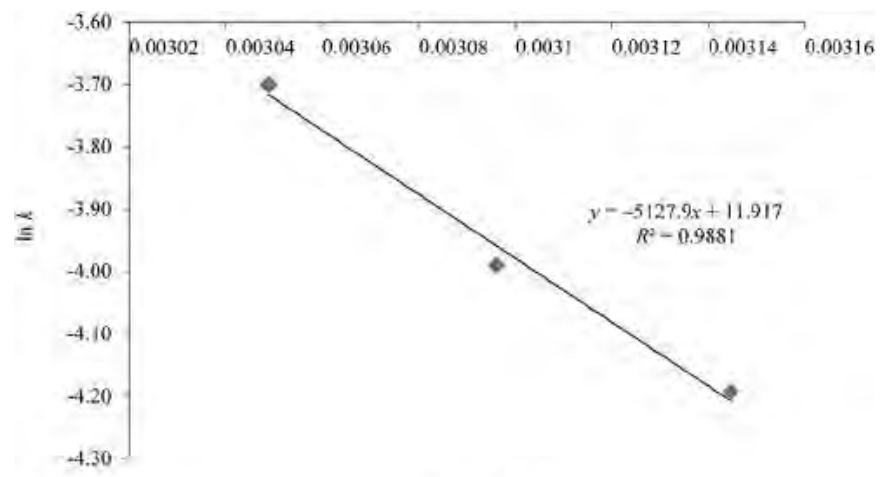

VIT $\left(\mathrm{K}^{-1}\right)$

Fig. 10. Plot of $\ln k$ versus $1 / T$.

to cause the transesterification reaction) was determined from the intercept of the Arrhenius plot (Johns and Hutton, 2017) and the value is found to be $1.49\left(10^{5}\right) \mathrm{min}^{-1}$. Since the value of the activation energy is positive, this indicates that the transesterification reaction is endothermic, where heat energy is required for the reaction to take place.

\section{Conclusions}

In this study, a novel modeling approach (Artificial neural network (ANN) coupled with Ant colony algorithm (ACO)) was used to optimize the process variables (methanol-to-oil molar ratio, $\mathrm{KOH}$ catalyst concentration, and reaction time) of alkaline-catalyzed transesterification in order to maximize the Calophyllum inophyllum-Ceiba pentandra methyl ester (CICPME) yield. The physicochemical properties of the four crude Calophyllum inophyllumCeiba pentandra oil mixture (CICPO) mixtures (CI20CP80, CI40CP60, CI60CP40, and CI80CP20) were measured and the CI40CP60 oil mixture was chosen for in situ acid-catalyzed esterification and alkaline-catalyzed transesterification as well as optimization of the transesterification process variables because the oil mixture offered the best trade-off in terms of the kinematic viscosity at $40^{\circ} \mathrm{C}$, density at $15^{\circ} \mathrm{C}$, acid value, and higher heating value. Next, the ANN-ACO model was used to optimize the transesterification process variables in order to maximize the CICPME yield. Sensitivity analysis was also performed to determine the relative importance of each process variable on the CICPME yield. Next, acid-catalyzed esterification followed by alkaline-catalyzed transesterification were used to produce the CICPME. The physicochemical properties of the CICPME were measured according to the ASTM D6751 and EN 14214 standards and compared with those of other fuels including diesel. Finally, kinetics study was performed to understand the mechanism of the transesterification of CI40CP60 oil mixture.

The following conclusions were drawn based on the findings of this study:

1. The optimum methanol-to-oil molar ratio, $\mathrm{KOH}$ catalyst concentration, and reaction time of the alkaline-catalyzed transesterification process predicted by the ANN-ACO model were
37\%, $0.78 \mathrm{wt} \%$, and $153 \mathrm{~min}$, respectively. The corresponding CICPME yield was $95.87 \%$.

2. The CICPME yield values predicted by the ANN-ACO model were plotted against those predicted by the Box-Behnken experimental design. The $R^{2}$ value is found to be 0.9951 , indicating that the ANN-ACO model describes $99.51 \%$ of the variability in the CICPME yield. The mean absolute percentage error (MAPE) is found to be $0.2260 \%$. The $R^{2}$ value and MAPE indicate that the ANN-ACO model is reliable to predict the optimum alkalinecatalyzed transesterification process variables.

3. The ANN-ACO model was validated by performing independent experiments to produce the CICPME using the optimum transesterification process variables predicted by the ANN-ACO model. The average CICPME yield determined from experiments is $95.18 \%$, which is close to the maximum CICPME yield predicted by the ANN-ACO model (95.87\%) for the same optimum values of process variables.

4. Based on the sensitivity analysis, the methanol-to-oil molar ratio has the most significant effect on the CICPME yield (35.46\%), followed by the $\mathrm{KOH}$ catalyst concentration (33.88\%), and least of all, the reaction time (30.66\%).

5. The CICPME produced from the in situ $\mathrm{H}_{2} \mathrm{SO}_{4}$-catalyzed esterification and $\mathrm{KOH}$-catalyzed transesterification has lower kinematic viscosity and acid value, higher heating value, and superior cold flow properties (pour point, cloud point, and cold filter plugging point) compared with Calophyllum inophyllum methyl ester (CIME) and Ceiba pentandra methyl ester (CPME), indicating the advantages of producing biodiesel from a mixture of crude Calophyllum inophyllum oil (CCIO) and crude Ceiba pentandra oil (CCPO). The flash point, oxidation stability, and cetane number of the CICPME are midway between those for CIME and CPME. However, the oxidation stability of the CICPME $(8.44 \mathrm{~h})$ needs to be improved (perhaps by the addition of antioxidants) because it is significantly lower than that compared with diesel (13.2 h).

6. The CICPME (biodiesel produced from the CI40CP60 oil mixture) fulfills the specifications in the ASTM D6751 and EN 14214 standards and therefore, it is a potential diesel substitute.

7. The results of the kinetics study indicate that the global reaction rate constant of the transesterification obeys the Arrhenius law. The global reaction rate constant increases from 0.0347 to $0.0496 \mathrm{~min}^{-1}$ as the temperature is increased from 323 to $333 \mathrm{~K}$. The activation energy and frequency factor of the transesterification reaction determined from the Arrhenius plot are $42.63 \mathrm{~kJ} \mathrm{~mol}^{-1}$ and $1.49\left(10^{5}\right) \mathrm{min}^{-1}$, respectively.

The novel ANN-ACO model developed in this study offers a simple, reliable alternative to other optimization tools such as response surface methodology (RSM), which is typically used to optimize the process variables for biodiesel production, and it eliminates the trial and error associated with traditional experimentation. Even though the ANN-ACO model is only implemented to maximize the biodiesel yield from transesterification of CCIO and CCPO mixture in this study, it is believed that the model can be used to optimize other biodiesel production processes such as seed oil extraction and acid-catalyzed esterification for various types of 
biodiesels and biodiesel blends.

Studies can be carried out in the future to compare the accuracy of the ANN-ACO model with other optimization tools such as the Taguchi method and kernel extreme learning machine in order to determine which method gives the highest accuracy in predicting the optimum values of biodiesel production process parameters. Studies can also be carried out to analyze the engine performance (brake specific fuel consumption, brake power, brake thermal efficiency, and exhaust gas temperature) and exhaust emissions (carbon dioxide, carbon monoxide, nitrogen oxide, total unburned hydrocarbons, particulate matter, and soot) of a diesel engine fueled with different CICPMEs produced from acid-catalyzed esterification and alkaline-catalyzed transesterification using the optimum values of process variables and the results can be compared with those of a diesel engine fueled with diesel or other second-generation biodiesel blends. In addition, studies can be carried out to use the ANN-ACO model to optimize the process parameters of seed oil extraction from unconventional oil sources such as Durio zibethinus (durian) and Citrullus lanatus (watermelon) seed oils in order to maximize the crude oil yield.

\section{Acknowledgments}

The authors wish to express their appreciation to the Ministry of Education Malaysia and University of Malaya, Kuala Lumpur Malaysia, for funding this work under FRGS-MRSA (grant no: MO014-2016). The authors would like to acknowledge this research as supported the AAIBE Chair of Renewable grant no: 201801 KETTHA, Malaysia for supporting this research. The authors also wish to acknowledge the financial support provided by the Direktorat Jenderal Penguatan Riset dan Pengembangan Kementerian Riset, Teknologi dan Pendidikan Tinggi Republik Indonesia and Politeknik Negeri Medan, Medan, Indonesia. The authors wish to thank Ms. Nadia Abdullah from The Golden Touch LanguageEditing Service (TGTLES) for polishing the language in this manuscript.

\section{Appendix A. Supplementary data}

Supplementary data to this article can be found online at https://doi.org/10.1016/j.jclepro.2019.02.048.

\section{References}

Abdul Kapor, N.Z., Maniam, G.P., Rahim, M.H.A., Yusoff, M.M., 2017. Palm fatty acid distillate as a potential source for biodiesel production-a review. J. Clean. Prod. $143,1-9$.

Abedin, M.J., Kalam, M.A., Masjuki, H.H., Sabri, M.F.M., Rahman, S.M.A., Sanjid, A., Fattah, I.M.R., 2016. Production of biodiesel from a non-edible source and study of its combustion, and emission characteristics: a comparative study with B5. Renew. Energy 88, 20-29.

Afework, B., Hanania, J., Stenhouse, K., Donev, J., 2018. Cetane Number.

Arumugam, A., Ponnusami, V., 2014. Biodiesel production from Calophyllum inophyllum oil using lipase producing Rhizopus oryzae cells immobilized within reticulated foams. Renew. Energy 64, 276-282.

Ashraful, A.M., Masjuki, H.H., Kalam, M.A., Rizwanul Fattah, I.M., Imtenan, S. Shahir, S.A., Mobarak, H.M., 2014. Production and comparison of fuel properties, engine performance, and emission characteristics of biodiesel from various non-edible vegetable oils: a review. Energy Convers. Manag. 80, 202-228.

Atabani, A.E., Silitonga, A.S., Ong, H.C., Mahlia, T.M.I., Masjuki, H.H., Badruddin, I.A. Fayaz, H., 2013. Non-edible vegetable oils: a critical evaluation of oil extraction, fatty acid compositions, biodiesel production, characteristics, engine performance and emissions production. Renew. Sustain. Energy Rev. 18, 211-245.

Belagur, V.K., Chitimi, V.R., 2013. Few physical, chemical and fuel related properties of Calophyllum inophyllum linn (honne) oil and its blends with diesel fuel for their use in diesel engine. Fuel 109, 356-361.

Betiku, E., Ajala, S.O., 2014. Modeling and optimization of Thevetia peruviana (yellow oleander) oil biodiesel synthesis via Musa paradisiacal (plantain) peels as heterogeneous base catalyst: a case of artificial neural network vs. response surface methodology. Ind. Crops Prod. 53, 314-322.

Betiku, E., Okunsolawo, S.S., Ajala, S.O., Odedele, O.S., 2015. Performance evaluation of artificial neural network coupled with generic algorithm and response surface methodology in modeling and optimization of biodiesel production process parameters from shea tree (Vitellaria paradoxa) nut butter. Renew. Energy 76, 408-417.

Betiku, E., Omilakin, O.R., Ajala, S.O., Okeleye, A.A., Taiwo, A.E., Solomon, B.O., 2014. Mathematical modeling and process parameters optimization studies by artificial neural network and response surface methodology: a case of non-edible neem (Azadirachta indica) seed oil biodiesel synthesis. Energy 72, 266-273.

Bindhu, C. Reddy, J., Rao, B., Ravinder, T., Chakrabarti, P., Karuna, M., Prasad, R. 2012. Preparation and evaluation of biodiesel from Sterculia foetida seed oil. J. Am. Oil Chem. Soc. 89, 891-896.

Cardoso, L.d.C., Almeida, F.N.C.d., Souza, G.K., Asanome, I.Y., Pereira, N.C., 2019. Synthesis and optimization of ethyl esters from fish oil waste for biodiesel production. Renew. Energy 133, 743-748.

Chen, X., Du, W., Liu, D., 2008. Response surface optimization of biocatalytic biodiesel production with acid oil. Biochem. Eng. J. 40, 423-429.

Damanik, N., Ong, H.C., Chong, W., Silitonga, A., 2017. Biodiesel production from Calophyllum inophyllum- palm mixed oil. Energy Sources, Part A. 39, 1283-1289.

Dharma, S., Masjuki, H.H., Ong, H.C., Sebayang, A.H., Silitonga, A.S., Kusumo, F. Mahlia, T.M.I., 2016. Optimization of biodiesel production process for mixed Jatropha curcas-Ceiba pentandra biodiesel using response surface methodology. Energy Convers. Manag. 115, 178-190.

Dhawane, S.H., Karmakar, B., Ghosh, S., Halder, G., 2018. Parametric optimisation of biodiesel synthesis from waste cooking oil via Taguchi approach. J. Environ. Chem. Eng. 6, 3971-3980.

Dhingra, S., Dubey, K.K., Bhushan, G., 2014. A polymath approach for the prediction of optimized transesterification process variables of polanga biodiesel. J. Am. Oil Chem. Soc. 91, 641-653.

Dias, J.M., Alvim-Ferraz, M.C., Almeida, M.F., 2008. Mixtures of vegetable oils and animal fat for biodiesel production: influence on product composition and quality. Energy Fuels 22, 3889-3893.

Dorigo, M., 2007. Ant colony optimization. J. Scholarpedia. 2, 1461.

Dorigo, M., Maniezzo, V., Colorni, A., 1996. Ant system: optimization by a colony of cooperating agents. Ieee T. Syst. Man Cy. B. 26, 29-41.

Dwivedi, G., Sharma, M., 2014. Impact of cold flow properties of biodiesel on engine performance. Renew. Sustain. Energy Rev. 31, 650-656.

Esen, H., Inalli, M., Sengur, A., Esen, M., 2008. Artificial neural networks and adaptive neuro-fuzzy assessments for ground-coupled heat pump system. Energy Build. 40, 1074-1083.

Esen, H., Ozgen, F., Esen, M., Sengur, A., 2009. Artificial neural network and wavelet neural network approaches for modelling of a solar air heater. Expert Syst. Appl. 36, 11240-11248.

Fadhil, A.B., Al-Tikrity, E.T., Albadree, M.A., 2017. Biodiesel production from mixed non-edible oils, castor seed oil and waste fish oil. Fuel 210, 721-728.

Garson, G.D., 1991. Interpreting neural-network connection weights. Artif. Intel. Expert 6, 46-51.

Hadiyanto, H., Yuliandaru, I., Hapsari, R., 2018, Production of biodiesel from mixed waste cooking and Castor oil. In: MATEC Web of Conferences. EDP Sciences.

Hafshah, H., Prajitno, D.H., Roesyadi, A., 2017. Hydrotalcite catalyst for hydrocracking Calophyllum inophyllum oil to biofuel: a comparative study with and without nickel impregnation. Bull. Chem. React. Eng. Catal. 12, 273-280.

Hajjari, M., Tabatabaei, M., Aghbashlo, M., Ghanavati, H., 2017. A review on the prospects of sustainable biodiesel production: a global scenario with an emphasis on waste-oil biodiesel utilization. Renew. Sustain. Energy Rev. 72, 445-464.

Handayani, N., Santosa, H., Sofyan, M., Tanjung, I., Chyntia, A., Putri, P., Ramadhan, Z., 2013. Biodiesel production from kapok (Ceiba pentandra) seed oil using naturally alkaline catalyst as an effort of green energy and technology. Int. J. Renew. Energy Dev. 2, 169-173.

Handayani, P.A., Abdullah, A., Hadiyanto, H., 2018. Process evaluation of biodiesel production from nyamplung (Calophyllum inophyllum) oil enhanced by ionic liquid $+\mathrm{NaOH}$ catalyst and microwave heating system. J. Phys. Sci. 29, 265-275.

Hasni, K., Ilham, Z., Dharma, S., Varman, M., 2017. Optimization of biodiesel production from Brucea javanica seeds oil as novel non-edible feedstock using response surface methodology. Energy Convers. Manag. 149, 392-400.

Jahirul, M.I., Brown, R.J., Senadeera, W., Ashwath, N., Rasul, M.G., Rahman, M.M., Hossain, F.M., Moghaddam, L., Islam, M.A., O'Hara, I.M., 2015. Physio-chemical assessment of beauty leaf (Calophyllum inophyllum) as second-generation biodiesel feedstock. Energy Rep. 1, 204-215.

Jain, S., Sharma, M., Rajvanshi, S., 2011. Acid base catalyzed transesterification kinetics of waste cooking oil. Fuel Process. Technol. 92, 32-38.

Johns, D., Hutton, A., 2017. The Arrhenius Law: Arrhenius Plots.

Joshi, S.M., Gogate, P.R., Suresh Kumar, S., 2018. Intensification of esterification of karanja oil for production of biodiesel using ultrasound assisted approach with optimization using response surface methodology. Chem. Eng. Process.- Process Intensification. 124, 186-198.

Jurac, Z., Zlatar, V., 2013. Optimization of raw material mixtures in the production of biodiesel from vegetable and used frying oils regarding quality requirements in terms of cold flow properties. Fuel Process. Technol. 106, 108-113.

Kaabachi, I., Jriji, D., Madany, F., Krichen, S., 2017. A Bi-criteria ant colony optimization for minimizing fuel consumption and cost of the traveling salesman problem with time windows. Procedia Comput. Sci. 112, 886-895.

Keera, S.T., El Sabagh, S.M., Taman, A.R., 2018. Castor oil biodiesel production and optimization. Egypt. J. Petrol. 
Kusumo, F., Silitonga, A., Masjuki, H., Ong, H.C., Siswantoro, J., Mahlia, T., 2017. Optimization of transesterification process for Ceiba pentandra oil: a comparative study between kernel-based extreme learning machine and artificial neural networks. Energy 134, 24-34.

Malaysian Palm Oil Board, 2018. Refinery: Monthly Production of Selected Processed Palm Oil for the Month of December 2015. (Accessed 21 October 2018).

Meneghetti, S.M.P., Meneghetti, M.R., Serra, T.M., Barbosa, D.C., Wolf, C.R., 2007. Biodiesel production from vegetable oil mixtures: cottonseed, soybean, and castor oils. Energy Fuels 21, 3746-3747.

Milano, J., Ong, H.C., Masjuki, H.H., Silitonga, A.S., Kusumo, F., Dharma, S., Sebayang, A.H., Cheah, M.Y., Wang, C.-T., 2018. Physicochemical property enhancement of biodiesel synthesis from hybrid feedstocks of waste cooking vegetable oil and Beauty leaf oil through optimized alkaline-catalysed transesterification. Waste Manag. 80, 435-449.

Miraculas, G.A., Bose, N., Raj, R.E., 2018. Process parameter optimization for biodiesel production from mixed feedstock using empirical model. Sustain. Energy Technol. Assess. 28, 54-59.

Mueanmas, C., Nikhom, R., Petchkaew, A., Iewkittayakorn, J., Prasertsit, K., 2018. Extraction and esterification of waste coffee grounds oil as non-edible feedstock for biodiesel production. Renew. Energy.

Muthukumaran, C., Praniesh, R., Navamani, P., Swathi, R., Sharmila, G., Manoj Kumar, N., 2017. Process optimization and kinetic modeling of biodiesel production using non-edible Madhuca indica oil. Fuel 195, 217-225.

Noordin, M.Y., Venkatesh, V.C., Sharif, S., Elting, S., Abdullah, A., 2004. Application of response surface methodology in describing the performance of coated carbide tools when turning AISI 1045 steel. J. Mater. Process. Technol. 145, 46-58.

Pinjare, S., Kumar, A., 2012. Implementation of neural network back propagation training algorithm on FPGA. Int. J. Comput. Appl. 52.

Prakash Maran, J., Priya, B., 2015a. Comparison of response surface methodology and artificial neural network approach towards efficient ultrasound-assisted biodiesel production from muskmelon oil. Ultrason. Sonochem. 23, 192-200.

Prakash Maran, J., Priya, B., 2015b. Modeling of ultrasound assisted intensification of biodiesel production from neem (Azadirachta indica) oil using response surface methodology and artificial neural network. Fuel 143, 262-267.

Pullen, J., Saeed, K., 2012. An overview of biodiesel oxidation stability. Renew. Sustain. Energy Rev. 16, 5924-5950.

Pullen, J., Saeed, K., 2014. Experimental study of the factors affecting the oxidation stability of biodiesel FAME fuels. Fuel Process. Technol. 125, 223-235.
Rajendra, M., Jena, P.C., Raheman, H., 2009. Prediction of optimized pretreatment process parameters for biodiesel production using ANN and GA. Fuel 88 868-875.

Sánchez-Borroto, Y., Piloto-Rodriguez, R., Errasti, M., Sierens, R., Verhelst, S., 2014 Prediction of cetane number and ignition delay of biodiesel using artificial neural networks. Energy Procedia 57, 877-885.

SathyaSelvabala, V., Selvaraj, D.K., Kalimuthu, J., Periyaraman, P.M., Subramanian, S. 2011. Two-step biodiesel production from Calophyllum inophyllum oil: optimization of modified $\beta$-zeolite catalyzed pre-treatment. Bioresour. Technol. 102 1066-1072.

Senthil Kumar, T., Senthil Kumar, P., Annamalai, K., 2015. Experimental study on the performance and emission measures of direct injection diesel engine with Kapok methyl ester and its blends. Renew. Energy 74, 903-909.

Shweta, K., Singh, A., 2013. An effect and analysis of parameter on ant colony optimization for solving travelling salesman problem. Int. J. Comput. Sci. Mob. Comput. 2, 222-229.

Silitonga, A., Masjuki, H., Ong, H.C., Sebayang, A., Dharma, S., Kusumo, F. Siswantoro, J., Milano, J., Daud, K., Mahlia, T., 2018. Evaluation of the engine performance and exhaust emissions of biodiesel-bioethanol-diesel blends using kernel-based extreme learning machine. Energy 159, 1075-1087.

Silitonga, A.S., Masjuki, H.H., Mahlia, T.M.I., Ong, H.C., Chong, W.T., Boosroh, M.H. 2013. Overview properties of biodiesel diesel blends from edible and nonedible feedstock. Renew. Sustain. Energy Rev. 22, 346-360.

Silitonga, A.S., Masjuki, H.H., Ong, H.C., Kusumo, F., Mahlia, T.M.I., Bahar, A.H., 2016. Pilot-scale production and the physicochemical properties of palm and Calophyllum inophyllum biodiesels and their blends. J. Clean. Prod. 126, 654-666.

Stamenković, O.S., Rajković, K., Veličković, A.V., Milić, P.S., Veljković, V.B., 2013. Optimization of base-catalyzed ethanolysis of sunflower oil by regression and artificial neural network models. Fuel Process. Technol. 114, 101-108.

Toksari, M.D., 2006. Ant colony optimization for finding the global minimum. J. Appl. Math. Comp. 176, 308-316.

Yogish, H., Chandrashekara, K., Kumar, M.P., 2012. Optimization of experimenta conditions for composite biodiesel production from transesterification of mixed oils of Jatropha and Pongamia. Heat Mass Transf. 48, 1955-1960.

Yunus Khan, T.M., Atabani, A.E., Badruddin, I.A., Ankalgi, R.F., Mainuddin Khan, T.K. Badarudin, A., 2015. Ceiba pentandra, Nigella sativa and their blend as prospective feedstocks for biodiesel. Ind. Crops Prod. 65, 367-373. 


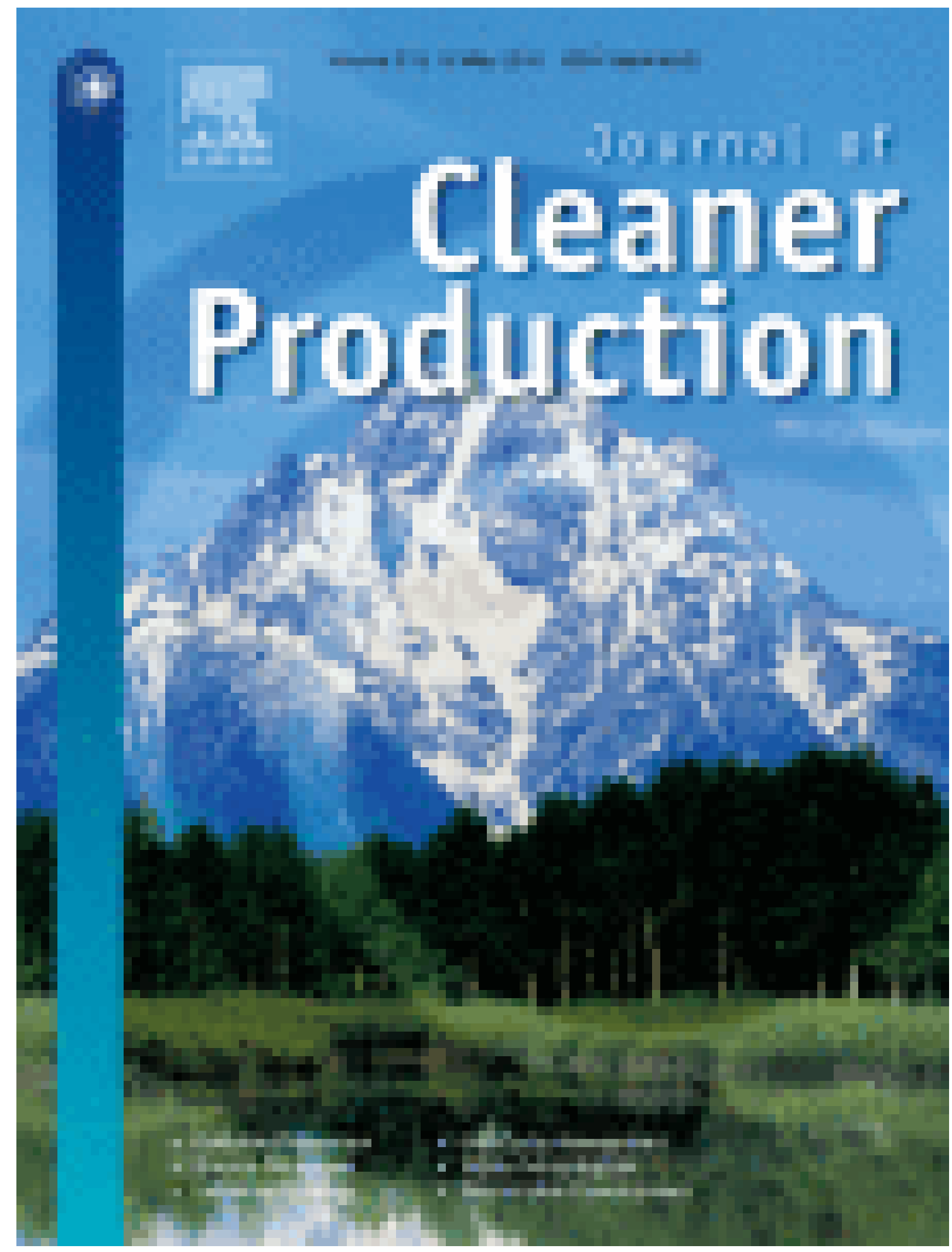




\section{ScienceDirect}

\section{Keywords}

\section{Author name}

Journal of Cleaner Production

\section{Volume}

\section{Issue}

Pages

\section{Journal of Cleaner Production}
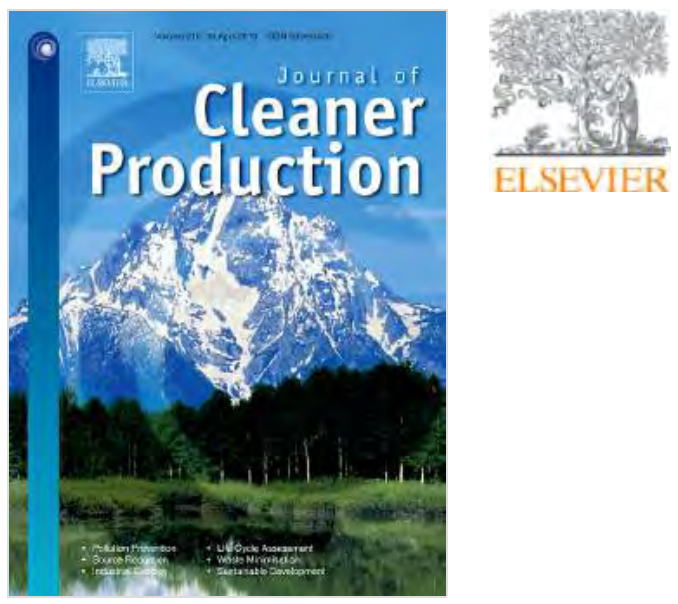

Explore journal content

Latest issı

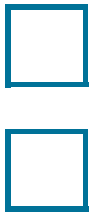

Latest issue

Volume 2:

In progress (1

Articles in press

Special issues

Volume 2:

In progress (1

Volume 2:

All issues

In progress (2

Volume 2:

pp. 1-626 (1 


\section{Articles}

Articles in press Latest published articles

Research article $\bigcirc$ Abstract only

In situ loading metal oxide particles on bio-chars: Reusable materials for efficient removal of methylene blue from wastewater

Shimin Zhai, ... Shaohai Fu

In Press, Accepted Manuscript, Available online 16 February 2019

品 Purchase PDF

Research article $\bigcirc$ Abstract only

Characterization on the recycling of waste seashells with Portland cement towards sustainable cementitious materials

Junjie Wang, ... Liang Li

In Press, Accepted Manuscript, Available online 16 February 2019

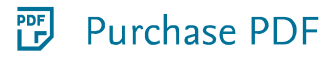


anaerobic digestion process for platform chemicals and biogas production

Francesco Valentino, ... Mauro Majone

In Press, Accepted Manuscript, Available online 16 February 2019

맘 Purchase PDF

Research article $\bigcirc$ Abstract only

Butadiene substance flow analysis and management in South Korea

Seung-Jin Lee, ... Sha Chen

In Press, Accepted Manuscript, Available online 16 February 2019

帤 Purchase PDF

Research article $\bigcirc$ Abstract only

Potential bioethanol production from sweet sorghum on marginal land in China

Dong Jiang, ... Xiaoxi Yan

In Press, Accepted Manuscript, Available online 16 February 2019

많) Purchase PDF

Research article $\bigcirc$ Abstract only

Corporate sustainability in Canadian and US maritime ports

Mehrnaz Ashrafi, ... Michelle Adams

In Press, Accepted Manuscript, Available online 16 February 2019 
$\stackrel{\text { Dof }}{\leftarrow}$ Purchase PDF

Research article $\bigcirc$ Abstract only

Reuse of mining waste as aggregates in fly ash-based geopolymers

I. Capasso, ... B. Liguori

In Press, Accepted Manuscript, Available online 16 February 2019

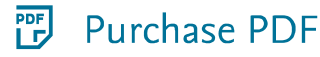

Research article $\bigcirc$ Abstract only

Eco-friendly anti-felting treatment of wool top based on biosurfactant and enzymes

Martín S. Iglesias, ... Nelda L. Olivera

In Press, Accepted Manuscript, Available online 16 February 2019

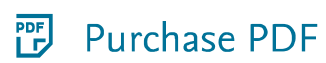

More articles in press

\section{Special issues}


Edited by Neven Duic, Krzysztof Urbaniec, Hrvoje Mikulčić

15 February 2019

Understanding and Managing Product Lifetimes in support of a Circular Economy

Edited by Conny Bakker, Ruth Mugge, Masahiro Oguchi, Casper Boks

15 February 2019

Sustainability for Smart Cities

Edited by Bin Chen, Louise Poissant, Jin Yang, Xiao Li, Yee Van FAN

15 February 2019

Special Issue: Mainstreaming Ecosystem Services in Decision making: Assessment, Governance and Management for Sustainability

Edited by Zhi-Yun Ouyang, Stephen Polasky, Rudolf de Groot, Hua Zheng, Mary Ruckelshaus 
14 February 2019

View all issues

View all special issues

\section{Journal info}

ISSN

$0959-6526$

\section{Copyright}

Copyright (C) 2019 Elsevier Ltd. All rights reserved

More journal info

\section{ELSEVIER About ScienceDirect Remote access Shopping cart Contact and support}

Terms and conditions Privacy policy

We use cookies to help provide and enhance our service and tailor content and ads. By continuing you agree to the use of cookies.

Copyright (C) 2019 Elsevier B.V. or its licensors or contributors. ScienceDirect $₫$ is a registered 
trademark of Elsevier B.V.

RRELX GOup

15.1 


\section{ScienceDirect}

\section{Keywords}

Author name

Journal of Cleaner Production

\section{Volume}

Issue

Pages

\section{Journal of Cleaner Production}

SUPPORTS OPEN ACCESS

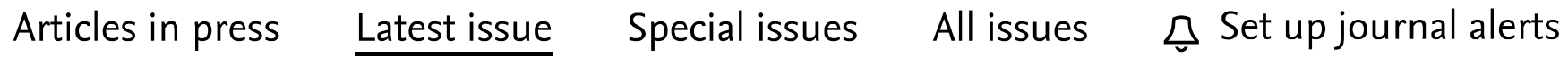

\section{Volume 219}

In progress (10 May 2019)

This issue is in progress but contains articles that are final and fully citable.
$<$ Previous vol/issue
Next vol/issue

Research article $\bigcirc$ Abstract only

Biodiversity conservation actions as a tool to improve the management of sustainable corporations and their needs ecosystem services

Ricardo Reale, Teresa Cristina Magro, Luiz César Ribas

Pages 1-10 
맏 Purchase PDF Article preview $\vee$

Research article $\bigcirc$ Abstract only

Study on the impact of haze pollution on residents' green consumption behavior: the case of Shandong Province

Ming Zhang, Shu Guo, Chunyu Bai, Wenwen Wang

Pages 11-19

$\stackrel{\text { DOF }}{[}$ Purchase PDF Article preview $\vee$

Research article $\bigcirc$ Abstract only

Collaboration between designers and contractors to improve building energy performance

Xiaoxiao Xu, Clyde Zhengdao Li, Jiayuan Wang, Wenke Huang

Pages 20-32

品 Purchase PDF Article preview $\vee$

Correspondence $\bigcirc$ Abstract only

Response to 'Life-cycle green-house gas emissions of onshore and offshore wind turbines'

Josefine Marx, Andrea Schreiber, Petra Zapp

Pages 33-34

맏 Purchase PDF Article preview $\vee$

Research article $\bigcirc$ Abstract only

Triggering a large scale luminescent solar concentrators market: The smart window project

N. Aste, M. Buzzetti, C. Del Pero, R. Fusco, ... D. Testa

Pages 35-45

맘 Purchase PDF Article preview $\vee$

Research article $\bigcirc$ Abstract only

Mechanical recycling of poly(lactic acid): Evaluation of a chain extender and a peroxide as additives for upgrading the recycled plastic. 
Freddys R. Beltrán, Celia Infante, Ma Ulagares de la Orden, Joaquín Martínez Urreaga

Pages 46-56

帤 Purchase PDF Article preview $\vee$

Research article $\bigcirc$ Abstract only

How does foreign direct investment influence energy intensity convergence in

China? Evidence from prefecture-level data

Wei Li, Tao Zhao, Yanan Wang, Xiaodan Zheng, Jingxiang Yang

Pages 57-65

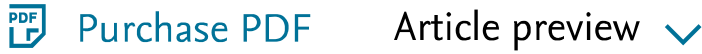

Research article $\bigcirc$ Abstract only

Rhizosphere management by biochar and leaching improved plant performance in fresh bauxite residue sand

Mehran Rezaei Rashti, Maryam Esfandbod, Ian R. Phillips, Chengrong Chen

Pages 66-74

唰 Purchase PDF Article preview $\vee$

Research article $\bigcirc$ Abstract only

Cost and effectiveness of emissions trading considering exchange rates based on an agent-based model analysis

Zi-Sheng Peng, Yong-Liang Zhang, Guang-Ming Shi, Xiao-Hong Chen

Pages 75-85

帤 Purchase PDF Article preview $\vee$

Research article $\bigcirc$ Abstract only

Effective treatment of palm oil mill effluent using $\mathrm{FeSO}_{4} \cdot 7 \mathrm{H}_{2} \mathrm{O}$ waste from titanium oxide industry: Coagulation adsorption isotherm and kinetics studies

Md. Sohrab Hossain, Fatehah Omar, Ahmad Jaril Asis, Robert Thomas Bachmann, ... Mohd Omar Ab Kadir

Pages 86-98

品 Purchase PDF Article preview $\vee$ 
Research article $\bigcirc$ Abstract only

Life Cycle Assessment for the Cuban pig production: Case study in Sancti Spiritus Yasmani Alba Reyes, Ernesto L. Barrera, Anisley Sarduy Valle, Maylier Pérez Gil, ... Jo Dewulf

Pages 99-109

$\stackrel{\text { pof }}{\sim}$ Purchase PDF Article preview $\vee$

Research article $\bigcirc$ Abstract only

Sustainable extraction of lead and re-use of valuable metals from lead-rich

secondary materials

Bin Yang, Guozheng Zha, William Hartley, Xiangfeng Kong, ... Xinyu Guo

Pages 110-116

$\stackrel{\text { DoF }}{\longleftarrow}$ Purchase PDF Article preview $V$

Research article $\bigcirc$ Abstract only

Thermoeconomic and environmental feasibility of waste heat recovery of a data

center using air source heat pump

Mahdi Deymi-Dashtebayaz, Sajad Valipour-Namanlo

Pages 117-126

橗 Purchase PDF Article preview $\checkmark$

Research article $\bigcirc$ Abstract only

The green advantage: Exploring the convenience of issuing green bonds

Gianfranco Gianfrate, Mattia Peri

Pages 127-135

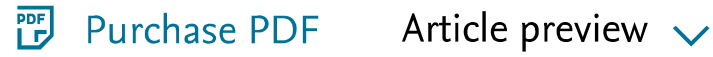

Research article $\bigcirc$ Abstract only

Conservation agriculture based on diversified and high-performance production system leads to soil carbon sequestration in subtropical environments

Daniel Ruiz Potma Gonçalves, João Carlos de Moraes Sá, Umakant Mishra, Allison José Fornari, ... Clever Briedis

Pages 136-147

$\stackrel{\text { DDF }}{\text { P }}$ Purchase PDF Article preview $V$ 
Review article $\bigcirc$ Abstract only

Key guidelines for designing integrated solutions to support development of marginalised societies

Santosh Jagtap

Pages 148-165

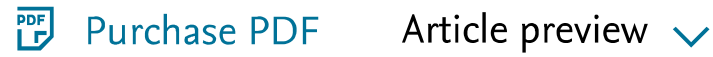

Research article $\bigcirc$ Abstract only

Alternative fuel vehicle-routing problem: A life cycle analysis of transportation fuels Hiva Ashtineh, Mir Saman Pishvaee

Pages 166-182

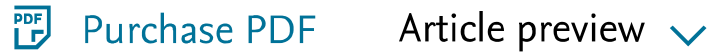

Research article $\bigcirc$ Abstract only

Biodiesel production from Calophyllum inophyllum-Ceiba pentandra oil mixture:

Optimization and characterization

Hwai Chyuan Ong, Jassinnee Milano, Arridina Susan Silitonga, Masjuki Haji Hassan, ... Joko Sutrisno

Pages 183-198

많 Purchase PDF Article preview

Research article $\bigcirc$ Abstract only

Understanding the expansion of oil palm cultivation: A case-study in Papua

Pablo Acosta, María Dolores Curt

Pages 199-216

品 Purchase PDF Article preview $\vee$

Research article $\bigcirc$ Abstract only

A semi-closed loop microalgal biomass production-platform for ethanol from renewable sources of nitrogen and phosphorous

Lara Sanchez Rizza, Camila D. Coronel, Maria E. Sanz Smachetti, Mauro Do Nascimento, Leonardo Curatti

Pages 217-224

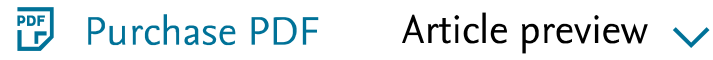


Research article $\bigcirc$ Abstract only

Leaching of rare earth elements (REEs) and impurities from phosphogypsum: A preliminary insight for further recovery of critical raw materials

C.R. Cánovas, S. Chapron, G. Arrachart, S. Pellet-Rostaing

Pages 225-235

羿 Purchase PDF Article preview $\checkmark$

Research article $\bigcirc$ Abstract only

Nanoparticles from construction wastes: A problem to health and the environment Marcos L.S. Oliveira, Maria Izquierdo, Xavier Querol, Roy N. Lieberman, ... Luis F.O. Silva Pages 236-243

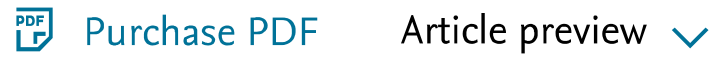

Research article $\bigcirc$ Abstract only

The role of the intensity of environmental regulation and corruption in the employment of manufacturing enterprises: Evidence from China

Jichuan Sheng, Weihai Zhou, Sanfeng Zhang

Pages 244-257

骂 Purchase PDF Article preview $\vee$

Research article $\bigcirc$ Abstract only

Synthesis and characterization of pure phase zeolite 4A from coal fly ash Asifa lqbal, Hamed Sattar, Rizwan Haider, Shahid Munir

Pages 258-267

羿 Purchase PDF Article preview $\checkmark$

Research article $\bigcirc$ Abstract only

Pre-assessment of the circular economic benefits and challenges of biogas production in Denmark when utilizing sand bedding in dairy cow stables Rikke Lybæk, Tyge Kjær

Pages 268-277

呵 Purchase PDF Article preview 
Research article $\bigcirc$ Abstract only

The combined role of policy and incentives in promoting cost efficient decarbonisation of energy: A case study for biomethane Karthik Rajendran, Brian O'Gallachoir, Jerry D. Murphy

Pages 278-290

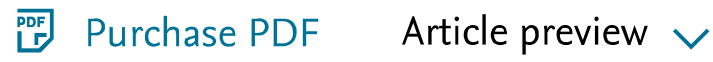

Research article $\bigcirc$ Abstract only

Organizational coordination in sustainable humanitarian supply chain: An evolutionary game approach

Congdong Li, Fanshun Zhang, Cejun Cao, Yang Liu, Ting Qu

Pages 291-303

羿 Purchase PDF Article preview $\checkmark$

Research article $\bigcirc$ Abstract only

Comparative assessments of the performances of $\mathrm{PV} / \mathrm{T}$ and conventional solar plants Antonio Gagliano, Giuseppe M. Tina, Stefano Aneli, Sandro Nižetić

Pages 304-315

맘 Purchase PDF Article preview

Research article $\bigcirc$ Abstract only

Optimal activated carbon production from corn pericarp: A life cycle assessment approach

Darithsa Loya-González, Margarita Loredo-Cancino, Eduardo Soto-Regalado, Pasiano Rivas-García, ... Alejandro Estrada-Baltazar

Pages 316-325

맘 Purchase PDF Article preview

Research article $\bigcirc$ Abstract only

Performance assessment of a marine freshwater generator through exergetic optimization

Onur Yuksel, Yigit Gulmez, Olgun Konur, S. Aykut Korkmaz, ... C. Ozgur Colpan

Pages 326-335 
맏 Purchase PDF Article preview $\vee$

Review article $\bigcirc$ Abstract only

Decision support systems for sustainable manufacturing surrounding the product and production life cycle - A literature review

Maximilian Zarte, Agnes Pechmann, Isabel L. Nunes

Pages 336-349

만) Purchase PDF Article preview $\vee$

Research article $\bigcirc$ Abstract only

The role of source separation in nutrient recovery - Comparison of alternative wastewater treatment systems

R. Malila, S. Lehtoranta, E.-L. Viskari

Pages 350-358

맏) Purchase PDF Article preview $\vee$

Research article $\bigcirc$ Abstract only

Thermal management of low concentrated photovoltaic module with phase change material

S. Manikandan, C. Selvam, Nikunj Poddar, Kishlay Pranjyal, ... S.C. Kaushik

Pages 359-367

맘 Purchase PDF Article preview $\vee$

Research article $\bigcirc$ Abstract only

Wind shear effect on aerodynamic performance and energy production of horizontal axis wind turbines with developing blade element momentum theory

Ghazale Kavari, Mojtaba Tahani, Mojtaba Mirhosseini

Pages 368-376

品 Purchase PDF Article preview $\vee$

Research article $\bigcirc$ Abstract only

Improved gray water footprint calculation method based on a mass-balance model and on fuzzy synthetic evaluation 
Hui Li, Gengyuan Liu, Zhifeng Yang

Pages 377-390

帤 Purchase PDF Article preview $\vee$

Research article $\bigcirc$ Abstract only

Impact assessment of supply-side and demand-side policies on energy consumption and $\mathrm{CO}_{2}$ emissions from urban passenger transportation: The case of Istanbul İran Batur, Islam Safak Bayram, Muammer Koc

Pages 391-410

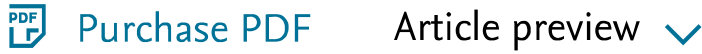

Review article $\bigcirc$ Abstract only

Life cycle assessment of manure biogas production: A review

Elisa Maria Mano Esteves, Ana Maria Naranjo Herrera, Victor Paulo Peçanha Esteves, Cláudia do Rosário Vaz Morgado

Pages 411-423

品 Purchase PDF Article preview $\vee$

Research article $\bigcirc$ Abstract only

Recycled coarse aggregates from pelletized unused concrete for a more sustainable concrete production

M. Bassani, J.C. Diaz Garcia, F. Meloni, G. Volpatti, D. Zampini

Pages 424-432

郘 Purchase PDF Article preview $\vee$

Research article Open access

Designing an organizational system for economically sustainable demand-side management in district heating and cooling Antti Peltokorpi, Madis Talmar, Klaus Castrén, Jan Holmström

Pages 433-442

$\Perp$ Download PDF Article preview $\vee$

Research article $\bigcirc$ Abstract only 
Complementarity in mid-point impacts for water use in life cycle assessment applied to cropland and cattle production in Southern Amazonia

Michael J. Lathuillière, Cécile Bulle, Mark S. Johnson

Pages 497-507

맘 Purchase PDF Article preview $\vee$

Research article $\bigcirc$ Abstract only

Optimising the regional mix of intermittent and flexible energy technologies Carl Haikarainen, Frank Pettersson, Henrik Saxén

Pages 508-517

郘 Purchase PDF Article preview $\vee$

ISSN: 0959-6526

Copyright (C) 2019 Elsevier Ltd. All rights reserved

ELSEVIER About ScienceDirect Remote access Shopping cart Contact and support Terms and conditions Privacy policy

We use cookies to help provide and enhance our service and tailor content and ads. By continuing you agree to the use of cookies.

Copyright @ 2019 Elsevier B.V. or its licensors or contributors. ScienceDirect $₫$ is a registered trademark of Elsevier B.V. 


\section{Q ${ }_{\text {SEARCH }} \equiv$ MEnU}

Home (https://www.elsevier.com/) > Journals (https://www.elsevier.com/catalog?producttype=...

> (https://www welsevier.c ournal of Cleaner Production (https://www.journals.else...

> Editorial Board (https://www.journals.elsevier.com:443/journal-of-cleaner-production/editorial-board)

\section{Submit Your Paper}

Supports Open Access (http://www.elsevier.com/journals/journal-of-cleaner-production /o959-6526/open-access-options)

View Articles (https://www.sciencedirect.com/science/journal/09596526)

\section{Guide for Authors}

Abstracting/ Indexing (http://www.elsevier.com/journals/journal-of-cleaner-production /0959-6526/abstracting-indexing)

\section{Track Your Paper}

Order Journal

Journal Metrics

$>$ CiteScore: $\mathbf{5 . 7 9}$ (i)

Impact Factor: 5.651 (i)

5-Year Impact Factor: 6.352 (i)

Source Normalized Impact per Paper (SNIP): 2.194 (i)

SCImago Journal Rank (SJR): 1.467 (i)

$>$ View More on Journal Insights

Your Research Data

$>$ Share your research data (https://www.elsevier.com/authors/author-services/research-data) 
7) Visuralize your data (http://www.elsevier.com/authors/author-services/data-visualization)

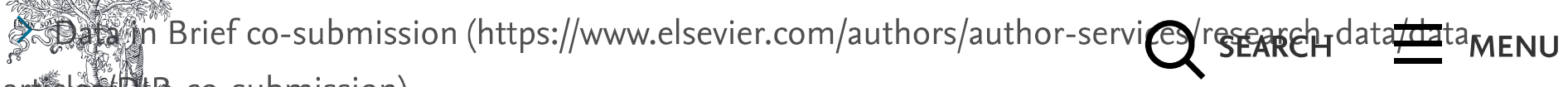

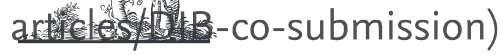

ELSEVIER

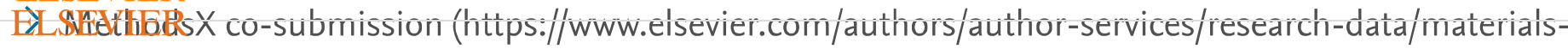

and-methods/mex-co-submission)

(https://www.elsevier.c

om)

Related Links

$>$ Author Stats (i)

$>$ Researcher Academy

$>$ Author Services (https://www.elsevier.com/authors/author-services)

$>$ Try out personalized alert features

\section{Article Collection}

Urban environmental studies

from the Chinese Academy of

Science

Free Access until

March 2019

ELSEVIER

\section{Journal of Cleaner Production - Editorial Board}

\section{Co-Editors-in-Chief}

Jiří Jaromír Klemeš (https://www.journals.elsevier.com:443/journal-of-cleanerproduction/editorial-board/jiri-jaromir-klemes)

Brno University of Technology (VUT Brno), Brno, Czech Republic Email Jiř́ Jaromír Klemeš (https://www.journals.elsevier.com:443/journal-ofcleaner-production/editorial-board/jiri-jaromir-klemes)

Cleaner Production and Technical Processes; Green/sustainable engineering; Green/sustainable supply chains; Biomass; Energy use and consumption; Waste minimisation; Pollution reduction; Renewable energy; Environmental assessment; Emergy/exergy analyses; LCA of product and process - Footprints and other assessment types; Supply chains (modelling, mathematical, and engineering); Eco-industrial parks; 


\section{Enengy water nexus}

Céchining Maria Villas Bôas de Almeida

\section{Q SEARCH}

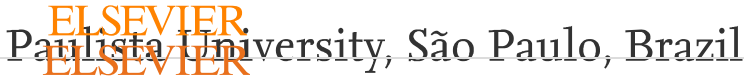

Email Cecília Maria Villas Bôas de Almeida

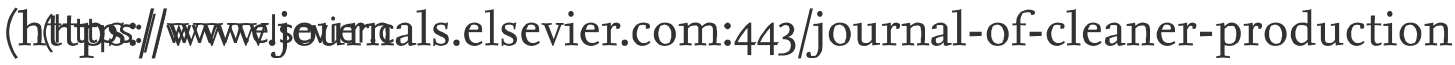

/eftitorial-board/cecilia-maria-villas-boas-de-almeida)

${ }^{*}$ Cecilia is the first contact point for Review articles*

Sustainability indicators; Cleaner production practices (industrial, agricultural and supply chains); Emergy and exergy analysis (resource and energy use); Regional sustainability; Education for sustainability; Environmental and sustainability assessment; Sustainable products and services; Corporate sustainability, Corporate social responsibility; Sustainable consumption

\section{Yutao Wang}

Fudan University, Shanghai, China

Email Yutao Wang (https://www.journals.elsevier.com:443/journal-of-cleanerproduction/editorial-board/yutao-wang)

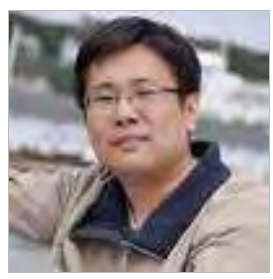

Cleaner production; Circular economy; Climate change policy and adaptation; Bio-based industry; Extended producer responsibility; Industrial ecology; Life cycle assessment; Eco-efficiency; Sustainable products and services; Waste management; Ecological management and natural capital; Renewable resource; Environmental behavior; Urban metabolism; Environmental nexus; Energy policy; Sustainable consumption; Sustainable urbanization and Regional sustainability; Education for sustainability

\section{Editorial Assistant}

Kevin Zhang

Delft University of Technology, Delft, Netherlands

\section{Founder and Editor-in-Chief Emeritus}

Don Huisingh (https://www.journals.elsevier.com:443/journal-of-cleaner-production /editorial-board/don-huisingh)

University of Tennessee, Knoxville, Tennessee, USA 
Associgte Editors

\section{Q SEARCH $\equiv$ MENU}

Ketrigenteriso

De La Salle University, Manilla, Philippines

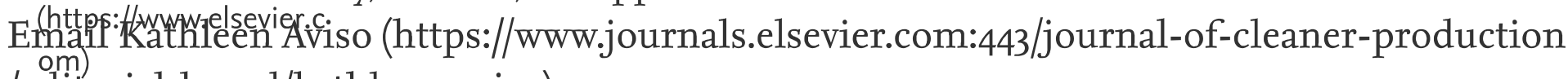
/editorial-board/kathleen-aviso)

Giovanni Baiocchi (https://www.journals.elsevier.com:443/journal-of-cleanerproduction/editorial-board/giovanni-baiocchi)

University of Maryland, College Park, Maryland, USA

Email Giovanni Baiocchi (https://www.journals.elsevier.com:443/journal-ofcleaner-production/editorial-board/giovanni-baiocchi)

Climate change mitigation; sustainable lifestyles; environmental accounting; environmental economics; sustainable agriculture; industrial ecology; input-output sustainability analyses; trade and environment; alternative consumption patterns; carbon footprints of cities

Giorgio Besagni (https://www.journals.elsevier.com:443/journal-of-cleanerproduction/editorial-board/giorgio-besagni)

Ricerca sul Sistema Energetico - RSE S.p.A., Milan, Italy Email Giorgio Besagni (https://www.journals.elsevier.com:443/journal-ofcleaner-production/editorial-board/giorgio-besagni)

Energy efficiency; Computational Fluid Dynamics, Energy Poverty; Multiphase flows; Energy system analysis; Ejector and refrigeration technology; Rational use of energy, Energy storage; Renewable energy; Energy use and consumption

Jun Bi (https://www.journals.elsevier.com:443/journal-of-cleaner-production /editorial-board/jun-bi)

Nanjing University, Nanjing, China

Email Jun Bi (https://www.journals.elsevier.com:443/journal-of-cleanerproduction/editorial-board/jun-bi)

environmental policy, environmental risk management, environmental health, environmental governance, environmental behavior, low carbon development, air pollution, watershed management, enterprise environmental management, EHS (environment, health \& safety)

Sandra Caeiro

Universidade Aberta, Lisbon, Portugal 
Email Sandra Caeiro (https://www.journals.elsevier.com:443/journal-of-cleaner-production /ectilgrialotoard/sandra-caeiro)

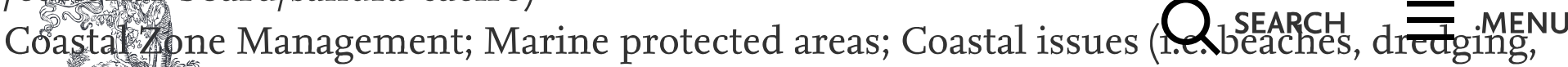
natasal disasters, hazards management, pollution, etc.)Keywords: Water pollution;

Envirínhenental risk assessment; Sediment quality assessment; - Education for sustainability;

Tools for environmental management;

(https://www.elsevier.c

om)

Hua Cai

Purdue University, West Lafayette, Indiana, USA

Email Hua Cai (https://www.journals.elsevier.com:443/journal-of-cleaner-production /editorial-board/hua-cai)

Urban sustainability; Data-driven modeling; Sustainable consumption and production; Green supply chain; Sustainable transportation; Complex system; Operations research; Industrial ecology

\section{Bin Chen}

Beijing Normal University, Beijing, China

Email Bin Chen (https://www.journals.elsevier.com:443/journal-of-cleanerproduction/editorial-board/bin-chen)

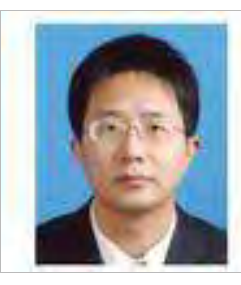

Environmental and ecological management; Environmental nexus; Energy economics; Thermoeconomics; Urban metabolism; Systems ecology

Charbel Jose Chiappetta Jabbour (https://www.journals.elsevier.com:443 /journal-of-cleaner-production/editorial-board/charbel-jose-chiappettajabbour)

Montpellier Business School, Montpellier, France

Email Charbel Jose Chiappetta Jabbour (https://www.journals.elsevier.com:443 /journal-of-cleaner-production/editorial-board/charbel-jose-chiappetta-jabbour)

Change management for sustainability; environmental training and awareness; human aspects of cleaner production; green human resource management; sustainable human resource management; corporate social responsibility; corporate environmental management.

Kannan Govindan

University of Southern Denmark, Odense M, Denmark

Email Kannan Govindan (https://www.journals.elsevier.com:443/journal-ofcleaner-production/editorial-board/kannan-govindan)

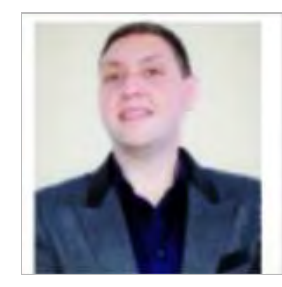

Sustainable Supply Chain Management, Sustainable Operations Management, Green Supply Chain Management, Reverse Logistics, Closed Loop Supply Chain, Corporate 
Social Responsibility, Corporate Sustainability, Sustainable Consumption and Production, Exterded Producer Responsibility, Optimizations Methods, Decision Analysis, Multi Atfribute Decision Making methods (Multi Criteria Decision Makingsnd SEARH ti OJjective Decision Making), Analytical Modelling, Fuzzy and Grey Set Theory ELSEVIER

Bagshan Huang Hhttps://www.journals.elsevier.com:443/journal-of-cleanerpropduction/editorial-board/baoshan-huang)

University of Tennessee, Knoxville, Tennessee, USA

Email Baoshan Huang (https://www.journals.elsevier.com:443/journal-ofcleaner-production/editorial-board/baoshan-huang)

Sustainable Geo/Transportation Infrastructure - Multi-Scale Characterization and Modeling of Infrastructure Materials; Innovative Technologies Supporting Sustainable and Environmentally Friendly Subsurface Infrastructure Systems

\section{Mingzhou Jin}

University of Tennessee - Knoxville, Knoxville, Tennessee, USA Email Mingzhou Jin (https://www.journals.elsevier.com:443/journal-of-cleaner-production /editorial-board/mingzhou-jin)

Advanced and Sustainable Manufacturing; Green Supply Chain; Sustainable Operations; Energy Efficiency; Optimization; Remanufacturing; Environmental Policy; Life Cycle Assessment

Jin-Kuk Kim (https://www.journals.elsevier.com:443/journal-of-cleanerproduction/editorial-board/jin-kuk-kim)

Hanyang University, Seoul, The Republic of Korea

Email Jin-Kuk Kim (https://www.journals.elsevier.com:443/journal-of-cleanerproduction/editorial-board/jin-kuk-kim)

Environmental process modeling and simulation; Process systems engineering; Energy system analysis; Techno-economic analysis; Process optimization; $\mathrm{CO}_{2}$ capture and utilization; Water minimization; Natural gas processing; Industrial energy saving; Waste heat recovery

Chew Tin Lee (https://www.journals.elsevier.com:443/journal-of-cleanerproduction/editorial-board/chew-tin-lee)

Universiti Teknologi Malaysia, Skudai, Johor, Malaysia

Email Chew Tin Lee (https://www.journals.elsevier.com:443/journal-of-cleanerproduction/editorial-board/chew-tin-lee)

Organic waste management; Composting; LCA of products and processes; Waste treatment technology; Wastewater treatment; Environmental assessment; Waste to energy; Low-carbon 
emissions policy; Socio-economic impacts; Greenhouse gas mitigation

s.

Zhen Hed (https://www.journals.elsevier.com:443/journal-of-cleaner- SEARCH

proddectioin/editorial-board/zhen-leng)

The Hong Kong Polytechnic University, Hunghom, Kowloon, Hong Kong Email Zhhen Leng (https://www.journals.elsevier.com:443/journal-of-cleanerpropduction/editorial-board/zhen-leng)

Sustainable infrastructure; Environment-friendly construction materials; Clean infrastructure construction technologies; Green pavement material and technologies; Life cycle assessment; Eco-efficiency analysis; Value-added waste recycling; Nondestructive evaluation of transportation infrastructure

Mattias Lindahl (https://www.journals.elsevier.com:443/journal-of-cleanerproduction/editorial-board/mattias-lindahl)

Linköping Universitet, Linköping, Sweden

Email Mattias Lindahl (https://www.journals.elsevier.com:443/journal-ofcleaner-production/editorial-board/mattias-lindahl)

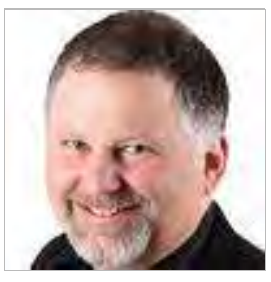

Ecodesign (Environmentally Conscious Design, Design for Environment (DfE)); Sustainable Business Models; Circular Economy; Sustainable Consumption; Product Development; Engineering Design Methods; Product-Service Systems (PSS); Integrated Product and Service Engineering (IPSE); Service Engineering

Zhifu Mi (https://www.journals.elsevier.com:443/journal-of-cleaner-production /editorial-board/zhifu-mi)

University College London (UCL), London, England, UK

Email Zhifu Mi (https://www.journals.elsevier.com:443/journal-of-cleanerproduction/editorial-board/zhifu-mi)

Climate change economics; energy policy; air pollution; green economy; carbon footprint; low carbon; econometrics; optimization model; input output analysis; integrated assessment model

Maria Theresa (Maite) Moreira Vilar

Universidade de Santiago de Compostela, Santiago de Compostela, Spain Email Maria Theresa (Maite) Moreira Vilar

(https://www.journals.elsevier.com:443/journal-of-cleaner-production

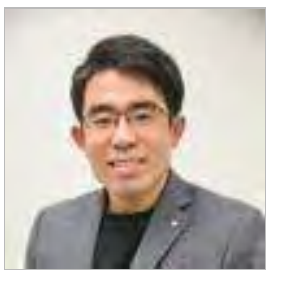
/editorial-board/maria-theresa-maite-moreira-vilar)

Biochemical Engineering, Enzyme Reactors, Wastewaster Treatment, Environmental Management, Life Cycle Assessment, Carbon Footprint, Eco-design, Eco-efficiency 


\section{Tonás Ramos}

U1yider

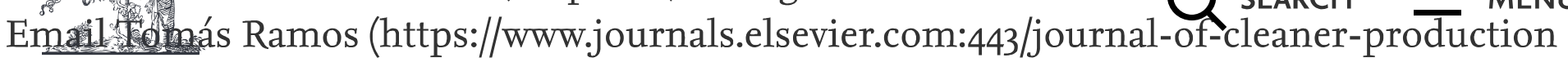
/ediderialeBoard/tomas-ramos)

Sustainability Assessment and Indicators, Sustainability Reporting, Strategic Environmental

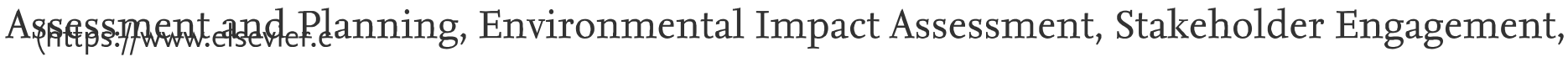
Oøgænisational Sustainability, Environmental Management, Green Jobs

Tomohiko Sakao (https://www.journals.elsevier.com:443/journal-of-cleaner-production /editorial-board/tomohiko-sakao)

Linköping Universitet, Linköping, Sweden

Email Tomohiko Sakao (https://www.journals.elsevier.com:443/journal-of-cleaner-production /editorial-board/tomohiko-sakao)

Ecodesign (environmentally conscious design); Engineering design methods; Life Cycle Engineering; Life Cycle Management; Product-Service System (PSS); Circular Economy; Sustainable Consumption and Production; Computer support; Intelligent machines

Panos Seferlis (https://www.journals.elsevier.com:443/journal-of-cleanerproduction/editorial-board/panos-seferlis)

Aristotle University of Thessaloniki, Thessaloniki, Greece

Email Panos Seferlis (https://www.journals.elsevier.com:443/journal-of-cleanerproduction/editorial-board/panos-seferlis)

Process design, Process optimization, Energy efficiency, Mathematical modeling, Automatic control, Sustainable process design, Energy conversion systems, Renewable energy systems, Emission reduction, Energy and water integration

Lei Shi (https://www.journals.elsevier.com:443/journal-of-cleaner-production /editorial-board/lei-shi)

Tsinghua University, China Email Lei Shi (https://www.journals.elsevier.com:443/journal-of-cleanerproduction/editorial-board/lei-shi)

Industrial ecology, industrial complexity, complex network, complex systems, industrial ecosystem, industrial symbiosis, industrial metabolism, eco-innovation, circular economy, process systems engineering, cleaner production in developing countries

Vladimir Strezov (https://www.journals.elsevier.com:443/journal-of-cleanerproduction/editorial-board/vladimir-strezov)

Macquarie University, New South Wales, Australia

Email Vladimir Strezov (https://www.journals.elsevier.com:443/journal-of-

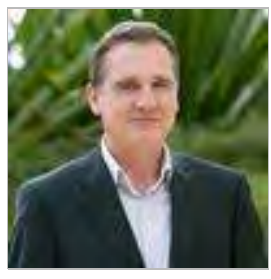


cleaner-production/editorial-board/vladimir-strezov)

sustalinat

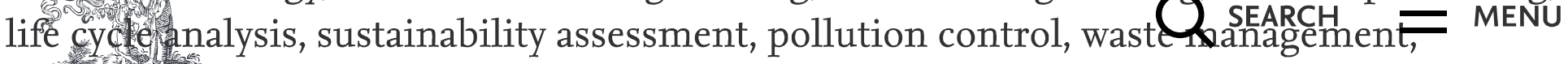
envizenmeental impact assessment, industrial ecology

\section{ELSEVIER}

Xin Topgr (https://www.journals.elsevier.com:443/journal-of-cleanerproplyction/editorial-board/xin-tong)

Peking University, Beijing, China

Email Xin Tong (https://www.journals.elsevier.com:443/journal-of-cleanerproduction/editorial-board/xin-tong)

Extended Producer Responsibility; Sustainable consumption and production; Industrial ecology; Sustainable behaviour studies; Green supply chain; Spatial analysis; Global production network; Rural-urban transition; Technological transition; Urban and regional planning

Zheming Tong (https://www.journals.elsevier.com:443/journal-of-cleanerproduction/editorial-board/zheming-tong)

Zhejiang University, Zhejiang, China

Email Zheming Tong (https://www.journals.elsevier.com:443/journal-ofcleaner-production/editorial-board/zheming-tong)

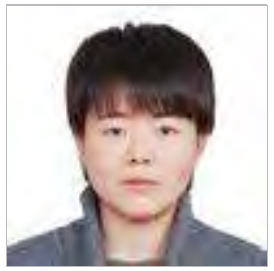

Air Pollution; Sustainable building; Built environment; Urban Physics; Urban vegetation; Traffic emission; Cabin environmental quality; Emission control; Computational Fluid Dynamics (CFD); Sustainable manufacturing

Sharifah Rafidah Wan Alwi

Universiti Teknologi Malaysia, Johor, Malaysia

Email Sharifah Rafidah Wan Alwi (https://www.journals.elsevier.com:443 /journal-of-cleaner-production/editorial-board/sharifah-rafidah-wan-alwi) process systems engineering, water, energy, Pinch Technology, Optimisation, Industrial applications

\section{Honorary Board Members}

\section{Nicholas Ashford}

Massachusetts Institute of Technology, Cambridge, Massachusetts, USA

Mark Brown (https://www.journals.elsevier.com:443/journal-of-cleaner-production/editorial- 
boand/mark-brown)

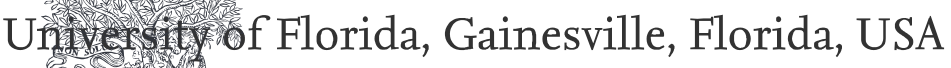

Gorahyirinnveden

ELSEVIER

KTH Royal Institute of Technology, Stockholm, Sweden

(https://www.elsevier.c

Ole Jorgen Hanssen

Stiftelsen Ostfoldforskning, Frederikstad, Norway

Gjalt Huppes (https://www.journals.elsevier.com:443/journal-of-cleanerproduction/editorial-board/gjalt-huppes)

Universiteit Leiden, Leiden, Netherlands

Industrial Ecology, Climate Policy, Resource Policy, Policy Instrumentation, Systems Analysis

Conrad Luttropp

KTH Royal Institute of Technology, Stockholm, Sweden

\section{Darrel Reeve}

Cleaner Production Australia, Eltham, Victoria, Australia

\section{Philip Vergragt}

Tellus Institute, Boston, Massachusetts, USA

Zhifeng Yang (https://www.journals.elsevier.com:443/journal-of-cleanerproduction/editorial-board/zhifeng-yang)

Guangdong University of Technology, Guangzhou, China

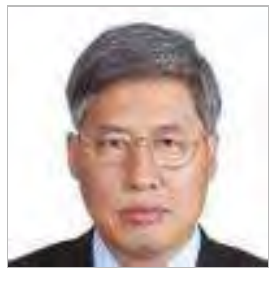

\section{Academic Board Members}

Rupert Baumgartner

Karl-Franzens-Universität Graz, Graz, Austria 


\section{Vincent Blok}

or

Wergen

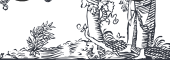

FrangEVIER

University of Manchester, Manchester, England, UK (https://www.elsevier.c om)

Anthony Chiu

De La Salle University, Manila, Philippines

\section{Xiangzheng Deng}

Chinese Academy of Sciences (CAS), Chaoyang District, China Environmental and Natural Resource Economics; Land Change Science; Agricultural Policy and Sustainable Development; Water Management and Water Footprint; Ecosystem Services and Functions; Urbanization and Global Environment Change; Energy Economics and climate Policy; Sustainability-based Decision Making

\section{Stephen DeVito}

US Environmental Protection Agency, Washington, District of Columbia, USA Pollution prevention; green chemistry; pollutant release and transfer registers; PRTRs; sustainable development

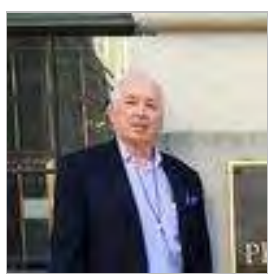

\section{Javier Dufour Andía}

Rey Juan Carlos University, Spain sustainability, life cycle assessment (LCA), life cycle sustainability assessment (LSCA), process optimization, energy modelling, bioenergy, biofuels,

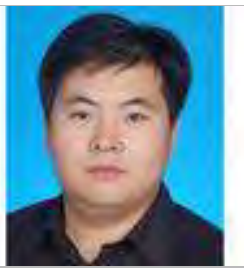

\section{Q SEARCh $\equiv$ MENU}




\section{Boundaries}

or

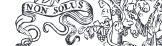

Johnum ar Fresner

\section{Q SEARCH}

STESEM M

Resource efficiency; Cleaner production; Cleaner technology; Energy

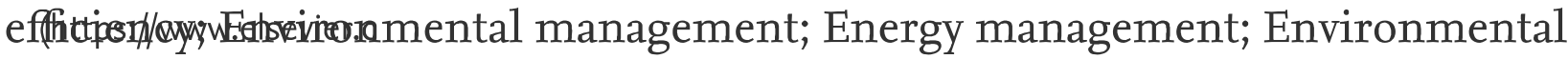

sơnild technology; Chemical engineering; Process control; Sectors (metal

processing, plastic processing, agroindustries, food, chemicals, wood processing, tourism);

Product development; Eco innovation; Circular economy

\section{Xavier Gabarrell Durany}

Universitat Autònoma de Barcelona (UAB), Barcelona, Spain industrial ecology, ecodesign, circular economy, LCA, MFA, waste management, water management, energy-water-food nexus, regions and urban sustainable transformation

\section{Shabbir Gheewala}

King Mongkut's University of Technology Thonburi, Bangkok, Thailand Life cycle assessment, sustainability assessment of energy systems, sustainability indicators, carbon footprint, water footprint, certification issues in biofuels and agro-industry

\section{Biagio F. Giannetti}

Paulista University, São Paulo, Brazil

\section{Stefan Gold}

Nottingham University Business School, Nottingham, England, UK

\section{Reinout Heijungs}

Vrije Universiteit Amsterdam, Amsterdam, Netherlands

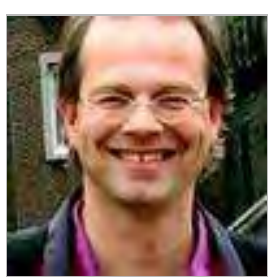

\section{Gavin Hilson}

University of Surrey, Guildford, Surrey, England, UK 


\section{Davidkrakulka}

Thesstalde University of New York at Buffalo, Buffalo, New York, USA

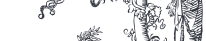

ELSEVIER

Q SEARCH

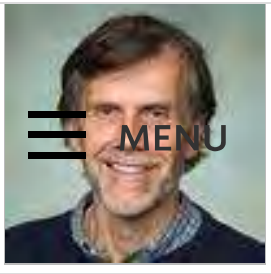

\section{ELSEVIER}

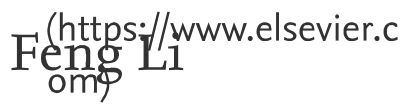

Chinese Academy of Sciences (CAS), Beijing, China

urban ecology, ecosystem services, urban land-use change, ecological infrastructure, ecological planning and management

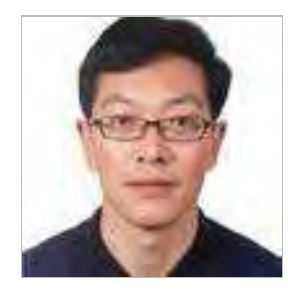

\section{Gang Liu}

University of Southern Denmark, Odense, Denmark

Material, substance, and energy flow analysis; Life cycle sustainability assessment; Urban metabolism; Industrial Ecology; Circular economy;

Sustainable resource and waste management; Built environment stocks;

Prospective modelling; Climate change mitigation; Linkages of sustainability

\section{Yang Liu}

University of Vaasa, Vaasa, Finland

\section{Zhi-Yong Liu}

Hebei University of Technology, Tianjin, China

Wastewater minimization, debottlenecking of distillation columns, energy

saving, applied thermodynamics, and simulation and optimization of chemical processes

\section{Thokozani Majozi}

University of the Witwatersrand, WITS, South Africa

Optimization; Batch processes; Water minimization; Energy optimization;

Scheduling, Synthesis and Design of batch plants
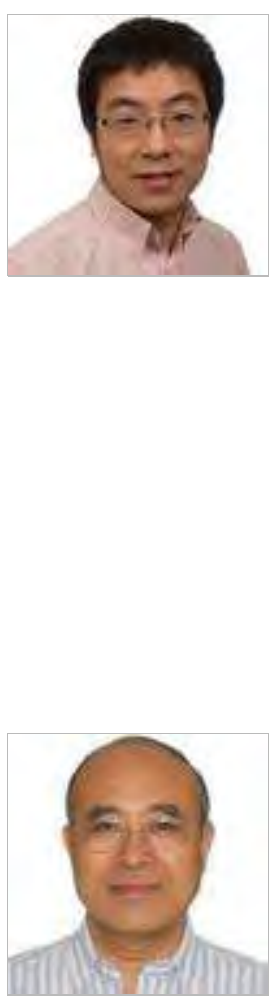


\section{Sandro*Nižetić}

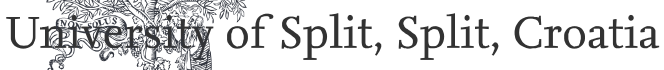

Clean I I ngy \& Sustainable Engineering; Energy Efficiency; Mechanical

En Fide erring; Thermodynamics \& Fluid Mechanics; Energy and Exergy

Analysis; Renewable Energy; Heating and Cooling; Energy Economics; Energy

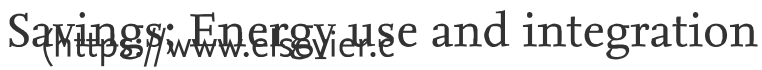

om)

\section{Jaco Quist}

Delft University of Technology, Delft, Netherlands

Sustainable Production and Consumption (SPC); Industrial Ecology; Circular Economy;

Renewable Energy; Climate Adaptation; Urban Agriculture and Food

Joan Rieradevall Pons

Universitat Autònoma de Barcelona (UAB), Bellaterra, Spain

Agrourban, Sustainability cites, Life cycle assessment, Eco-design, Eco innovation services, Prevention and recycling of waste, Industrial Ecology, Rainwater, Biomass and Smart cities

\section{Matteo V. Rocco}

Politecnico di Milano, Milano, Italy

Exergy analysis; Thermoeconomic analysis; Energy conversion systems; Life Cycle Assessment; Input-Output analysis; Energy Modeling; Energy resources;

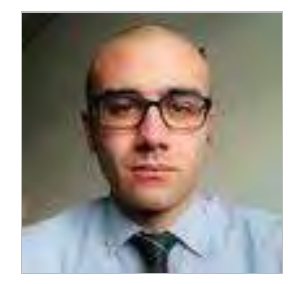
Industrial ecology; Computational sustainability; Environmental policy

\section{Hans Schnitzer}

Technische Universität Graz, Graz, Austria

Cleaner Production process intensification, resource and energy efficient technologies process assessment energy concepts, use of renewable resources innovations for urban quality of life with the focus on sustainable urban technologies systematic innovation

\section{Malin Song}

Anhui University of Finance and Economics, Anhui Bengbu, China Environmental regulation; Environmental efficiency; Sustainable development; Big data analysis

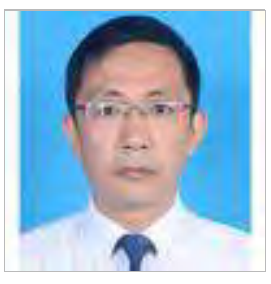


U.S. Environmental Protection Agency (EPA), Research Triangle Park, North Carolina, USA

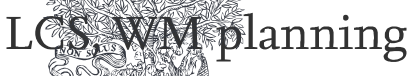
ร马ำ

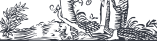

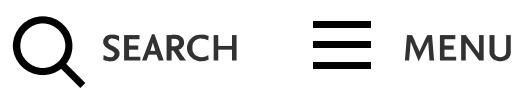

Arrdsedrtianni

ELSEVIER

University of Technology Sydney, Ultimo, New South Wales, Australia

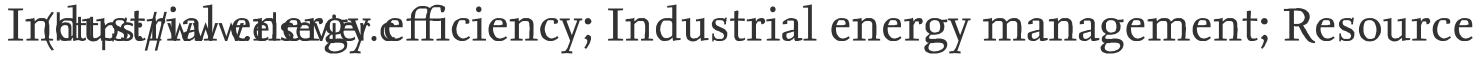

effrelency; Sustainable production; Sustainable products and services;

Sustainable operations management; Closed loop supply chain; Green supply

chain management

Arnold Tukker

Leiden University, Leiden, Netherlands

Sergio Ulgiati

Università degli Studi di Napoli Parthenope, Napoli, Italy

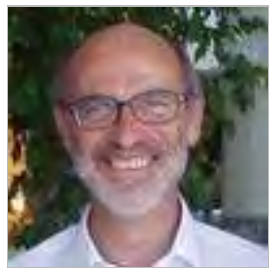

\section{Bart van Hoof}

Universidad de Los Andes, Bogotá, Colombia

Petar S. Varbanov

Brno University of Technology (VUT Brno), Brno, Czech Republic

\section{Timothy Walmsley}

Brno University of Technology (VUT Brno), Brno, Czech Republic

Process Integration including process modelling, optimisation and design;

industrial energy efficiency, waste heat recovery, waste-to-energy; macro

energy systems modelling, Footprint assessment and sustainability

\section{Zhaohua Wang}

Beijing Institute of Technology, Beijing, China

Energy Economics and Policy; $\mathrm{CO}_{2}$ Emission and Climate Change;

Sustainable Production and Consumption; Big Data and Behavior

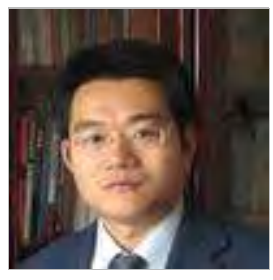


Northwestern Polytechnical University, Xi'an, China 3.

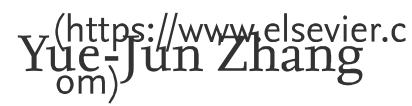

Hunan University, Changsha, China

Carbon emission reduction; Low-carbon policy evaluation; Energy economics; Energy price; Energy finance; Energy efficiency; Carbon trading mechanisms; Econometrics; Data Envelopment Analysis (DEA); Input output method

Jian Zuo

University of Adelaide, Adelaide, South Australia, Australia Resource efficiency; Corporate sustainability; Solid waste management; Sustainable higher education; Green building; Stakeholder engagement; Renewable energy in buildings; Behavioural change; Social sustainability; Indoor environmental quality

\section{Junior Board Members}

Syed Awais Ali Shah Bokhari (https://www.journals.elsevier.com:443/journal-ofcleaner-production/editorial-board/syed-awais-ali-shah-bokhari) Universiti Teknologi PETRONAS, Perak, Malaysia Biofuel production; Cleaner process development; Intensification technologies; Hydrodynamic cavitatio'; Ultrasonics; Biomass conversion; Energy; Sustainable Engineering; Non-edible oils; Biodiesel synthesis

Cassendra Bong Phun Chien (https://www.journals.elsevier.com:443/journalof-cleaner-production/editorial-board/cassendra-bong-phun-chien) Universiti Teknologi Malaysia, Skudai, Johor, Malaysia Organic waste management; Anaerobic digestion; Composting; Modelling \& Kinetics; GHG; Biomass \& Bioenergy; Low carbon; Environmental management; Wastewater; Solid waste

Ivan Bozhikin (https://www.journals.elsevier.com:443/journal-of-cleaner-production /editorial-board/ivan-bozhikin)

University of National and World Economy (UNWE), Sofia, Bulgaria 
Environmental Fiscal Policy; Sustainable Waste Management; CSR; Circular Econory, Social Entrepreneurship; Environmental Economics; Ecoefficlenc. Tools for Corporate Sustainability; Governmental Policy; QRoNEARCHC and finvizonmental Policy; Sustainable Business Models

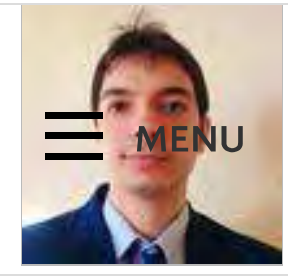
ELSEVIER

Lautros: Bưwwelsevier.ftps://www.journals.elsevier.com:443/journal-of-cleanerproduction/editorial-board/laura-bulgariu)

Technical University Gheorghe Asachi of Iaşi, Iaşi, Romania Environmental pollution; Environmental bioremediation; Heavy metals pollutants; Biosorption/adsorption; Batch and continuous systems; Low-cost biosorbents/adsorbents; Wastewater treatment; Waste recycling; Valorization of exhausted biosorbents/adsorbents; Ecological fertilizers for soils

Chin Kui Cheng (https://www.journals.elsevier.com:443/journal-of-cleanerproduction/editorial-board/chin-kui-cheng)

Universiti Malaysia Pahang (UMP), Pahang, Malaysia

Renewable energy; Wastewater treatment; Sustainable development; Clean energy; Carbon footprint; Water footprint; Biofuel; Waste-to-wealth; Biofuel; Green chemistry

Yee Van Fan (https://www.journals.elsevier.com:443/journal-of-cleanerproduction/editorial-board/yee-van-fan)

Brno University of Technology (VUT Brno), Brno, Czech Republic Solid waste treatment and management; Composting; Waste to energy; Emissions assessment and mitigation; Transportation Mode Choice; Life Cycle Assessment; Footprint and sustainability assessment; Biomass

Xuexiu Jia (https://www.journals.elsevier.com:443/journal-of-cleanerproduction/editorial-board/xuexiu-jia)

Brno University of Technology (VUT Brno), Brno, Czech Republic Water footprint; Water-energy-food nexus; GHG/carbon emissions; Economics and environmental management

Hesam Kamyab (https://www.journals.elsevier.com:443/journal-of-cleanerproduction/editorial-board/hesam-kamyab)

Universiti Teknologi Malaysia, Kuala Lumpur, Malaysia

Algal biotechnology; Wastewaster treatment; Biomass; Agro waste water; Industrial wastewater treatment; Biofuels; Energy; Environmental Biotechnology; Compost; Self-Healing Concrete 
Jeng Shiun Lim (https://www.journals.elsevier.com:443/journal-of-cleanerprodection/editorial-board/jeng-shiun-lim)

Univiers 16 Teknologi Malaysia, Johor Bahru, Malaysia

Q SEARCH

ProcSES S SEStems engineering for resource conservation; Renewable energy;

Carbon pianning

(https://www.elsevier.c

Jing) Meng

University of Cambridge, Cambridge, England, UK

Air pollution modeling; Low carbon manufacturing; Energy policy; Climate policy; Carbon footprint; Input output analysis; Learning curve

Yuanbo Qiao (https://www.journals.elsevier.com:443/journal-of-cleanerproduction/editorial-board/yuanbo-qiao)

Shandong University, Qingdao, China

Sustainable development; Environmental economics; Eco-innovation;

Environmental management; Environmental policy; Econometrics; Efficiency assessmen'; Land economics; Defense economics; Merger and acquisition

\section{Shen Qu}

University of Michigan, Ann Arbor, Michigan, USA

Trade and the environment; Urban food-water-energy nexus; Water risk; Sustainable production and consumption

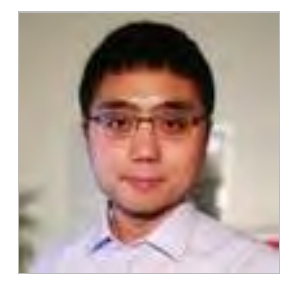

Mingxing Sun (https://www.journals.elsevier.com:443/journal-of-cleanerproduction/editorial-board/mingxing-sun)

Tsinghua University, Beijing, China

Life cycle assessment (LCA); Material flow analysis (MFA); Cleaner production; Circular economy; Environmental policy; Extended producer responsibility (EPR); Bio-industry; Pulp and paper; Eco-efficiency; Waste management.

Yi Yang (https://www.journals.elsevier.com:443/journal-of-cleaner-production /editorial-board/yi-yang)

University of Minnesota, Minneapolis, Minnesota, USA

\section{Journal of Cleaner Production}




\section{Readers \\ Vievilintides \\ Volinge/ 1 sque Alert \\ Persions \\ ELSEVIER \\ Authors (http:y/www.elsevier.com/authors/home)}

\section{Q SEARCH $\equiv$ MENU}

Author Information Pack (http://www.elsevier.com/journals/journal-of-cleaner-production

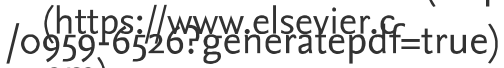

Submit Your Paper

Track Your Paper

Early Career Resources (http://www.elsevier.com/early-career-researchers/training-and-workshops)

Rights and Permissions (https:/www.elsevier.com/about/policies/copyright/permissions)

Webshop

Support Center

Librarians (https://www.elsevier.com/librarians)

Ordering Information and Dispatch Dates (http://www.elsevier.com/journals/journal-of-cleaner-production/o959-6526 /order-journal)

Abstracting/ Indexing (http://www.elsevier.com/journals/journal-of-cleaner-production/0959-6526/abstractingindexing)

Editors (http://www.elsevier.com/editors/home)

Publishing Ethics Resource Kit (http://www.elsevier.com/editors/perk)

Guest Editors (http://www.elsevier.com/editors/guest-editors)

Support Center

Reviewers (http://www.elsevier.com/reviewers/home)

Reviewer Guidelines (http://www.elsevier.com/reviewersguidelines)

Log in as Reviewer

Reviewer Recognition (https://www.elsevier.com/reviewers/becoming-a-reviewer-how-and-why\#recognizing)

Support Center

Advertisers Media Information (https://www.elsevier.com/advertisers)

Societies (http://www.elsevier.com/societies/home)

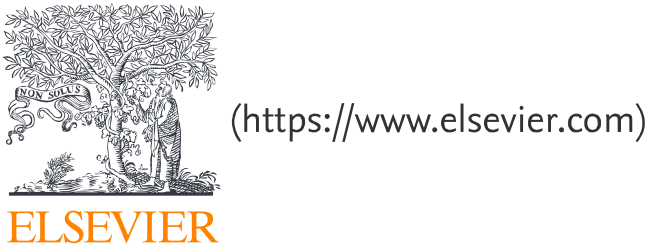

Copyright (C) 2019 Elsevier B.V.

Careers (https://www.elsevier.com/careers/careers-with-us) - Terms and Conditions (https://www.elsevier.com/legal /elsevier-website-terms-and-conditions) - Privacy Policy (https://www.elsevier.com/legal/privacy-policy)

Cookies are used by this site. To decline or learn more, visit our Cookies page. 


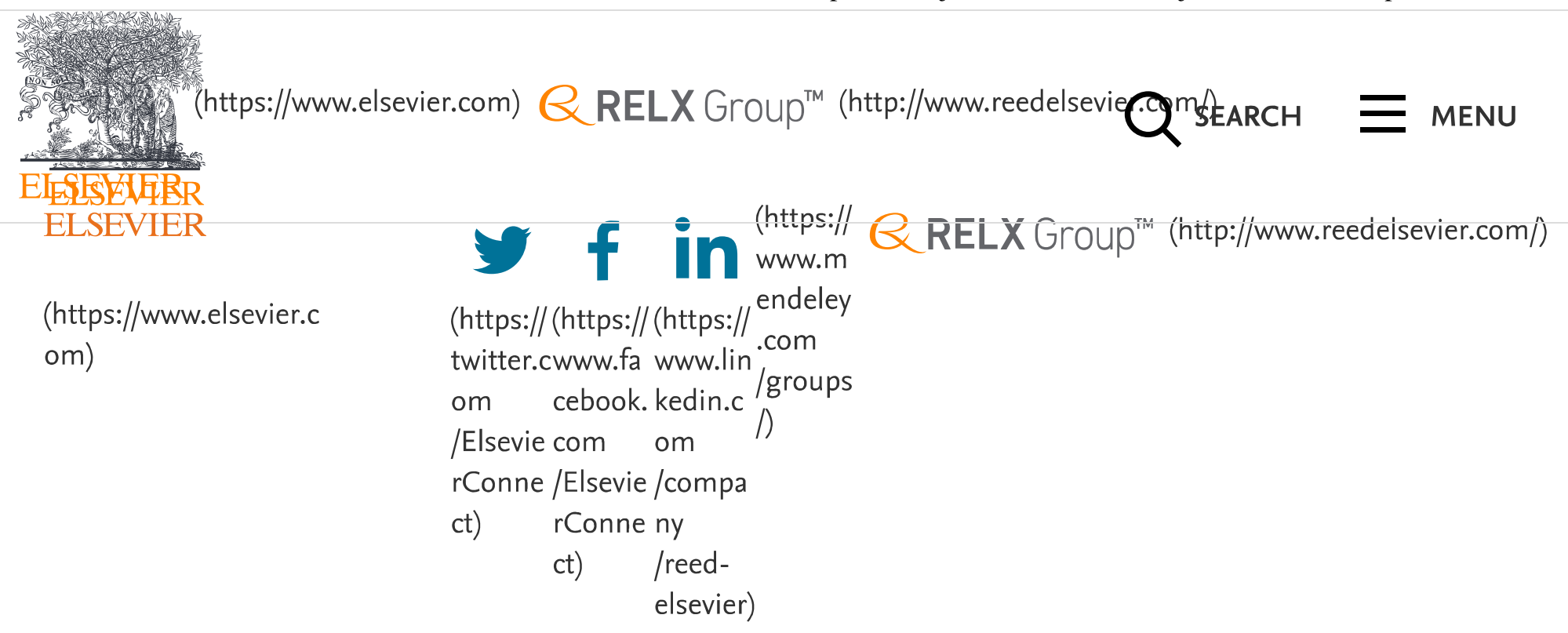

(https://www.elsevier.c

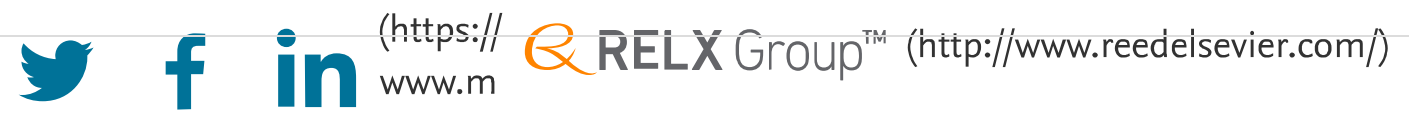
om) (https:// (https:// (https:// endeley twitter.cwww.fa www.lin /groups
om cebook. kedin.c
/Elsevie com om rConne /Elsevie /compa ct) rConne ny ct) $\quad /$ reedelsevier) 


\section{Journal of Cleaner Production}

\section{COUNTRY}

unied Kingdom

\section{Unversibes and reseatch} instiutions in United Kingdam

\section{SUBJECT AREA AND CATEGORY}

Eustmes, Management and Accouriting Strategy and Management

Eriergy

Renewable Enetgy. Sustainability and

the Envitonmeni

Engineering

industrial and Manufacturing

Engineering

Environmental Sclence

Environmental Sojenct

(mitscellaneous)
PUBUSHER

Elreviet tad

ISSN

09596526,18791786
COVERAGE

1993-2021
H-INDEX

\section{0}

INFORMATION

Homepage

How to publiah in this joumal

contact

SCOPE

The Journal of Cleaner Production is an international, transdisciplinary journal focusing on Cleaner Production, Environmental, and Sustainability research and practice. Through our published articles, we aim at helping societies become more sustainable. 'Cleaner Production' is a concept that aims at preventing the production of waste. while increasing efficiencies in the uses of energy, water, resources, and human capital. The Journal of Cleaner Production serves as a platform for addressing and discussing theoretical and practical cleaner production, encompassing environmental, and sustainability issues in corporations, governments, education institutions, regions, and societies. Subject areas include, but are not limited to: - Cleaner production and technical processes -Sustainable Development and Sustainability -Sustainable Consumption -Environmental and sustainability assessment -Sustainable Products and Services -Corporate sustainability and Corporate Social Responsibility -Education for Sustainable Development-Governance, legislation, and policy for sustainability Sustainable Production and Consumption NLD Management of Environmental Quality similarity Resources, Conservation and Recycling NLD
4

Clean Technologies and Environmental Policy DEU International Journal of Sustainable Development and GBR 


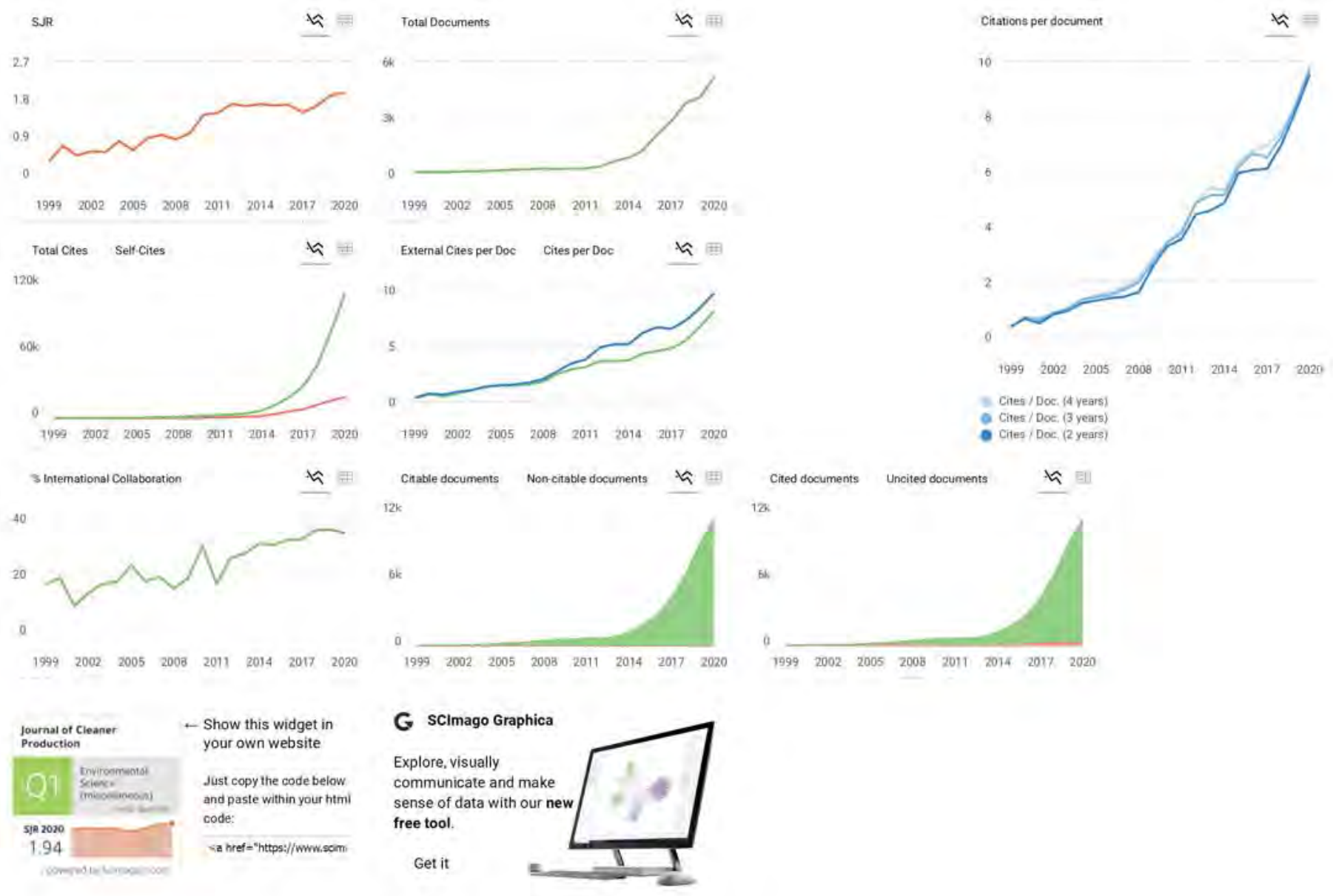

Metrics based on Scopus@ data as of April 2021

N มกี่โขติรล รกทจง 8 months ago

Could you please tell me how many databases this journal was found in?

reply

Melanie Ortiz 8 months ago

Dear Sir/Madam,

Thank you for contacting us.

SJR is a portal with scientometric indicators of joumals indexed in Elsevier/Scopus.

Unfortunately, we cannot help you with your request referring to the index status. We

suggest you consult Scopus database (see the current status of the journal) or other

databases for further information

Best Regards, SCImago Team

H Hoda Ibrahim 11 months ago

Hello,

I am a PhD student, and I would like to publish my paper on your Journal

I need to know what are the procedures, how much does it cost, and how long does it take to be published?

Does this journal listed in scopus?

My PhD work is related to sustainability, green building, and reducing carbon emission.

Kind Regards,

Hoda Ibrahim, Sustainability Consultant

PhD candidate, MSC, LEED AP BD C, Edge Expert, USGBC Faculty, USGBC Pro-Reviewer 
Mobile: 201004772020

reply

Melanie Ortiz 11 months ago

Dear Hoda,

thank you for contacting us.

We are sorry to tell you that SCImago Joumal 8 Country Rank is not a joumal. SJR is a portal with scientometric indicators of journals indexed in Elsever/Scopus. We suggest you consult the Scopus database directly Keep in mind that the S.JR is a static image (the update is made one time per year) of a database (Scopus) which is changing every day Unfortunately, we cannot help you with your request. we suggest you visit the joumal's homepage (See submisston/author guidelines) or contact the joumal's editorial staff . so they could inform you more deeply.

Best Regards, SCImago Team

AZIZUL KHOLIS 11 months ago

please inform me, about the Celaner production journal, is it a specialis for environtient issues only?

Regards

reply

Melanie Ortiz 13 months ago

Dear Azizul,

thank you for contaoting us.

Unfortunately, we cannot help you with your request, we suggest you visit the joumals

homepage or contact the journals editonal staff , so they could inform you more deeply Best Regards, SCImago Team

N Nuryusnita 1 year ago

Good day

May I know where to check for how many issues published by certain journal publication?

thank you

Regard,

Yusnita

reply

Melanle Ortiz 1 year ago

Dear Nuryusnita,

thànk you for contacting us.

We suggest you consult that information in the joumal's website.

Best Regards, ScImaga Team

Y Yolanda Bermudez 1 year ago

Dear Sr. Could you tell me when you will receive articles? We are intereating to send you an article about Circular economy and strategy

Thanks

Yolanda Bermūdez

reply

Dear Yolanda

thank you for contacting us

We are sorry to tell you that SCImago Journal \& Country Rank is not a journal. SJR is a

portal with scientometric indicators of journals indexed in Elsevier/Scopus.

Unfortunately, we cannot help you with your request, we suggest you visit the joumals 
homepage (See submission/author guidelines) or contact the joumal's editorial staff, so they could inform you more deeply.

Best Regards, SCImago Tearn

A

amir 2 years agc

dear Admin

Hello

how can i find 2019 and 2020 quartile in your website?

reply

Melanle Ortiz 2 years ago

sć.lmago Team

Dear Amir,

Thank you for contacting us. Our data come from Scopus, they annually send us an

updale of the data. This update is sent to us around April / May every year. Thus, the

indicators for 2019 will be avallable in June 2020. Best Regards, SCImago Team

C chakim 2 years ago

Dear editorial staff

Iam writing journal for iny study in Universitas Esa Unggul, indonesia

It is very difficult to find journal with title:

Huang, X.X. Hu, Z.P. Lu, C.S. Yu, D.J., and Yu, LF, 2016.

An examinatiomn of corporate reporting environmental

management practices and firm performance, Journal of

Cleaner Production, 112, 3456-3433.

Can you help me to find this journal in this proquest search.

Thank you

reply

DK 2 years ago

Not sure if this is what you are looking fot.

https://doi. org/10.1016/[jom.2006.10.003

Melanie Ortiz 2 years ago

SClmaggo Team

Dear Sir/Madam,

thank you for contacting us

We are sorry to tell you that SCImago Joumal \& Country Rank is not a joumal. SJR is a

portal with scientometric indicators of journals indexed in Elsevier/Scopus.

Unforturiately, we cannot help you with your request, we suggest you to contact the

journal's editorial staff, so they could inform you more deeply.

Best Regards, SCImago Team

\section{dina zaman 2 years ago}

Can anyone throw some light on the word limit for a review article in this journal. The author information guide states that the limit is 12000 words, but does not mention if it includes the references, abstract, tables etc

thanks

reply

D David Rulz 2 years ago

They are between 6000-8000 words withoul references, counting tables and tigures. 
$\gamma$ yousr 3 years ago

subscribe

reply

\section{Leave a comment}

Narne

Email

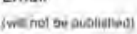

The users of Scimago Joumal \& Country Rank have the possibility to dialogue through comments linked to a specific journal. The purpose is to have a forum in which general doubts about the processes of publication in the joumal, experiences and other issues derived from the publication of papers are resolved. For topics on particular articles, maintain the dialogue through the usual channels with your editor

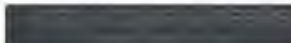




\section{Journal of Cleaner Production}

\section{COUNTRY}

unied Kingdom

\section{Unversibes and reseatch} instiutions in United Kingdam

\section{SUBJECT AREA AND CATEGORY}

Eustmes, Management and Accouriting Strategy and Management

Eriergy

Renewable Enetgy. Sustainability and

the Envitonmeni

Engineering

industrial and Manufacturing

Engineering

Environmental Sclence

Environmental Sojenct

(mitscellaneous)
PUBUSHER

Elreviet tad

ISSN

09596526,18791786
COVERAGE

1993-2021
H-INDEX

\section{0}

INFORMATION

Homepage

How to publiah in this joumal

contact

SCOPE

The Journal of Cleaner Production is an international, transdisciplinary journal focusing on Cleaner Production, Environmental, and Sustainability research and practice. Through our published articles, we aim at helping societies become more sustainable. 'Cleaner Production' is a concept that aims at preventing the production of waste. while increasing efficiencies in the uses of energy, water, resources, and human capital. The Journal of Cleaner Production serves as a platform for addressing and discussing theoretical and practical cleaner production, encompassing environmental, and sustainability issues in corporations, governments, education institutions, regions, and societies. Subject areas include, but are not limited to: - Cleaner production and technical processes -Sustainable Development and Sustainability -Sustainable Consumption -Environmental and sustainability assessment -Sustainable Products and Services -Corporate sustainability and Corporate Social Responsibility -Education for Sustainable Development-Governance, legislation, and policy for sustainability Sustainable Production and Consumption NLD Management of Environmental Quality similarity Resources, Conservation and Recycling NLD
4

Clean Technologies and Environmental Policy DEU International Journal of Sustainable Development and GBR 


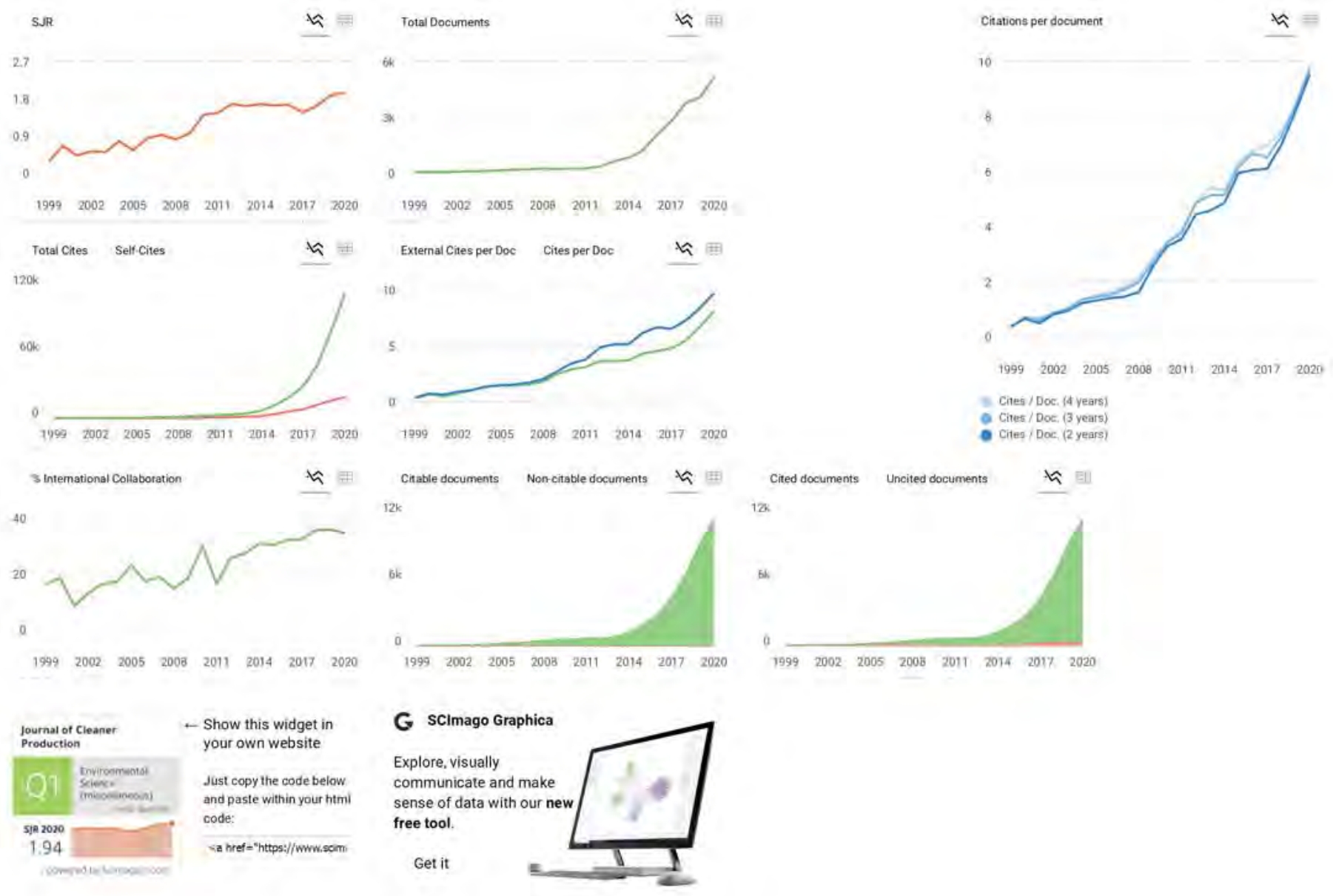

Metrics based on Scopus@ data as of April 2021

N มกี่โขติรล รกทจง 8 months ago

Could you please tell me how many databases this journal was found in?

reply

Melanie Ortiz 8 months ago

Dear Sir/Madam,

Thank you for contacting us.

SJR is a portal with scientometric indicators of joumals indexed in Elsevier/Scopus.

Unfortunately, we cannot help you with your request referring to the index status. We

suggest you consult Scopus database (see the current status of the journal) or other

databases for further information

Best Regards, SCImago Team

H Hoda Ibrahim 11 months ago

Hello,

I am a PhD student, and I would like to publish my paper on your Journal

I need to know what are the procedures, how much does it cost, and how long does it take to be published?

Does this journal listed in scopus?

My PhD work is related to sustainability, green building, and reducing carbon emission.

Kind Regards,

Hoda Ibrahim, Sustainability Consultant

PhD candidate, MSC, LEED AP BD C, Edge Expert, USGBC Faculty, USGBC Pro-Reviewer 
Mobile: 201004772020

reply

Melanie Ortiz 11 months ago

Dear Hoda,

thank you for contacting us.

We are sorry to tell you that SCImago Joumal 8 Country Rank is not a joumal. SJR is a portal with scientometric indicators of journals indexed in Elsever/Scopus. We suggest you consult the Scopus database directly Keep in mind that the S.JR is a static image (the update is made one time per year) of a database (Scopus) which is changing every day Unfortunately, we cannot help you with your request. we suggest you visit the joumal's homepage (See submisston/author guidelines) or contact the joumal's editorial staff . so they could inform you more deeply.

Best Regards, SCImago Team

AZIZUL KHOLIS 11 months ago

please inform me, about the Celaner production journal, is it a specialis for environtient issues only?

Regards

reply

Melanie Ortiz 13 months ago

Dear Azizul,

thank you for contaoting us.

Unfortunately, we cannot help you with your request, we suggest you visit the joumals

homepage or contact the journals editonal staff , so they could inform you more deeply Best Regards, SCImago Team

N Nuryusnita 1 year ago

Good day

May I know where to check for how many issues published by certain journal publication?

thank you

Regard,

Yusnita

reply

Melanle Ortiz 1 year ago

Dear Nuryusnita,

thànk you for contacting us.

We suggest you consult that information in the joumal's website.

Best Regards, ScImaga Team

Y Yolanda Bermudez 1 year ago

Dear Sr. Could you tell me when you will receive articles? We are intereating to send you an article about Circular economy and strategy

Thanks

Yolanda Bermūdez

reply

Dear Yolanda

thank you for contacting us

We are sorry to tell you that SCImago Journal \& Country Rank is not a journal. SJR is a

portal with scientometric indicators of journals indexed in Elsevier/Scopus.

Unfortunately, we cannot help you with your request, we suggest you visit the joumals 
homepage (See submission/author guidelines) or contact the joumal's editorial staff, so they could inform you more deeply.

Best Regards, SCImago Tearn

A

amir 2 years agc

dear Admin

Hello

how can i find 2019 and 2020 quartile in your website?

reply

Melanle Ortiz 2 years ago

sć.lmago Team

Dear Amir,

Thank you for contacting us. Our data come from Scopus, they annually send us an

updale of the data. This update is sent to us around April / May every year. Thus, the

indicators for 2019 will be avallable in June 2020. Best Regards, SCImago Team

C chakim 2 years ago

Dear editorial staff

Iam writing journal for iny study in Universitas Esa Unggul, indonesia

It is very difficult to find journal with title:

Huang, X.X. Hu, Z.P. Lu, C.S. Yu, D.J., and Yu, LF, 2016.

An examinatiomn of corporate reporting environmental

management practices and firm performance, Journal of

Cleaner Production, 112, 3456-3433.

Can you help me to find this journal in this proquest search.

Thank you

reply

DK 2 years ago

Not sure if this is what you are looking fot.

https://doi. org/10.1016/[jom.2006.10.003

Melanie Ortiz 2 years ago

SClmaggo Team

Dear Sir/Madam,

thank you for contacting us

We are sorry to tell you that SCImago Joumal \& Country Rank is not a joumal. SJR is a

portal with scientometric indicators of journals indexed in Elsevier/Scopus.

Unforturiately, we cannot help you with your request, we suggest you to contact the

journal's editorial staff, so they could inform you more deeply.

Best Regards, SCImago Team

\section{dina zaman 2 years ago}

Can anyone throw some light on the word limit for a review article in this journal. The author information guide states that the limit is 12000 words, but does not mention if it includes the references, abstract, tables etc

thanks

reply

D David Rulz 2 years ago

They are between 6000-8000 words withoul references, counting tables and tigures. 
$\gamma$ yousr 3 years ago

subscribe

reply

\section{Leave a comment}

Narne

Email

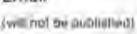

The users of Scimago Joumal \& Country Rank have the possibility to dialogue through comments linked to a specific journal. The purpose is to have a forum in which general doubts about the processes of publication in the joumal, experiences and other issues derived from the publication of papers are resolved. For topics on particular articles, maintain the dialogue through the usual channels with your editor

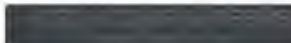

